\title{
NCMA GROUNDWATER MODEL USING USGS MODFLOW-2005/PEST
}

\author{
A Thesis \\ presented to \\ the Faculty of California Polytechnic State University, \\ San Luis Obispo \\ In Partial Fulfillment
of the Requirements for the Degree
Master of Science in Civil/Environmental Engineering
}

by

Brian Matthew Wallace

June 2016 
(C) 2016

\section{Brian Matthew Wallace}

\section{ALL RIGHTS RESERVED}


COMMITTEE MEMBERSHIP

TITLE: $\quad$ NCMA Groundwater Model using USGS MODFLOW-2005/PEST

AUTHOR: Brian Matthew Wallace

DATE SUBMITTED: June 2016

COMMITTEE CHAIR: $\quad$ Misgana Muleta, Ph.D. Associate Professor of Civil/Environmental Engineering

COMMITTEE MEMBER: Rebekah Oulton, Ph.D. Assistant Professor of Civil/Environmental Engineering

COMMITTEE MEMBER: Paul Sorensen, PG, CHG Principal Consultant at GSI Water Solutions, Inc.

COMMITTEE MEMBER: Daniel Heimel, MS, PE Engineer at Water Systems Consulting, Inc. 


\section{ABSTRACT \\ NCMA Groundwater Model using USGS MODFLOW-2005/PEST}

\section{Brian Matthew Wallace}

A numerical model for the NCMA aquifer complex is presented. The objective of the study is to develop a numerical groundwater model for the NCMA aquifer system to enhance the understanding of subsurface groundwater flow. Infiltration, streamflow, pumping, and return flows are implemented to characterize the aquifer complex over time. The numerical model is calibrated to municipal and monitoring well data, average monthly water balances, and hydraulic contours. Transient aquifer inflows and outflows are assessed in the results of the study and are compared to balance terms from previous studies.

Keywords: hydrogeology, groundwater, water, flow, characterization, modeling, model, modflow, numerical, california, study, thesis, arroyo grande, pismo beach, grover beach, oceano, geology, engineering, civil, environmental, geohydrology, san luis Obispo 


\section{ACKNOWLEDGMENTS}

The author acknowledges the support of his advisors Dr. Misgana Muleta and Dr. Rebekah Oulton from California Polytechnic State University, Dr. Robert Willis from Humboldt State University, Paul Sorensen with GSI Water Solutions, Inc., Dan Heimel and Jeff Szytel with Water Systems Consulting, Geoff English and Shane Taylor from Arroyo Grande Public Works, Tim Cleath and Spencer Harris from Cleath-Harris Geologists, Inc, Tony Marraccino with the Oceano Community Services District, Keith MacGregor, Greg Ray, and Lynn Pearson from the Grover Beach Public Works Department, Ray Dienzo with the San Luis Obispo County Public Works, Nicole Smith with the Coastal San Luis Resource Conservation District, Brayden McNeill, Jeremy Jeanson, Joseph Fernando, and Chasaya Sichilima from Waterloo Hydrogeologic, Craig Cooledge with $\mathrm{CH} 2 \mathrm{M}$ Hill, and Steven Phillips with USGS. A special thanks is expressed for family and friends that provided the author with the intellectual, psychological, social, and emotional strength to develop the numerical groundwater model presented in this study. 


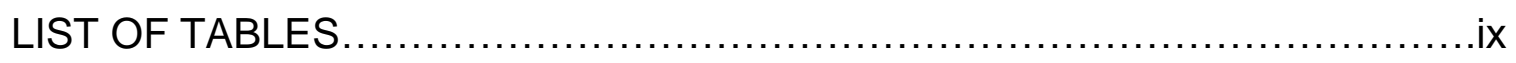

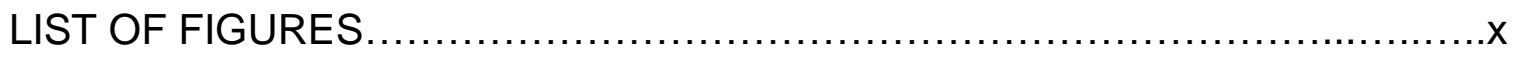

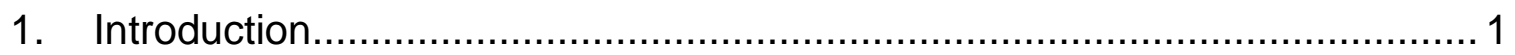

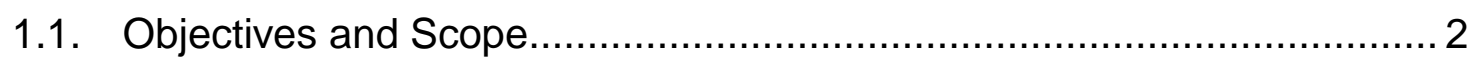

1.2. Introduction to Mathematical Models and Optimization ......................... 3

1.2.1. Mathematical Modeling …....................................................... 3

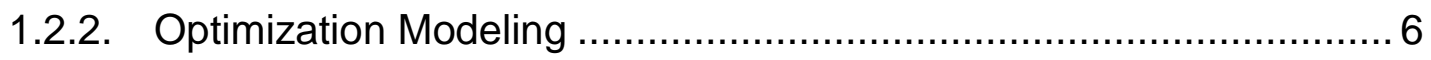

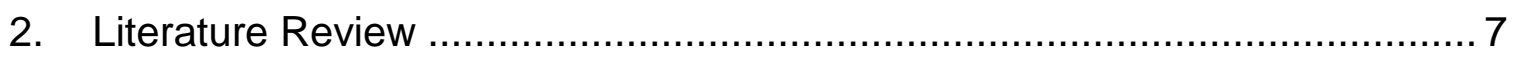

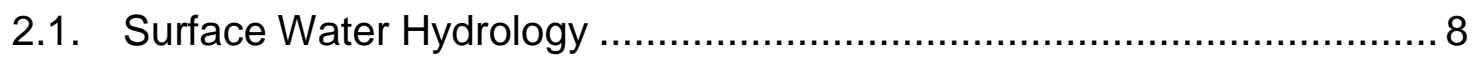

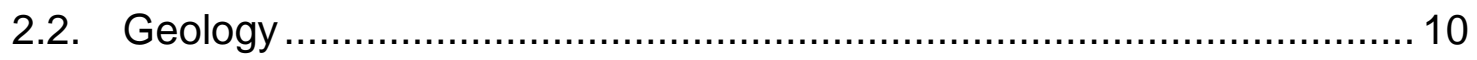

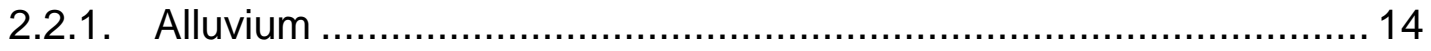

2.2.2. Dune Sand and Older Dune Sand ............................................ 15

2.2.3. Paso Robles Formation ......................................................... 15

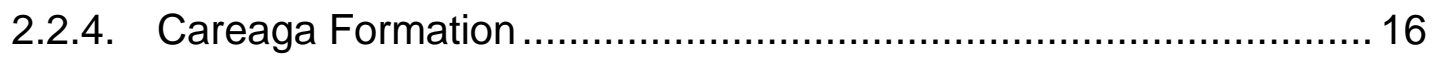

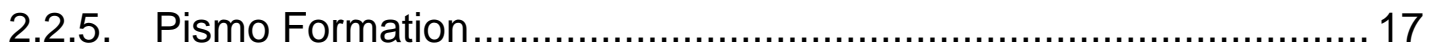

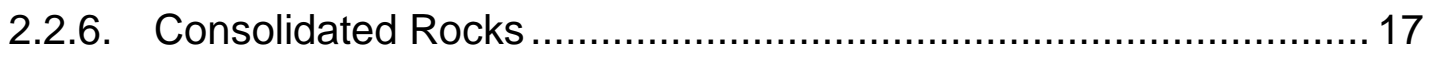

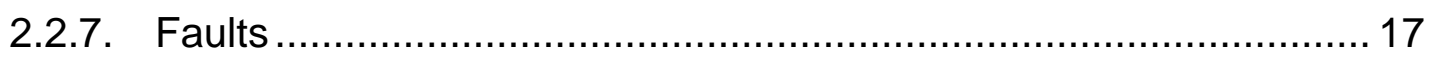

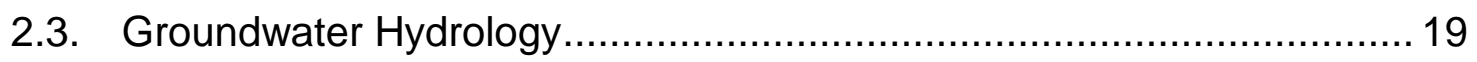


2.3.1. Groundwater Monitoring Program.

2.3.2. NCMA Regional Water Balance …............................................ 23

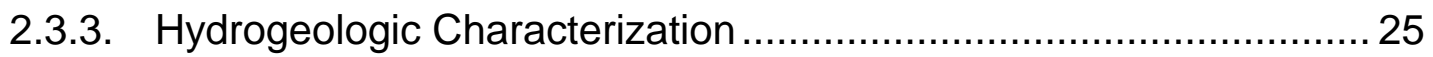

2.4. Previous Work using Visual MODFLOW® and ArcGIS® .................... 27

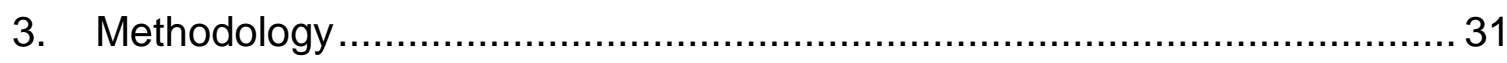

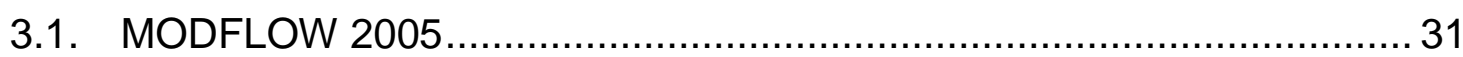

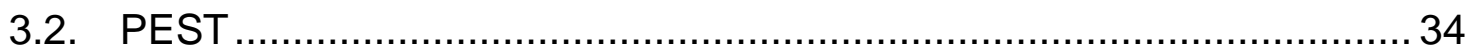

4. Steady State Model Development …………...................................... 37

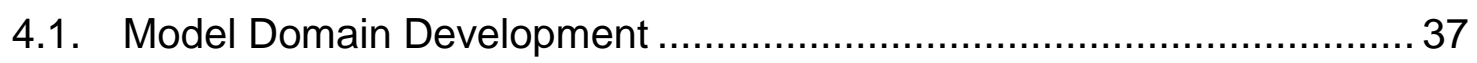

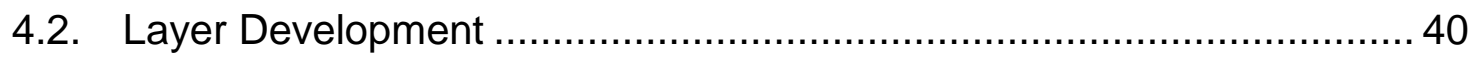

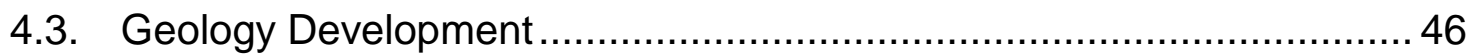

4.4. Boundary Condition Development ................................................ 48

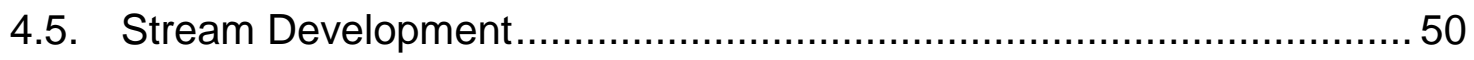

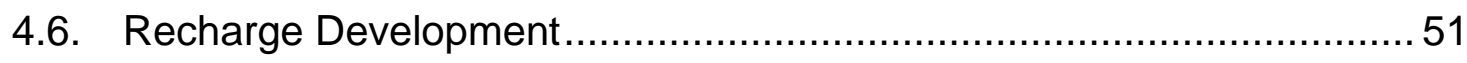

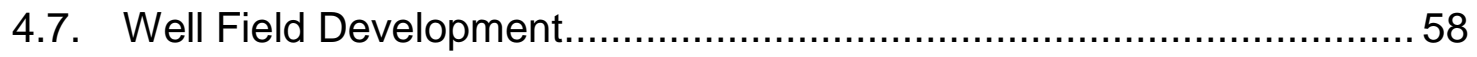

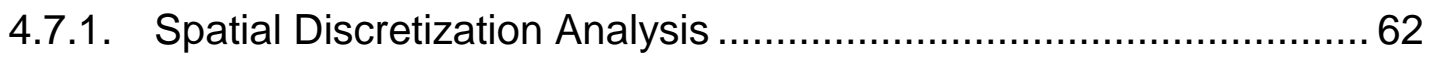

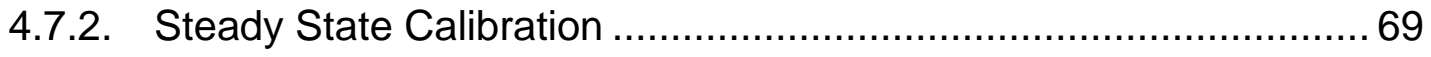

4.7.3. Calibration to Todd Engineers 2007 Water Balance Study Results...73

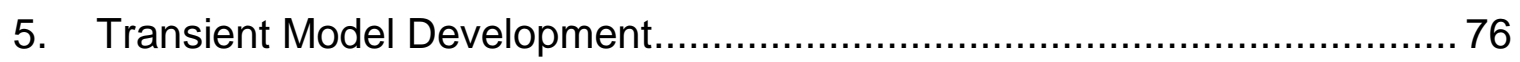

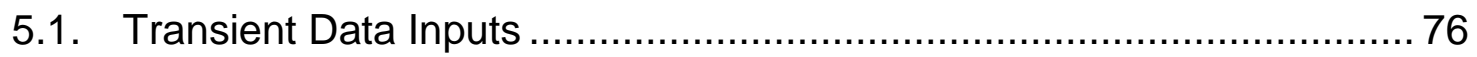


5.2. Transient Model Sensitivity Analysis

5.2.1. Stream Leakance Sensitivity Analysis ....................................... 86

5.2.2. Boundary Condition Sensitivity Analysis .................................... 88

5.2.3. Solver Package Sensitivity Analysis .......................................... 89

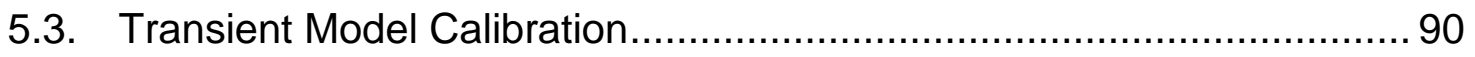

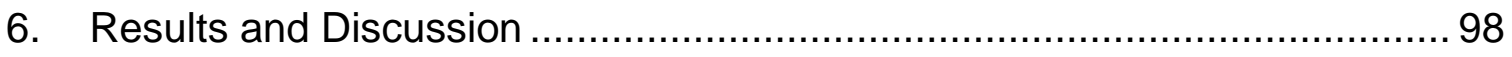

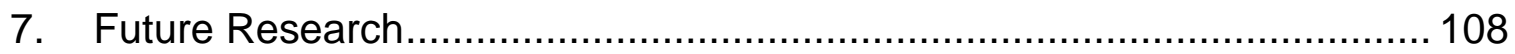

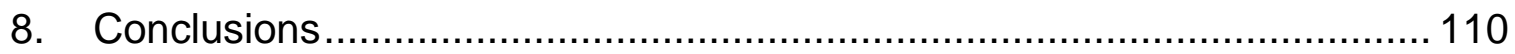

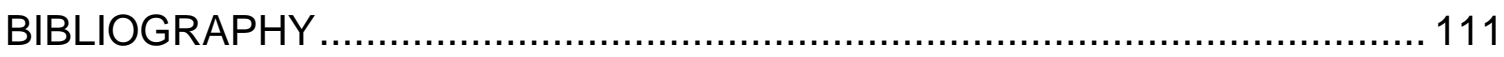




\section{LIST OF TABLES}

Table Page

Table 1 - NCMA Aquifer Budget (Todd Engineers, 2007) .............................. 23

Table 2 - Hydraulic Conductivities for Formations in Model Study Area ............ 25

Table 3 - Formation Hydraulic Conductivity using Different Methods ............... 26

Table 4 - Transmissivities for AG Formations (DWR, 2002) …........................ 27

Table 5 - Initial Hydraulic Conductivities for Each Zone ................................... 48

Table 6 - Assumed Boundary Condition Values ........................................... 50

Table 7 - Curve Number Linkages (Muleta, 2015) ….................................... 54

Table 8 - Infiltration Rates for Aggregated Infiltration Zones ........................... 56

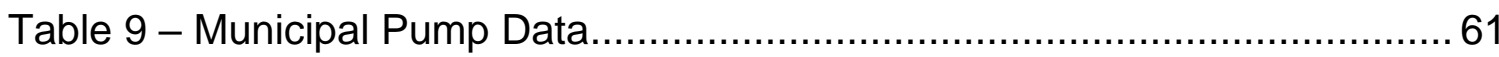

Table 10 - Discretization Analysis Results in Well Heads ................................. 64

Table 11 - Calibrated Boundary Conditions ................................................. 71

Table 12 - Modeled Steady State Budget Values Comparison ........................ 74

Table 13 - Changes in Boundary Budget Values .......................................... 88

Table 14 - Conjugate Gradient Solver (PCG) Tolerance-Run Time Tradeoffs... 89

Table 15 - Strongly Implicit Procedure (SIP) Tolerance-Run Time Tradeoffs .... 90

Table 16 - Compensation for Distance Between Wells and MODFLOW ........... 94

Table 17 - Model Results Compared to 2007 Todd Engineers Study ................. 98

Table 18 - K/S Calibrated Model Compared to 2007 Todd Engineers Study..... 99

Table 19 - K/S/Boundary Condition Calibrated Model Comparison ................. 100

Table 20 - Optimized Parameter Values .................................................... 100 


\section{LIST OF FIGURES}

Figure

Figure 1 - Study Area Boundary …........................................................ 1

Figure 2 - The Model Building Process (Willis \& Finney, 2004) ......................... 3

Figure 3 - Annual Rainfall at Pismo Beach (Todd Engineers, 2007) .................. 9

Figure 4 - Coast Ranges Geomorphic Province (DWR, 2002)........................ 10

Figure 5 - Northern Cities Management Area Geology Summary..................... 12

Figure 6 - Coast Interface (West) Cross Section (Todd Engineers, 2007) ........ 13

Figure 7 - East NCMA Cross Section (Todd Engineers, 2007) ....................... 14

Figure 8 - Paso Robles Formation in Upper Layer (Qpr) (DWR, 1994) ............. 15

Figure 9 - Wilmar Avenue and Oceano Faults (DWR, 1994) ......................... 18

Figure 10 - Depths of Sentry Wells (Fugro Consultants, Inc., 2015) ................. 19

Figure 11 - Hydraulic Gradient Contours 2014 and 2013 .............................. 20

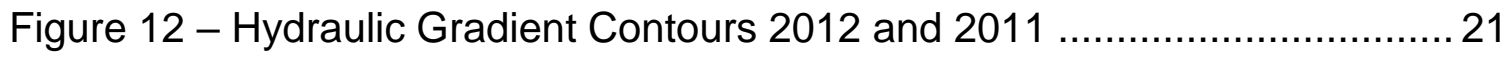

Figure 13 - Hydraulic Gradient Contours 2010, 2009, and 2008.................... 22

Figure 14 - MODFLOW Discretization System ………................................. 32

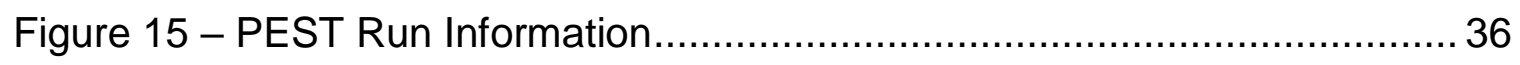

Figure 16 - Slope Map of the Arroyo Grande Creek Watershed ....................... 38

Figure 17 - Arroyo Grande Valley and Tri-Cities Watershed Model Domain...... 38

Figure 18 - Finalized NCMA Groundwater Model Domain ............................... 39

Figure 19 - Cross Section Map of the Santa Maria Groundwater Basin ........... 40

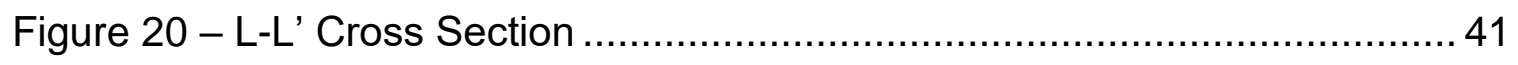

Figure 21 - Ground Surface and Layer Attribute Data ................................... 43 
Figure 22 - Kriging Interpolation Results for Layer Development..................... 44

Figure 23 - Raster Surfaces in Visual MODFLOW® Conceptual Model ............ 45

Figure 24 - Removal of Vertical Distortion by Clipping in Visual MODFLOW®.. 46

Figure 25 - Aggregated Surface Geology ................................................ 47

Figure 26 - Boundary Condition Development .............................................. 49

Figure 27 - Stream Implementation in Visual MODFLOW®............................51

Figure 28 - Soil Database Import Form.................................................... 52

Figure 29 - Land Use and Soil Group Demonstration .................................... 53

Figure 30 - Curve Number Distribution in Model Domain ............................... 55

Figure 31 - Aggregate Infiltration Zones ................................................ 57

Figure 32 - Infiltration Pond Development and Validation.............................. 57

Figure 33 - Lakes Removed from Infiltration Basin Analysis ............................ 58

Figure 34 - Arroyo Grande City Well Field and Attribute Data .......................... 59

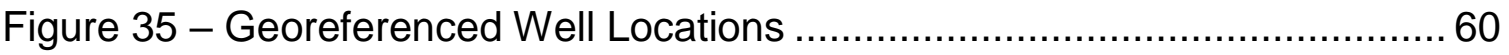

Figure 36 - Matching Simulated Drawdowns to Historical Drawdown Data ....... 60

Figure $37-300 \times 300$ Deformed Grid in Vertical $(\Delta z)$ Discretization................... 62

Figure 38 - Wells Used in Discretization Analysis........................................ 63

Figure 39 - Percent Change in Well Head Levels from Previous Iteration ......... 65

Figure 40 - Computational Time for Increasing Discretizations........................ 66

Figure 41 - Layer 1 Variations in Hydraulic Contours .................................... 67

Figure 42 - Layer 2 Variations in Hydraulic Contours...........................68

Figure 43 - Arroyo Grande City Well Hydrographs from NCMA..................69

Figure 44 - Grover Beach Hydrographs from NCMA ….............................. 70 
Figure 45 - Oceano Hydrographs from NCMA …........................................ 70

Figure 46 - Farm Well Hydrographs from NCMA ….................................... 70

Figure 47 - Hydraulic Head Residuals in Wells for Steady State ..................... 72

Figure 48 -Steady State Heads Compared to Spring 2013............................ 75

Figure 49 - Arroyo Grande Creek Hydrograph from 2008 to $2015 \ldots \ldots \ldots \ldots \ldots . . . .77$

Figure 50 - Monthly Precipitation at Oceano Rain Gauge 795 ........................ 78

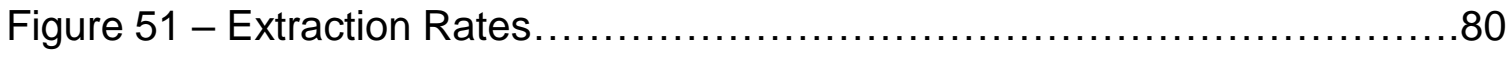

Figure 52 - Farm Well Monthly Extraction Assumptions ............................... 81

Figure 53 - AGPW Well Standing Water Levels (AGPW, 2016) ...................... 82

Figure 54 - GBPW Well Standing Water Levels (GBPW, 2016) ........................ 83

Figure 55 - Farm Well Standing Water Levels (Fugro Consultants, Inc., 2015)..84

Figure 56 - 32-C3 Agricultural Monitoring Well Hydrograph (Sorensen, 2016)...85

Figure 57 - Changes in River Leakage from Variations in Stream Stage ........... 86

Figure 58 - Changes in River Leakage from Variations in Leakance ................. 87

Figure 59 - Pre-Calibration Residual Plots................................................. 91

Figure 60 - Layer Thicknesses near North-East Boundary of MODFLOW........95

Figure 61 - Percent Change in $\Phi$ from Changes in Dirichlet Head Boundaries . 95

Figure 62 - Calibrated Simulated/Observed Hydraulic Heads......................... 97

Figure 63 - Storage and Pumping Rates from the Calibrated Groundwater .... 101

Figure 64 - Cumulated Aquifer Storage During 2008-2015.......................... 102

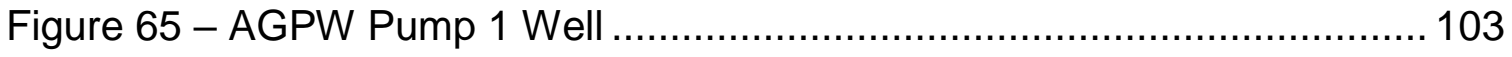

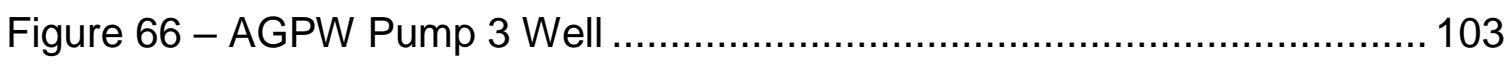

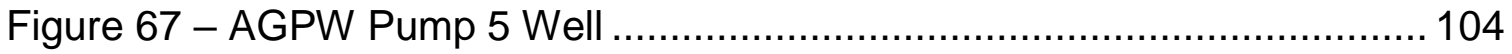




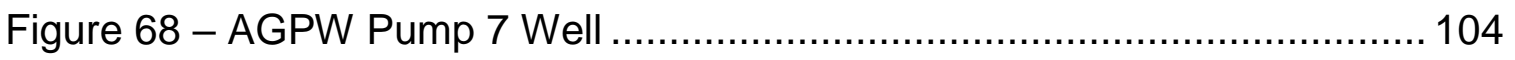

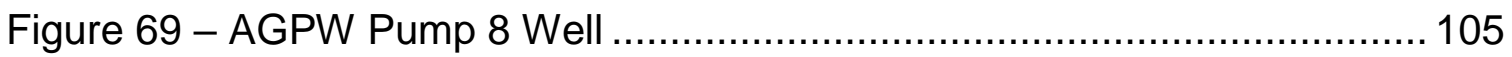

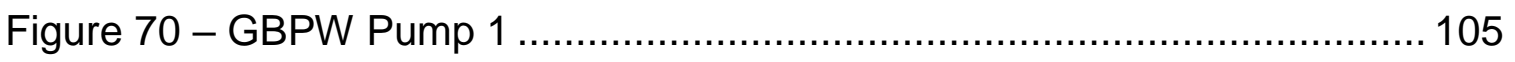

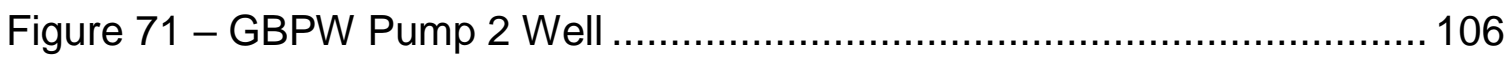

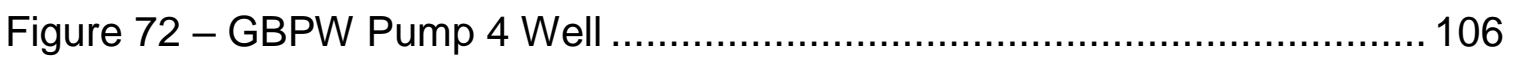

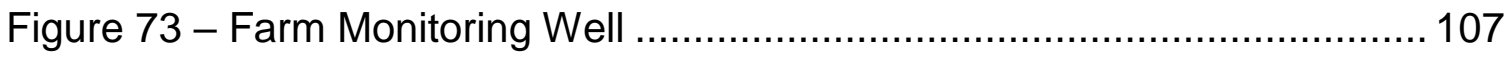




\section{Introduction}

The Northern Cities Management Area (NCMA) of the Santa Maria Groundwater Basin is located on the California's Central Coast. The NCMA includes Arroyo Grande, Oceano, Pismo Beach, and Grover Beach. The component of the NCMA included in this study is bounded by Highway 101, Highway 1, the ocean, and the Nipomo mesa to the southeast (Figure 1).

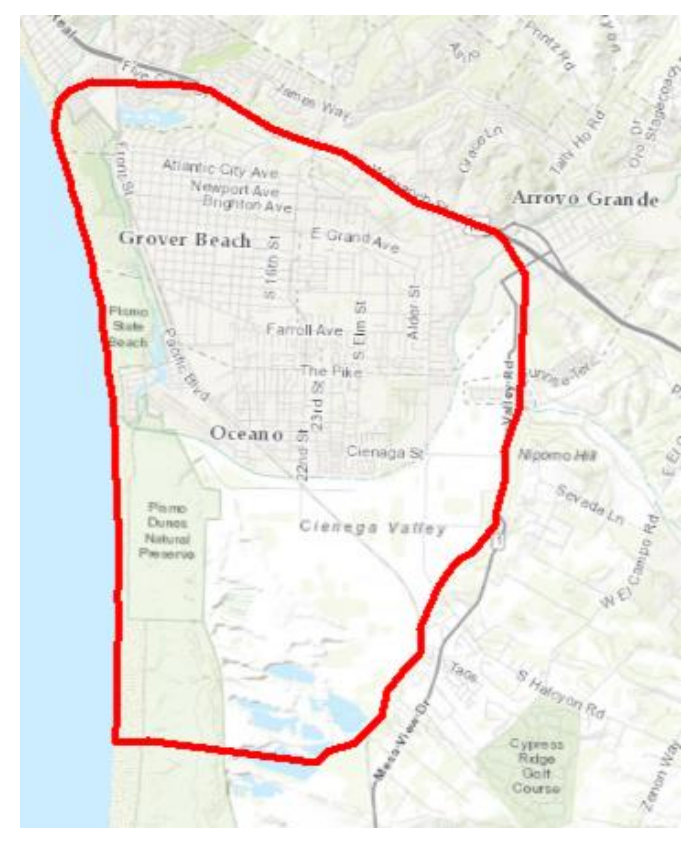

Figure 1 - Study Area Boundary

This thesis study developed a numerical groundwater model based on data from Todd Engineers, Fugro Consultants Inc., GEI Consultants Inc., the Department of Water Resources (DWR) that characterize the geology, hydrology, and aquifer systems in the NCMA. 


\subsection{Objectives and Scope}

A numerical model for the NCMA aquifer complex is presented. The objective of the study is to develop a numerical groundwater model for the NCMA aquifer system to enhance the understanding of subsurface groundwater flow. Infiltration, streamflow, pumping, and return flows are implemented to characterize the aquifer complex over time. The numerical model is calibrated to municipal and monitoring well data, average monthly water balances, and hydraulic contours. Steady state hydraulic head values are compared to farm well hydraulic head data from the 2011-2014 NCMA Annual Monitoring Reports. Well data is provided by Arroyo Grande Public Works (AGPW), Grover Beach Public Works (GBPW), Oceano Community Services District (OCSD), and Paul Sorensen with GSI Water Solutions, Inc. Streamflow and precipitation data for the study area is provided by San Luis Obispo County Public Works (SLOCPW). Transient aquifer inflows and outflows are assessed in the results of the study and are compared to monthly average balance terms from Water Balance Study for the Northern Cities Area by Todd Engineers (2007 Todd Engineers Study). The concept of a sustainable yield is discussed.

The project is unique because the presented numerical groundwater model is the first groundwater model created specifically for the NCMA study area. Uncertainty in the geologic and boundary conditions is addressed through sensitivity analysis. Post-processing and visualization of results are facilitated in Visual MODFLOW® Flex, ArcGIS®, and Microsoft® Excel. 


\subsection{Introduction to Mathematical Models and Optimization}

\subsubsection{Mathematical Modeling}

Mathematical models are important tools for dynamic water resource planning projects. Simulation models provide insight to how environmental processes, such as groundwater or surface water flow, occur over time. Numerical models are calibrated to past conditions, and are coupled with predictions of future inputs to provide predictions of future response. The model building process is described (Figure 2).

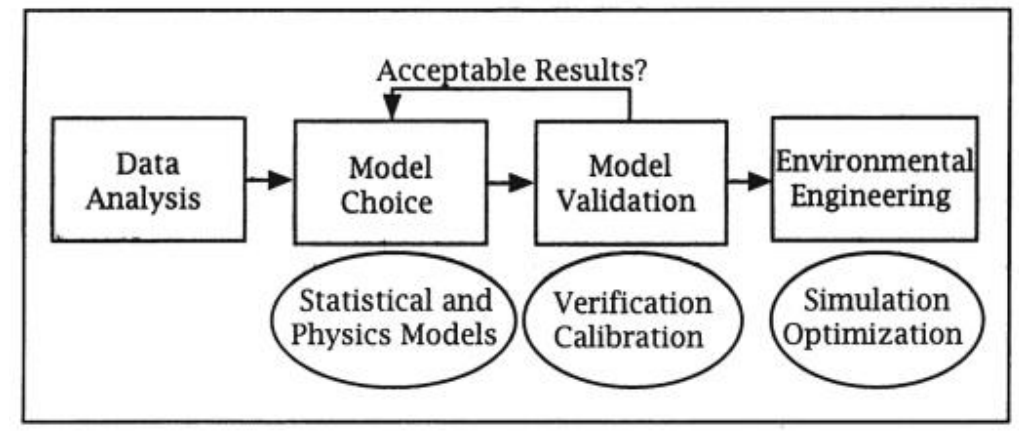

Figure 2 - The Model Building Process (Willis \& Finney, 2004)

The first step in the simulation model building process is data collection, analysis, and processing. Data is evaluated for consistency and reliability and is processed into a uniform time interval (or timestep) for model implementation. The second step in model development is model selection. It is important to identify if the project scale is large enough to benefit from a mathematical model or if an analytical solution can provide the desired results. Mathematical model development demands additional human and computational resources when compared to simple analytical models. In addition, different mathematical models 
can be used for different applications, and one model may serve well for one purpose but fail to provide valuable results for another purpose. The third step evaluates the mathematical model's ability to reproduce recorded data values for the state variables (or unknowns). The model parameter values are optimized during the validation phase to provide the best fit to observed data. Simulation modeling begins once the mathematical model has been properly validated and spatial and temporal discretization analysis and selection has been completed.

An environmental system can be described as a mathematical equation that includes applications of algebra, calculus, and physics. The mathematical model solves for the state variable of the system by evaluating the equation or set of equations with known parameter and decision variable values. The modeling process is initiated by relating tangible boundary and initial condition values to the unknown state variables. Mathematical models representing environmental systems are often represented by partial differential equations. For instance, review the three-dimensional representation of the groundwater flow equation (Harbaugh, 2005, Equation 1.2.1.1).

$$
\frac{\partial}{\partial x}\left(K_{x x} \frac{\partial h}{\partial x}\right)+\frac{\partial}{\partial y}\left(K_{y y} \frac{\partial h}{\partial y}\right)+\frac{\partial}{\partial z}\left(K_{z z} \frac{\partial h}{\partial z}\right)+W=S_{s} \frac{\partial h}{\partial t}
$$

where:

$$
\begin{aligned}
K_{x x}, K_{y y}, K_{z z}= & \text { are hydraulic conductivities in the Cartesian coordinate system } \\
& \text { which is aligned with the principal axis of the hydraulic conductivity } \\
& \text { tensor }(\mathrm{L} / \mathrm{T}) \\
h= & \text { the hydraulic head }(\mathrm{L}) \\
W= & \text { flow rate in }(+) \text { and out }(-) \text { divided by a unit volume }\left(\mathrm{T}^{-1}\right) \\
S_{S}= & \text { the specific storage }\left(\mathrm{L}^{-1}\right)
\end{aligned}
$$


The partial differential equation relates the hydraulic head to the parameters of the system over space and time. The temporal derivative of the hydraulic head on the right hand side of the equation is a function of the spatial derivative terms and the hydraulic conductivity, and storativity parameters of the model. In order for the equation to be solved, the concentration at an initial position at an initial time must be specified. Then, the model uses the parameters to progress the solution over space and time. The solution of partial differential equations is obtained using numerical methods. These methods approximate the spatial and temporal derivatives based on the specification of initial and boundary conditions. Finite difference and finite element methods are commonly used to solve partial differential equations in environmental engineering applications.

In groundwater applications, linear partial differential equations describe confined groundwater flow, and nonlinear partial differential equations describe unconfined groundwater flow. While linear partial differential equations demonstrate elliptic and parabolic characteristics, nonlinear partial differential equations demonstrate hyperbolic-wave-like characteristics that are difficult to solve using modern mathematics. In environmental engineering, simulation models are developed to solve partial differential equations that represent complex environmental systems over space and time. Advantages of simulation modeling include a higher resolution representation of an environmental system that is a function of spatial and temporal dimensions. A robust simulation model will provide small variations in the solution for minor variations in the system's parameters (Willis \& Finney, 2004). Disadvantages of a simulation model include increased 
capital investment for model development and calibration, computational expense, and the absence of trade-off information that is inherent in optimization models.

The value of a mathematical model is generated by accurately representing the current and previous state of a system. In groundwater modeling, calibration is facilitated by varying aquifer property values, like hydraulic conductivity and storativity, to best match the results of the model to time-series well and streamflow data. Automated calibration processes utilize optimization systems to solve the parameter estimation problem by iteratively running the model with varying inputs to identify the optimum parameter values.

\subsubsection{Optimization Modeling}

Assuming a global solution exists, optimization modeling can provide the best solution to solving an engineering design or planning problem. Optimization models have three mathematical components. The first component is the objective function. The objective function correlates the state variable of the environmental system to a function that can be maximized or minimized. The second component of an optimization model is a set of model constraints. The constraints bound the characterization of the decision variables (the dependent variables) to avoid generating invalid results. The third component of an optimization model are the decision variables. Optimization models also provide trade-off information that describes how the objective changes with respect to variations in the constraints of the model. The impacts of constraint variation on the objective of the optimization model can be assessed using the trade-off values without requiring additional model runs. 


\section{Literature Review}

The information described in the literature review is used to develop an understanding of geologic, climatic, and human influences on the groundwater environment. The groundwater model inputs are developed or estimated based on data from previous studies and historical monitoring.

Several geologic characterization studies of the Santa Maria Groundwater Basin have been conducted over the past 40 years. The Department of Water Resources completed geologic and water resource studies in 1994, 2000, and 2002. The 1994 DWR study included an extensive description of stratigraphy, unconsolidated sediments, consolidated sediments, consolidated rocks, geological structures, faults, and folds in the Santa Maria groundwater basin (Lewy, 1994). The 2002 DWR study described water demand, water supply, water-bearing formations, bedrock, aquifer recharge, water quality, water budget, yield, overdraft, and recommendations (DWR, 2002).

Geohydrologic inflows and outflows were evaluated for the NCMA (Todd Engineers, 2007). The 2007 Todd Engineers study included evapotranspiration coefficients, NRCS soil data for varying land use types, soil properties, averaged monthly contributions by different components of the water budget, and spreadsheets providing precipitation recharge per month, boundary condition flow rates, infiltration, agricultural and urban return flows, and hydraulic conductivity values.

Using grant funding from the California Department of Fish and Wildlife, Central Coast Salmon Enhancement (CCSE) reported on data analysis regarding 
climate, topography, land use, water quality, fish migration barriers, erosion, and water quality (CCSE, 2005). Stetson Engineering, Inc. provided data analysis characterizing historic streamflow in Arroyo Grande Creek, pre-and-post dam hydrology, reservoir inflow, dam-release data, and a reservoir operational model (HCP, 2004).

NCMA Annual Monitoring Reports have been provided by several engineering firms since 2008. The 2008 NCMA Annual Monitoring Report addressed precipitation, evapotranspiration, and water management, and provided an update describing drought response, desalination, and Lopez reservoir expansion (Todd Engineers, 2009). Hydraulic gradient contours were visualized based on data in 17 wells in the NCMA. Todd Engineers prepared the 2009 NCMA Annual Monitoring Report (Todd Engineers, 2010). The 2010, 2011, and 2012 NCMA Annual Monitoring Reports were completed by GEI Consultants (GEI, 2011, 2012, 2013). The 2013 and 2014 reports were written by Fugro Consultants, Inc. (Fugro Consultants, Inc., 2014, 2015). The 2011-2014 NCMA Annual Monitoring Reports are used to identify farm well hydraulic heads and hydraulic contours to aid in calibrating the presented NCMA numerical groundwater model.

\subsection{Surface Water Hydrology}

The NCMA lies within the Arroyo Grande Creek watershed and is a component of the Estero Bay Hydrologic Unit, the Arroyo Grande Hydrologic Area, and the Oceano Hydrologic Sub-Area (CCSE, 2005). Lopez Dam was completed in 1968 and releases an average of 2,330 AFY between April and October to meet 
agricultural and domestic demands (HCP, 2004). The stream flow rate is often 100 cfs or less. Dam releases for steelhead and other fish species began in 1998. Winter peak flow rates in Arroyo Grande Creek are proportional to the duration and intensity of the rainfall on the watershed and cause flash floods. Groundwater contributes flow to the stream until May when the streams are low and potentially provide recharge to the groundwater (Dvorsky, 2004). According to Stetson Engineering's data analysis, average inflows to Lopez Lake are roughly 16,000 AFY. The lake has a storage capacity of 49,400 AF. Consumption of Lopez Lake water increases in the later years of the groundwater model study and causes decreases in groundwater pumping. The annual rainfall for Pismo Beach is 16.84 inches (Figure 3).

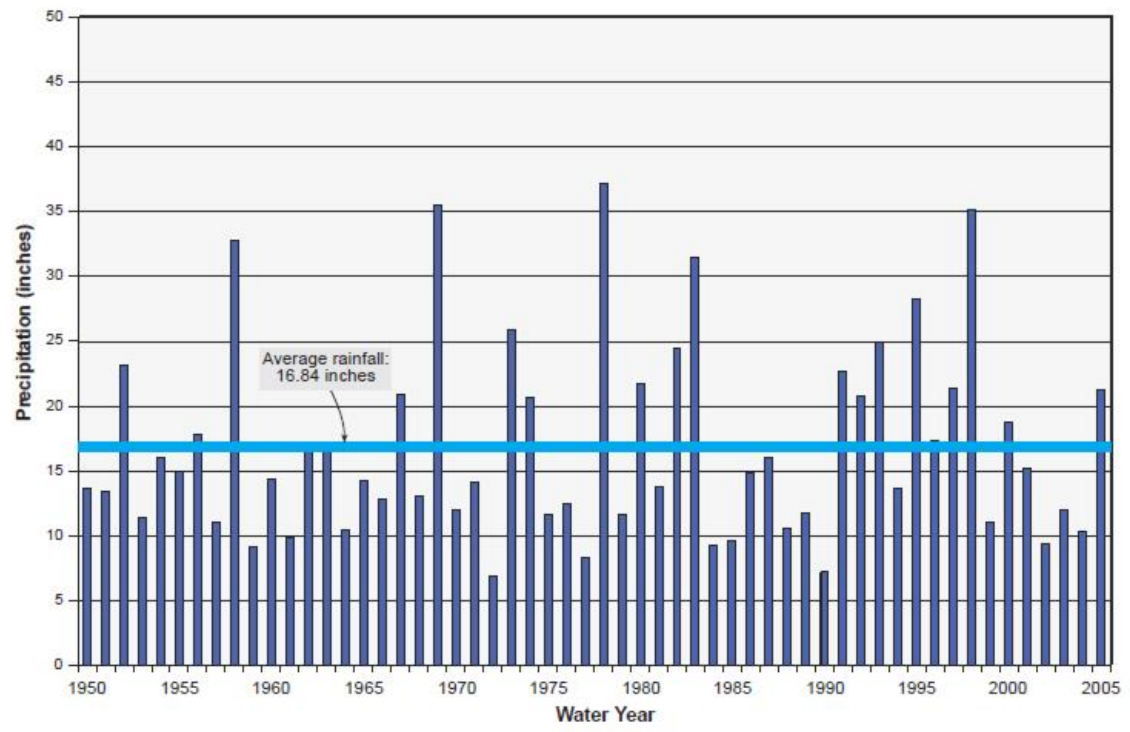

Figure 3 - Annual Rainfall at Pismo Beach (Todd Engineers, 2007)

Large scale rain events take place at a recurrence interval of roughly 10 years. Precipitation values range from 12 to 35 inches, with a maximum of 71 inches in 
Lopez Canyon. Averages for the Arroyo Grande Police Department, Pismo Beach Police Department, and Lopez dam are, respectively, 14.6 inches, 16.1 inches, and 20.0 inches. The Arroyo Grande Creek watershed has an area of approximately 190 square miles and has a maximum elevation of 3,200 feet (DWR, 2002).

\subsection{Geology}

Geologic characterization of the groundwater model study area is of paramount importance to model development and the interpretation of model results. The NCMA lies in the Coast Ranges Geomorphic Province on the Central Coast of California (Figure 4).

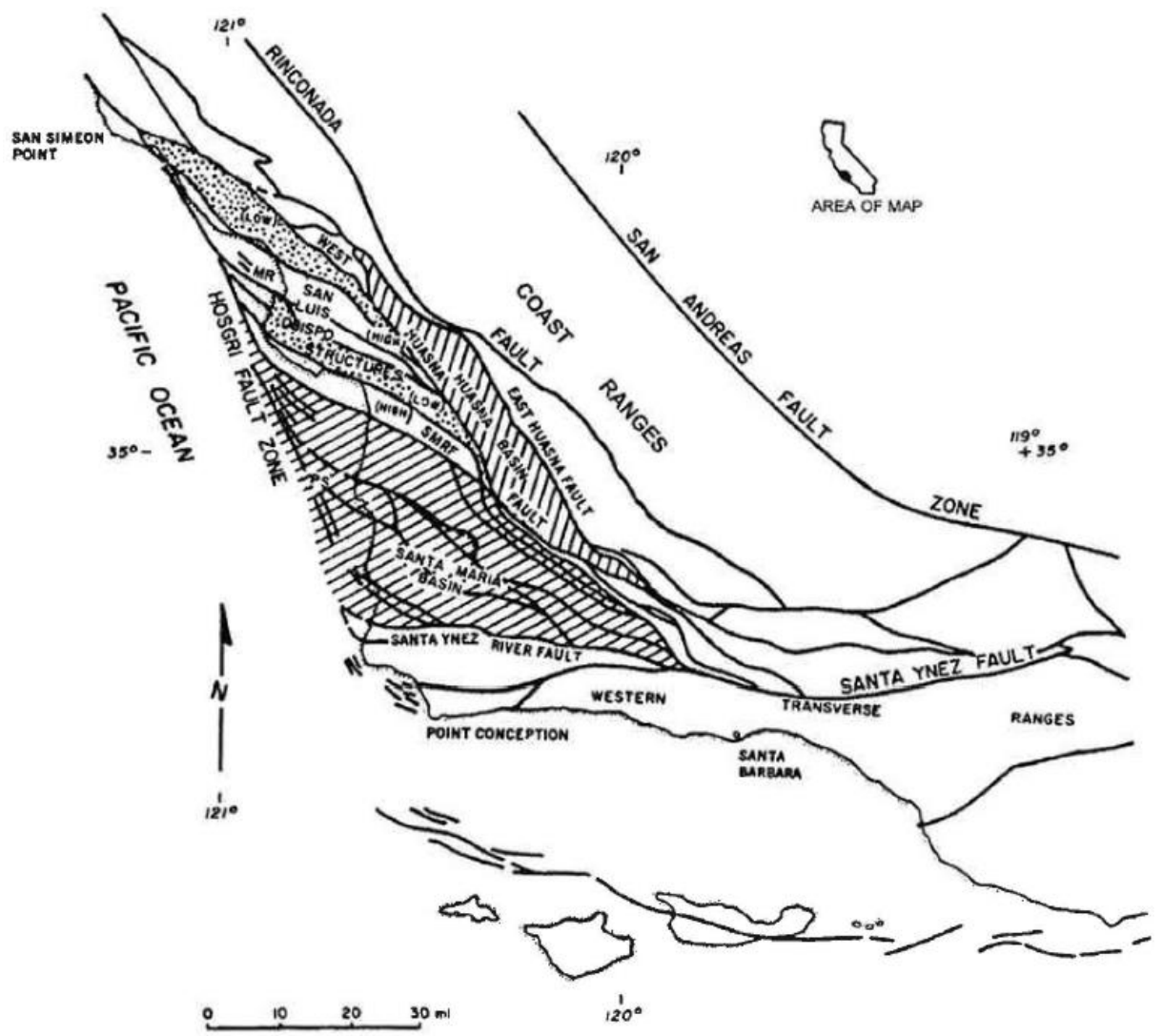

Figure 4 - Coast Ranges Geomorphic Province (DWR, 2002) 
The Coast Ranges Geomorphic Province stretches from the CaliforniaOregon border to Santa Barbara and includes northwest to southeast oriented mountains with complex geology. The ancient Mesozoic Franciscan complex lies beneath the other formations and contains bedrock from the Cretaceous, Jurassic, or Triassic periods. Over the past 11 million years, the tertiary marine sedimentary stratigraphy has been lifted by plate tectonics. This process has folded the mountains of the California Coast.

The study area includes three different types of lithologic units including unconsolidated sediments, consolidated sediments, and consolidated rocks. The unconsolidated sediment lithology includes water-bearing strata from the Pleistocene epoch (2 million years ago), the consolidated sediment lithology includes semi-water-bearing strata from the Pliocene ( 3 million years ago) and Miocene epochs (18 million years ago), and the consolidated rocks contain impermeable geology from the Miocene Monterey Formation (Blake, 1856), Obispo pyroclastic volcanics from the Miocene epoch (Hall, et al., 1966), and the Franciscan complex (Lawson, 1895). Faults are present in the study area and include right-lateral strike-slip faults and Quaternary reverse and thrust faults that are oriented west-northwest (Lewy, 1994). The geology in the upper layer of the study aquifer system contains dune sands, alluvium, and terrace deposits (Figure 5). 


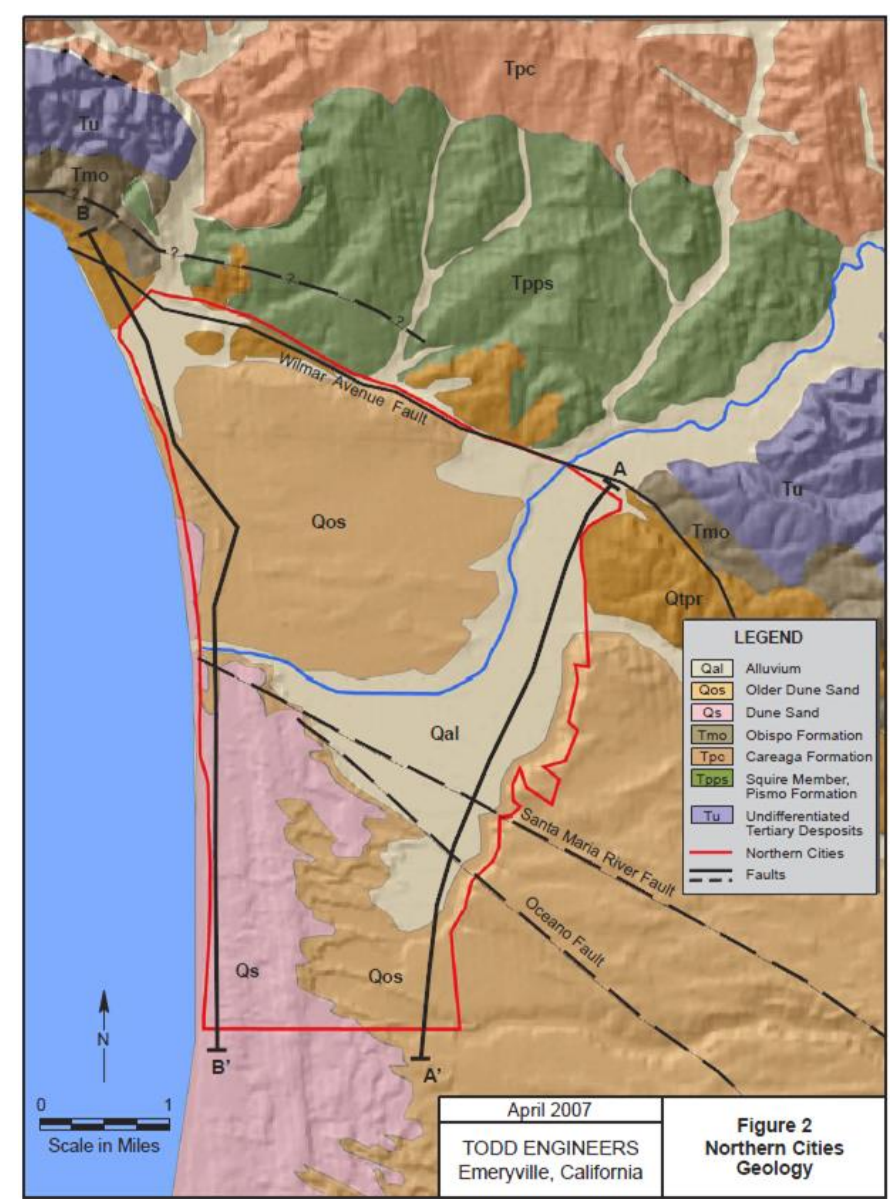

Figure 5 - Northern Cities Management Area Geology Summary (Todd Engineers, 2007)

The cross section near the coastal interface with the ocean contains layers of clay that confine varying geologic structures (Figure 6). The interface of the Santa Maria River Fault and the Oceano Fault create uncertainty in geologic layering. The presence of faults is integrated into the groundwater model via interpolation of cross-sections. The northern component of the west cross section includes the Paso Robles Formation, and the Pismo Formation with minor confining layers sporadically distributed. The southern component of the west cross section includes confining layers, the Paso Robles Formation, another 
confining layer, and the Careaga Formation with a depth of up to 900 feet. The east cross section describes the layering of alluvium deposits, the Paso Robles Formation, and the Pismo Formation towards the North, with a total depth of roughly 200 feet (Figure 7). The southern component of the coastal cross section contains distributed confining layers until a depth of approximately 350 feet that separate alluvium deposits from the Paso Robles Formation, the Careaga Formation. The Oceano fault separates the confining layers but the stratigraphy remains similar.

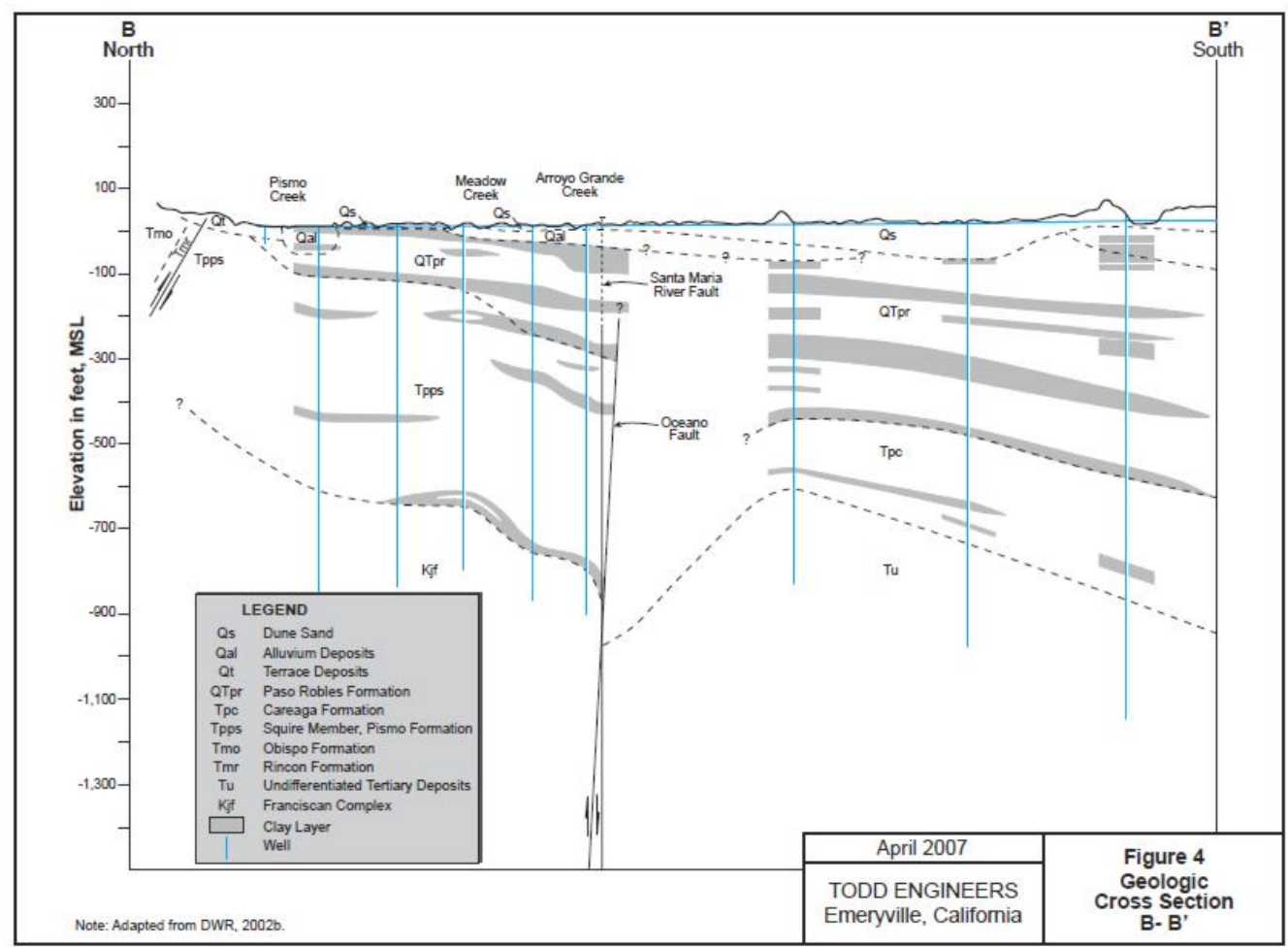

Figure 6 - Coast Interface (West) Cross Section (Todd Engineers, 2007) 


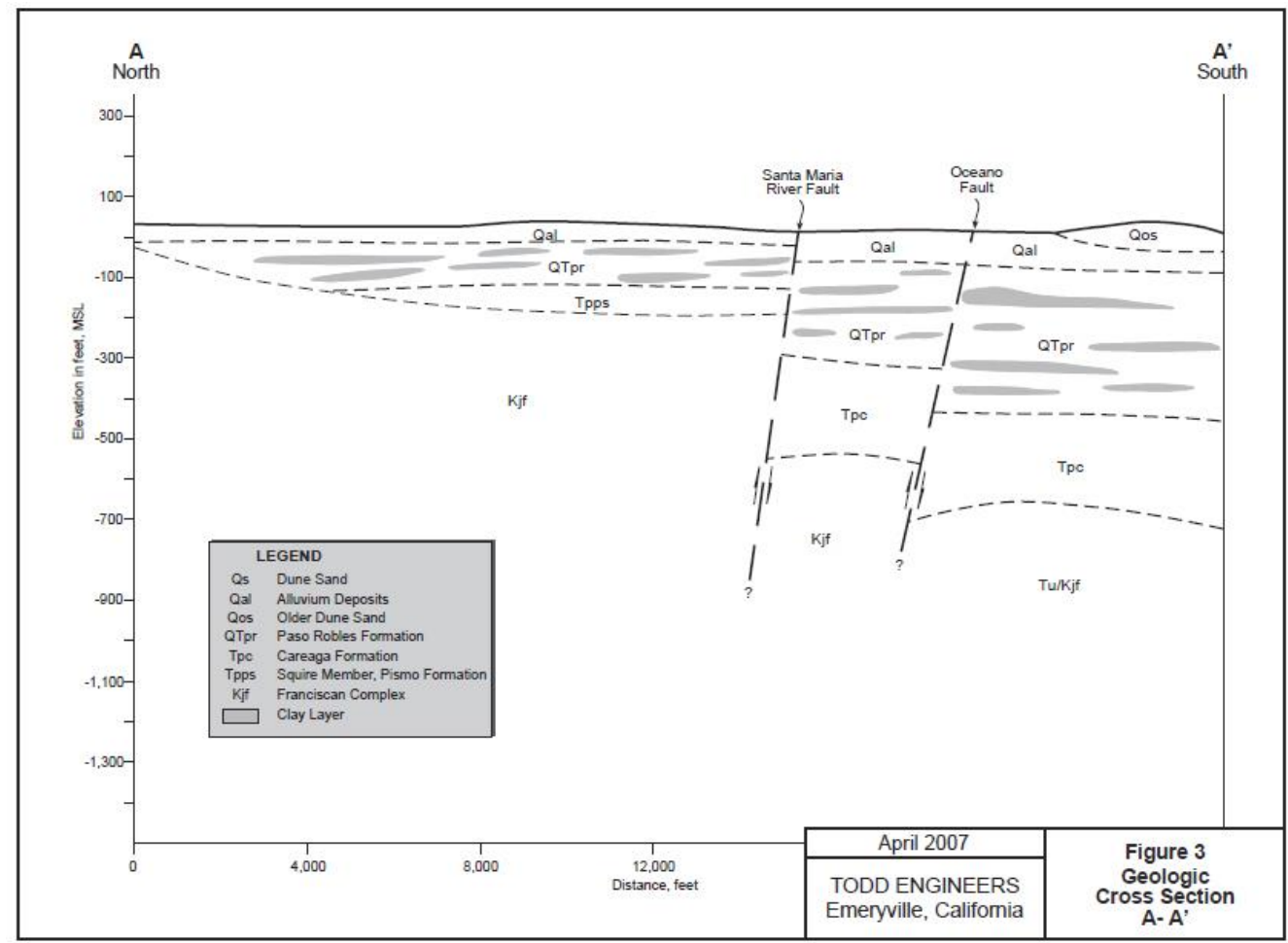

Figure 7 - East NCMA Cross Section (Todd Engineers, 2007)

\subsubsection{Alluvium}

The alluvium contains gravel, sand, silt, and clay located in the stream valleys and coastal plains. In the Arroyo Grande Valley, the alluvium thickness ranges from a few feet down gradient of Lopez Lake dam to approximately 100 feet near Highway 101 (Lewy, 1994). A 20-30-foot-thick confining layer of blue clay is present below the alluvium (California Department of Public Works, Division of Water Resources, 1945). West of Highway 101, the alluvium reaches greater thicknesses of 130 to 140 feet and becomes semiconfined near the coast. The alluvium in the Arroyo Grande Valley was also described to have an average thickness of 100 feet and is 175 feet thick above the confluence of Tar Spring and Arroyo Grande Creek (Goss and Reed, 1969). In the Arroyo Grande Valley, the 
well depths range from 38 to 155 feet deep with a median of 95 feet and provide well yields of 13 to 500 GPM with a median value of 60 GPM (DWR, 2002). Well depths pumping from the alluvium range from 25 to 155 feet in the Arroyo Grande Plain region with a median value of 100 feet and well yields are in the range of 10 1700 GPM (DWR, 2002).

\subsubsection{Dune Sand and Older Dune Sand}

Recent dune sands have high hydraulic conductivity and are usually unsaturated in the study area. The older dune sands are found south of the study area and are not developed for pumping. Thicknesses of the sand layers range from 40 feet in the study area to 150 feet near the Nipomo mesa (Lawrence, Fisk and McFarland Inc., 1987).

\subsubsection{Paso Robles Formation}

The Paso Robles Formation outcrops near the northeast boundary of the study area (Figure 8).

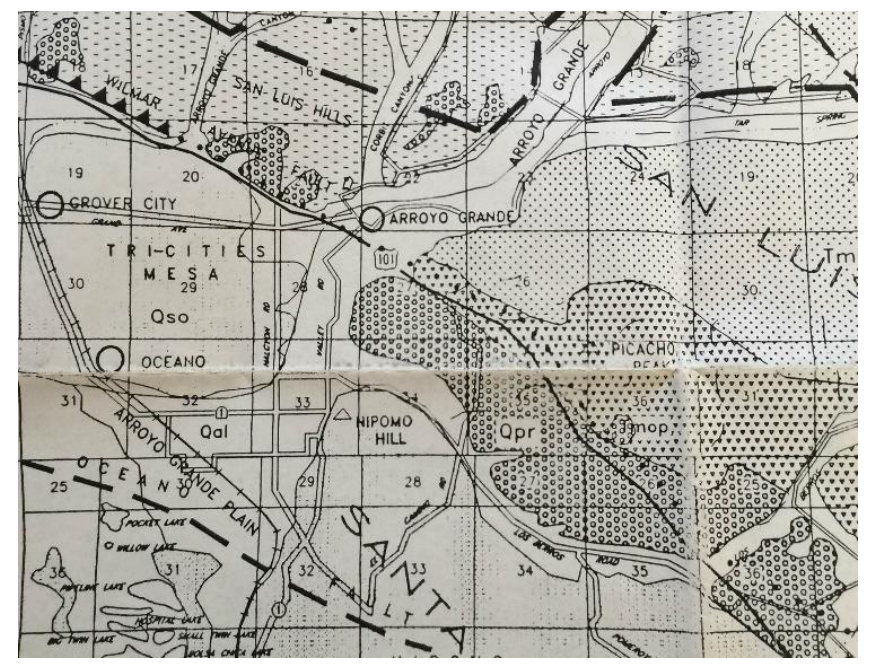

Figure 8 - Paso Robles Formation in Upper Layer (Qpr) (DWR, 1994) 
The Paso Robles Formation also underlies most of the alluvium layer below the NCMA. The Paso Robles Formation is typically the highest-yielding formation in the localized system and reaches a thickness of 850 feet (DWR, 1970). The geologic makeup of the formation is similar to the alluvium with poorly sorted gravel, sand, and random occurrences of silt and clay, but is more compacted. The Paso Robles aquifer system is separated into two components with semiconfined and unconfined properties inland and additional confinement towards the coast (DWR, 1979). The majority of municipal and agricultural pumping is drawn from the Paso Robles Formation. The Tri-Cities Mesa well depths range from 27 to 250 feet with a median value of 140 feet and well yields range from 10 to 2500 GPM (DWR, 2002).

\subsubsection{Careaga Formation}

The Careaga Formation is described as having potential for future extraction to meet increased demands in the area (Lewy, 1994). The geology of the Careaga Formation includes unconsolidated to well-cemented sand and gravel that is composed of calcium carbonate and inserts of silt and clay with medium to low hydraulic conductivity. Thicknesses of the Careaga Formation range from 750 feet on the southern boundary of the study area to 350 feet in the AG area (DWR, 1970). The formation is confined towards the coast and the majority of wells are perforated in both the Paso Robles Formation above and in the Careaga Formation. 


\subsubsection{Pismo Formation}

The Pismo Formation includes shale, diatomite, and fine to medium-grained arkosic sandstone with medium to low hydraulic conductivities (Lewy, 1994). The Pismo Formation extends between the cities of Arroyo Grande and Pismo Beach and contains water for domestic wells (Weber and Associates, 1990). Some sandstone components of the Pismo Formation are water bearing and have a thickness between 70 and 600 feet (DWR, 1970). The entire formation is as thick as 2,500 feet in some locations. The water quality is often saline due to the depth. Tri-Cities Mesa wells penetrating into the Squire member range from 300 to 600 feet with a median value of 460 feet and produce well yields of 150 to 2,000 GPM with a median of 1,070 GPM (DWR, 2002).

\subsubsection{Consolidated Rocks}

The consolidated rocks beneath the Careaga and Pismo formations (the Obispo pyroclastic volcanics, the Franciscan complex, and the Monterey Formation) are considered impermeable confining bedrock layers in this study.

\subsubsection{Faults}

Several faults intercept the study area. The northern boundary of the NCMA is a thrust fault called the Wilmar Avenue fault that offsets the lower Miocene rocks on top of Pliocene geology roughly 900 feet on the west section. The east section is visible at the surface as a monoclonal fold and is described as a blind thrust (Lewy, 1994). The fault is not expected to retard flow. The Oceano fault is approximately 9 miles long and parallels the Wilmar Avenue fault. The Oceano fault displaces the subsurface strata by roughly 300 feet but is not expected to 
retard groundwater flow. The Wilmar Avenue and Oceano faults are oriented northwest to southeast (Figure 9).

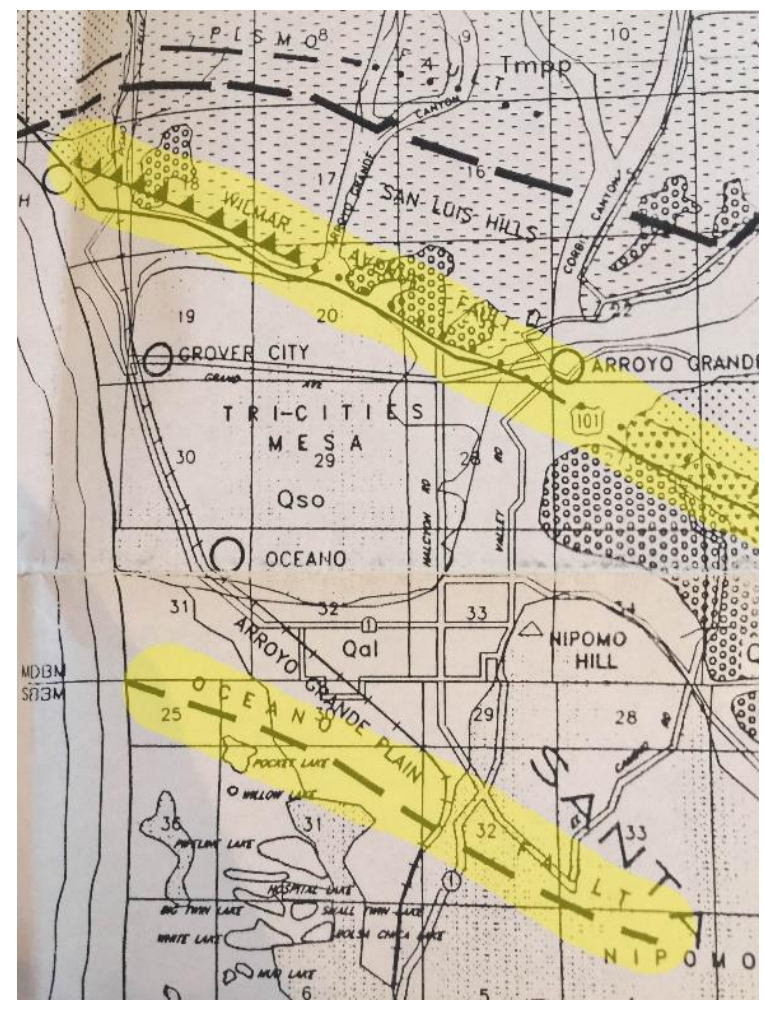

Figure 9 - Wilmar Avenue and Oceano Faults (DWR, 1994)

The West Huasana fault lies beneath Lopez Reservoir and is northwest oriented. The fault is confined to the Miocene rocks and does not cause vertical displacement and is not expected to affect groundwater flow; however, the similar west by northwest slip fault, the Edna fault, intersects the Arroyo Grande Valley one-and-one-half miles downstream of the dam and does cause groundwater flow to rise (Goss and Reed, 1969). The Santa Maria River fault, shown in Figure 5, is considered by some to be critically important to groundwater flow across the mesa (Paul Sorensen, 6/7/2016). 


\subsection{Groundwater Hydrology}

\subsubsection{Groundwater Monitoring Program}

More than 145 wells in the Santa Maria groundwater basin have been monitored by the SLOCPW for several decades. The groundwater monitoring network currently consists of 38 wells in the NCMA. Piezometer sentry wells are located near the ocean and are used to identify increases in saltwater intrusion (Fugro Consultants, Inc., 2015). The depths of the sentry wells are demonstrated (Figure 10).

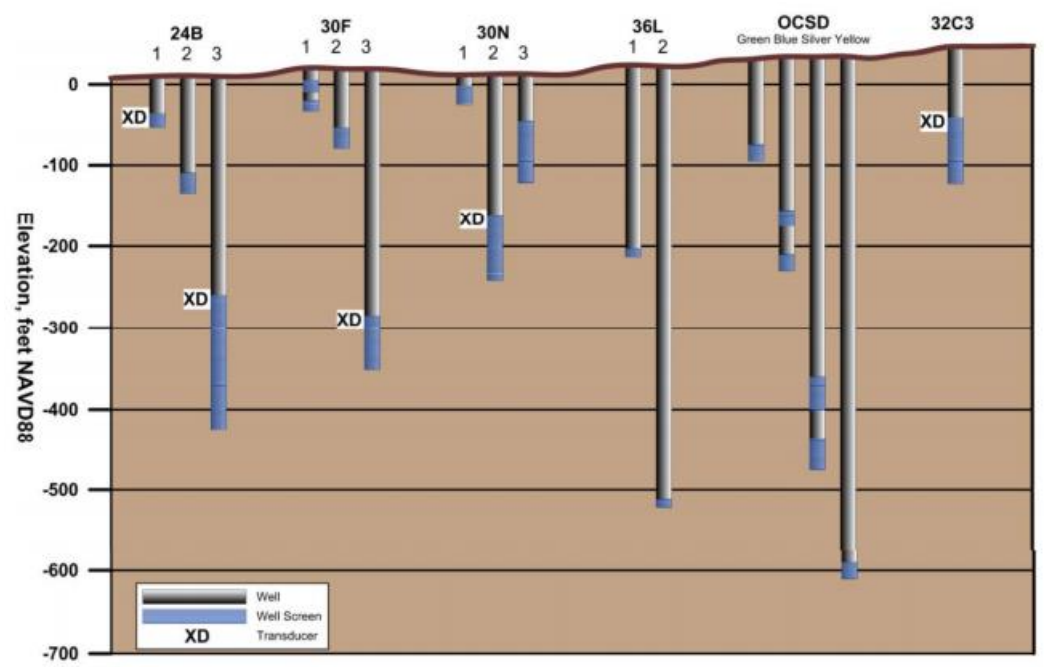

DEPTHS OF SENTRY WELLS

Northern Cities Management Area

San Luis Obispo County, California

Figure 10 - Depths of Sentry Wells (Fugro Consultants, Inc., 2015)

The NCMA Annual Monitoring Reports include hydraulic gradient profiles that are developed using data from farm, municipal, and monitoring wells. 
The most recent hydraulic contouring plots are developed by Fugro Consultants, Inc. (Figure 11).
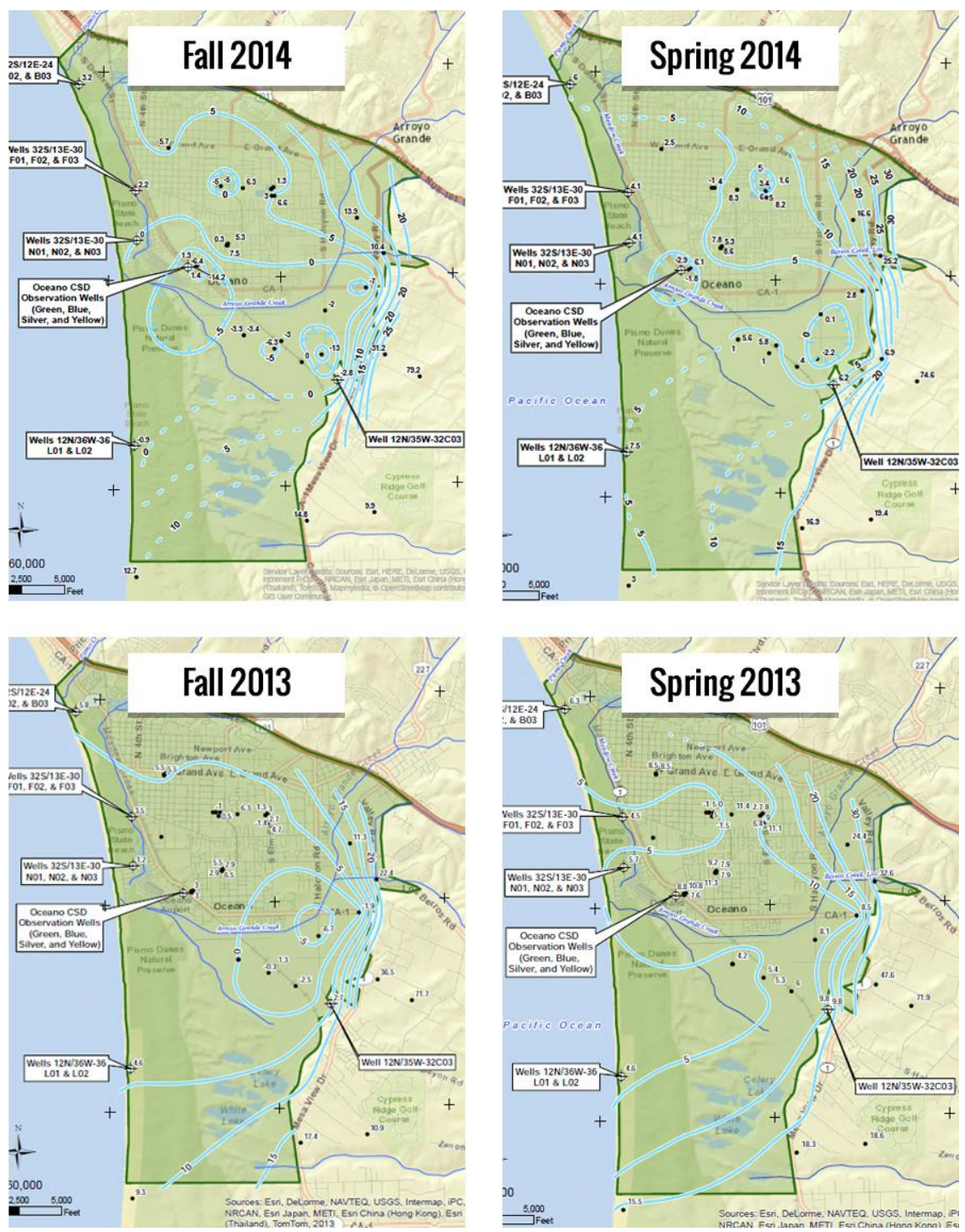

Figure 11 - Hydraulic Gradient Contours 2014 and 2013 (Fugro

Consultants, Inc., 2015, 2014)

Cones of depression are present in the Oceano CSD observation wells and Well 12N/35W-32C03 and are most apparent in the Fall of 2014 with head levels of -14.2 and -13 feet, respectively. The heads in Spring are higher than Fall as 
expected from increases in stream leakage and recharge, and decreases in agricultural pumpage through the winter season. Hydraulic contours are estimated to be higher in 2012 and 2011 (Figure 12).
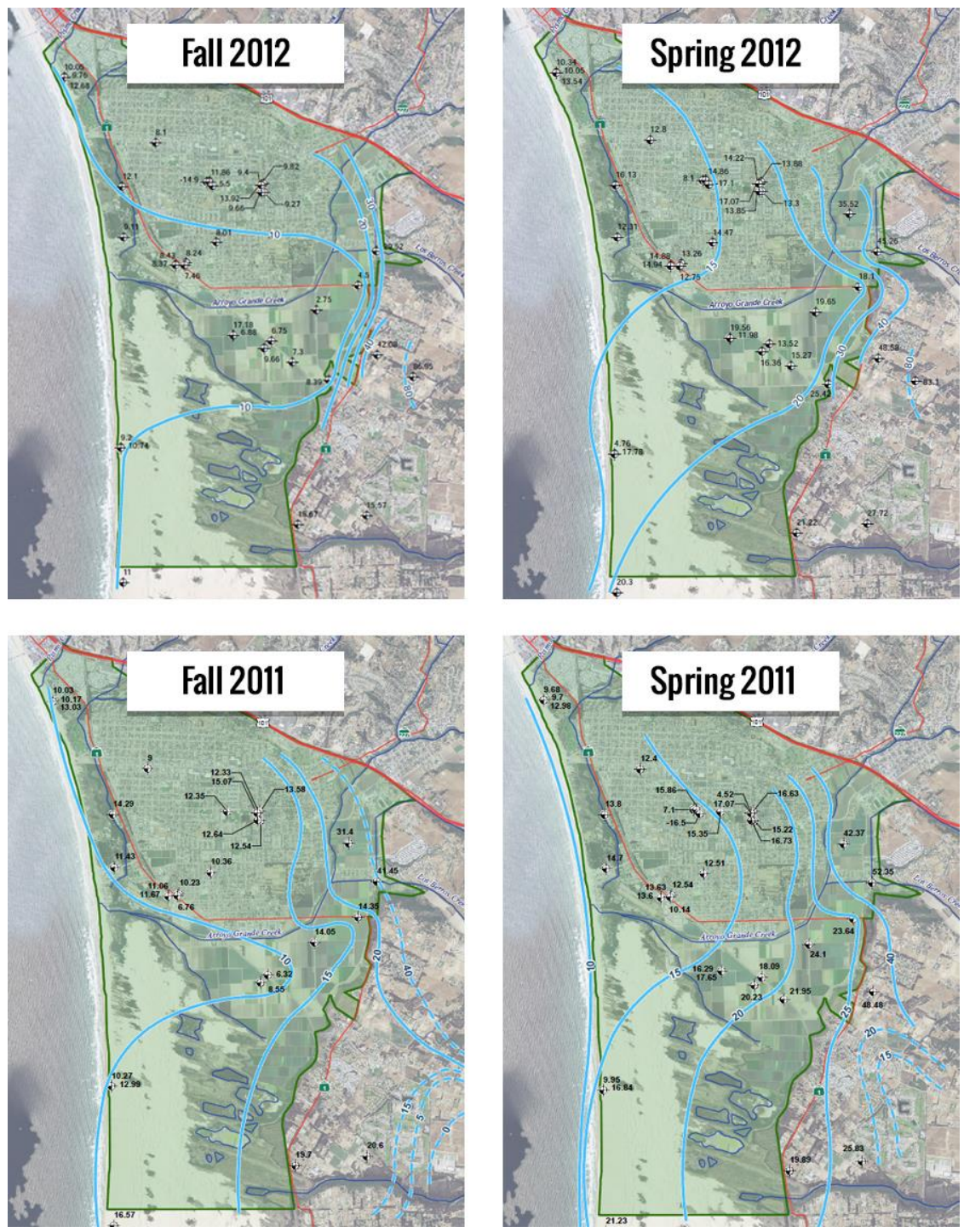

Figure 12 - Hydraulic Gradient Contours 2012 and 2011 (GEI Consultants, Inc., 2013, 2012) 
The Fall profile declined 10 feet for a region of the aquifer system. The heads were higher in 2011 than 2012 and the contour between the 10 feet and 15 feet gradient is larger than in Fall of 2012.

Hydraulic contours for 2010, 2009, and 2008 demonstrate a decreased hydraulic gradient (Figure 13).
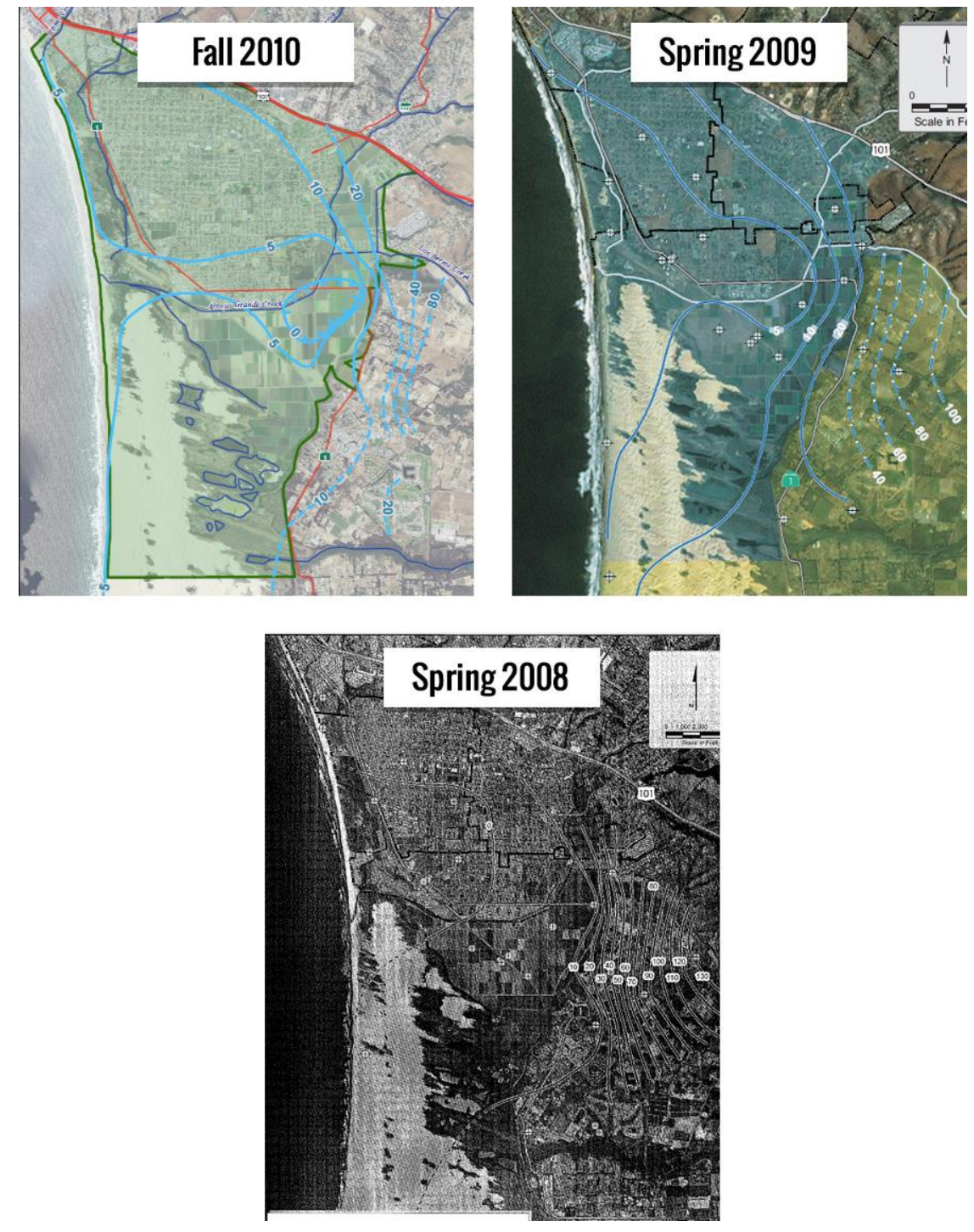

Figure 13 - Hydraulic Gradient Contours 2010, 2009, and 2008

(GEI Consultants, Inc., 2011, Todd Engineers, 2010, 2009) 
Heads in 2010, 2009, and 2008 were lower than the highs during 2011 and 2012 and more similar to the heads from 2013 and 2014. The mountain-front recharge hydraulic gradient from the southeast component of the NCMA region is demonstrated in the 2010,2009 , and 2008 contour maps more than the later maps.

\subsubsection{NCMA Regional Water Balance}

The 2007 Todd Engineers Study describes the NCMA aquifer budget (Table 1).

Table 1 - NCMA Aquifer Budget (Todd Engineers, 2007)

\begin{tabular}{|l|c|}
\hline Inflow Type & Inflow (AFY) \\
\hline Precipitation Recharge & 1,615 \\
\hline Stream Infiltration & 2,017 \\
\hline Subsurface Flow & 3,470 \\
\hline Urban Return Flow & 114 \\
\hline Agricultural Return Flow & 990 \\
\hline Infiltration Basins & 327 \\
\hline & \\
\hline Total Inflow & $\mathbf{8 , 5 3 4}$ \\
\hline
\end{tabular}

\begin{tabular}{|l|c|}
\hline Outflow Type & Outflow (AFY) \\
\hline Urban Pumping & 2,269 \\
\hline Agricultural Pumping & 3,300 \\
\hline Subsurface Flow & 2,959 \\
\hline & \\
\hline Total Outflow & $\mathbf{8 , 5 5 2}$ \\
\hline
\end{tabular}


The inflows and outflows are described to have little variation during the 1986 to 2004 study period. The estimated average annual outflow from storage is 17 AFY. The subsurface inflows and outflows are the most uncertain components of the aquifer budget. The fluxes in and out of the system are dependent on the geological characteristics that are estimated based on well completion and pump test data. The subsurface inflows are estimated to be between 1,000 and 10,000 AFY and may vary with time due to precipitation. The best estimate for the subsurface inflow provided by Todd Engineers is 3,470 AFY. The subsurface outflow estimated in the study is 2,959 AFY. The 2002 Groundwater Management Agreement identified a subsurface outflow of 200 AFY which is considerably less than both the Todd Engineers value and the value developed in the results of this groundwater model study. According to the 2007 Todd Engineers study, precipitation recharge contributes one-half of the inflows to the aquifer system during wet years, and the majority of precipitation recharge occurs between December and February. Tributaries to the Arroyo Grande Creek system are considered negligible due to a lack of permeable channel lengths.

Todd Engineers defines the "safe yield" of an aquifer as "the amount of water that can be safely pumped from a basin" (Todd Engineers, 2007). The word "safe" can be equated to the word "sustainable" in the same context. Todd Engineers continue to describe that the safe yield is not steady state and varies over time due to changes in hydrologic trends and groundwater development, and is re-defined as the "portion of total inflow that can be effectively captured by wells and pumped from a basin without causing negative effects." Negative effects in a 
coastal groundwater basin include saltwater intrusion, subsidence, and aquifer overdraft.

The 2002 Groundwater Management Agreement developed a steady-state safe yield of 9,500 AFY. This value includes 5,300 AFY for agricultural irrigation, 1,202 AFY for AGPW, 1,198 AFY for GBPW, 900 AFY for OCSD, 700 AFY for Pismo Beach Public Works, and 200 AFY flowing out to sea. The value of 9,500 AFY assumes that agricultural pumping, municipal pumping, boundary flows, infiltration, streamflow, and return flows are averaged over time.

\subsubsection{Hydrogeologic Characterization}

Hydraulic conductivity values for the formations present in the study area were also provided in the Todd Engineers water balance study (Table 2).

Table 2 - Hydraulic Conductivities for Formations in Model Study Area (Todd Engineers, 2007)

\begin{tabular}{|l|c|c|}
\hline Formation & $\mathrm{K}\left(\mathrm{GPD} / \mathrm{ft}^{2}\right)$ & $\mathrm{K}(\mathrm{ft} / \mathrm{day})$ \\
\hline Alluvial Deposits & 200 & 26.7 \\
\hline Older Dune Sand & 350 & 46.8 \\
\hline $\begin{array}{l}\text { Paso Robles } \\
\text { Formation }\end{array}$ & 100 & 13.4 \\
\hline Careaga Formation & 50 & 6.7 \\
\hline Pismo Formation & 50 & 6.7 \\
\hline
\end{tabular}


These hydraulic conductivities are used to generate the initial estimates of hydraulic conductivity in the groundwater model. The hydraulic conductivity (K) decreases with depth. The dune sands demonstrate the highest permeability values. The Franciscan Complex and undifferentiated Tertiary deposits laying below the Pismo Formation and the Careaga Formation are assumed impermeable and to have a hydraulic conductivity of $1 \mathrm{E}-9$ feet/day. Ranges for hydraulic conductivity based on aquifer tests, pump efficiency tests, and lithologic correlation were provided by the DWR (Table 3).

Table 3 - Formation Hydraulic Conductivity using Different Methods (DWR, 2002)

\begin{tabular}{|l|c|c|c|}
\hline \multirow{2}{*}{ Formation Name } & \multicolumn{2}{|c|}{ Hydraulic Conductivity (GPD/ft ${ }^{2}$ ) } \\
\cline { 2 - 4 } & Aquifer Test & Pump Efficiency & Lithologic Correlation \\
\hline Arroyo Grande Plain Alluvium & & $700-2,000$ & $40-4,200$ \\
\hline Arroyo Grande Valley Alluvium & 2,000 & 33,117 & $165-5,800$ \\
\hline Arroyo Grande Plain Paso Robles & $370-900$ & $120-2,700$ & $5-2,900$ \\
\hline Tri-Cities Mesa Paso Robles/Pismo & $50-130$ & $130-450$ & \\
\hline Tri-Cities Mesa Deep Pismo & $30-40$ & $20-110$ & $3-325$ \\
\hline
\end{tabular}

Transmissivity and aquifer thickness are calculated using flow equations based on the Theis Equation (Theis, 1935). 
Transmissivities were also provided (Table 4).

Table 4 - Transmissivities for AG Formations (DWR, 2002)

\begin{tabular}{|l|c|}
\hline Formation Name & Transmissivity Range (gallons/day/ft) \\
\hline Arroyo Grande Valley Alluvium & 100,000 \\
\hline Arroyo Grande Plain Paso Robles/Careaga & $20,000-130,000$ \\
\hline Arroyo Grande Plain Pismo Formation & $3,000-30,000$ \\
\hline
\end{tabular}

The large range in transmissivity values demonstrates the degree of uncertainty in characterizing aquifer systems.

\subsection{Previous Work using Visual MODFLOW ${ }_{\circledast}$ and ArcGIS ${ }_{\circledast}$}

ArcGIS®, MODFLOW, and Visual MODFLOW® have been utilized by the USGS, engineering firms, universities, and governments for several years. For example, the optimal pumping schedule of the Blue Lake aquifer system in Humboldt, County, California, was developed using a Linked-Simulation Optimization methodology integrating MINOS with MODFLOW. The software used by Galef parallels the software used to develop the numerical groundwater presented in this study (Galef, 2006). The results from Galef's study identified new extraction well locations and developed an inverse relationship between the cost of pumping and hydraulic conductivity.

Artificial groundwater recharge strategies were assessed using Visual MODFLOW® for an unconfined aquifer with a high hydraulic conductivity located in Delaware (with similar conductivities as the Alluvium strata in the study area). Groundwater residence times obtained using the model were on the order of a few 
days to up to 100 years and demonstrated that $95 \%$ of the water injected was "flushed" within 50 years. It was also found that groundwater flow to the stream system was increased during the injection period (Kasper et al., 2010).

A shallow groundwater system located in Handcart Gulch, Colorado, was characterized using Visual MODFLOW®. The results of the study demonstrated that water achieves deep recharge during normal precipitation and temperature conditions. The numerical model was used to create a watershed water budget and identify geohydrologic properties of the bedrock and surficial materials (Kahn, 2008).

Visual MODFLOW® was used to create a three-dimensional transient groundwater model for the Luancheng region of the North China Plain. The region has experienced aquifer overdraft and decreases in the unconfined water table of over a half-meter per year. The model results demonstrated a strong correlation between agricultural water use and decreases in the piezometric surface (Jia, et al., 2002).

The Balasore groundwater aquifer system, located in Orissa, India, was characterized using a 2D groundwater model addressing issues of saltwater intrusion and aquifer overdraft. The results of the study demonstrated that decreasing pumping by $50 \%$ in the downstream area and increasing pumping by $150 \%$ in other aquifer locations would dramatically enhance water resources performance (Rejani, et al., 2008). 
VMODFLOW was used to simulate steady-state and transient groundwater flow in the Leon-Chinandega aquifer system in northwest Nicaragua. The model was calibrated using well data and river flow rates. Management decisions can be enhanced using model results for short time horizons and the model is considered to be a useful instrument in water resources planning (Palma \& Laurence, 2007).

Several future scenarios were modeled for an aquifer in northwest Oklahoma using Visual MODFLOW®. The future scenarios incorporated increased pumping of $50 \%$ by 2050 , severe drought conditions, severe wet conditions, and a scenario that integrates possible water management practices. It was demonstrated that increased pumping and drought would cause extreme drawdown in localized areas, but would have a greater impact on the groundwater recharge for the stream system (Zume \& Tarhule, 2011).

An artificial stream was Marx Creek was created in Alaska to enhance salmon spawning grounds. The creek remains full due to groundwater recharge. The Marx Creek management group commissioned a VMODFLOW model to identify the effects of adding a 450-meter new component of the stream. Streamflow data and groundwater level data for 20 wells were gathered to calibrate the model. The simulated baseflow to Marx Creek was increased by $39 \%$ by adding the new component of the stream and demonstrates that there is adequate groundwater to create more salmon spawning habitat (Nelson \& Lachmar, 2013).

These studies demonstrate that Visual MODFLOW® and GIS have been used in several applications to quantify groundwater flow and analyze the impacts varying water resources management strategies. Coupling MODFLOW and GIS 
provides higher resolution spatial representation of model inputs and creates model accuracy advantages when compared to conceptual models. Utilization of Visual MODFLOW® also provides advantages using $3 \mathrm{D}$ visualization tools to gain better insight to model structure and provide more efficient representations of groundwater flow. 


\section{Methodology}

\subsection{MODFLOW 2005}

MODFLOW solves the three-dimensional groundwater flow equation (Harbaugh, 2005, Equation 3.1.1).

$$
\frac{\partial}{\partial x}\left(K_{x x} \frac{\partial h}{\partial x}\right)+\frac{\partial}{\partial y}\left(K_{y y} \frac{\partial h}{\partial y}\right)+\frac{\partial}{\partial z}\left(K_{z z} \frac{\partial h}{\partial z}\right)+W=S_{s} \frac{\partial h}{\partial t}
$$

where:

$K_{x x}, K_{y y}, K_{z z}=$ are hydraulic conductivities in the Cartesian coordinate system which is aligned with the principal axis of the hydraulic conductivity tensor $(\mathrm{L} / \mathrm{T})$

$$
\begin{aligned}
& h=\text { the hydraulic head }(\mathrm{L}) \\
& W=\text { flow rate in }(+) \text { and out }(-) \text { divided by a unit volume }\left(\mathrm{T}^{-1}\right) \\
& S_{S}=\text { the specific storage }\left(\mathrm{L}^{-1}\right)
\end{aligned}
$$

The groundwater flow equation is solved in MODFLOW using the finitedifference method (Harbaugh, 2005). The finite-difference method first discretizes the hydraulic head spatially according to a $x, y, z$ grid using unit vectors $i, j, k$. Each direction in space and time is traditionally discretized into a timestep, $\Delta x, \Delta y, \Delta z, \Delta t$, but the spatial components are now discretized using new variables: $\Delta c_{i}, \Delta r_{j}, \Delta v_{k}$ for the $i, j, k$ directions in MODFLOW. The accuracy of model results is influenced by the discretization. Course model resolutions may average over important factors, and resolutions with excessive definition consume unnecessary computational resources.

The MODFLOW grid is defined by rows, columns, and layers, which are defined as NROW, NCOL, and NLAY in MODFLOW (Figure 14). The solution of the groundwater flow equation using finite differences in MODFLOW involves the 
conservation of mass principle and assumes a constant density to approximate the physics into flow balances.

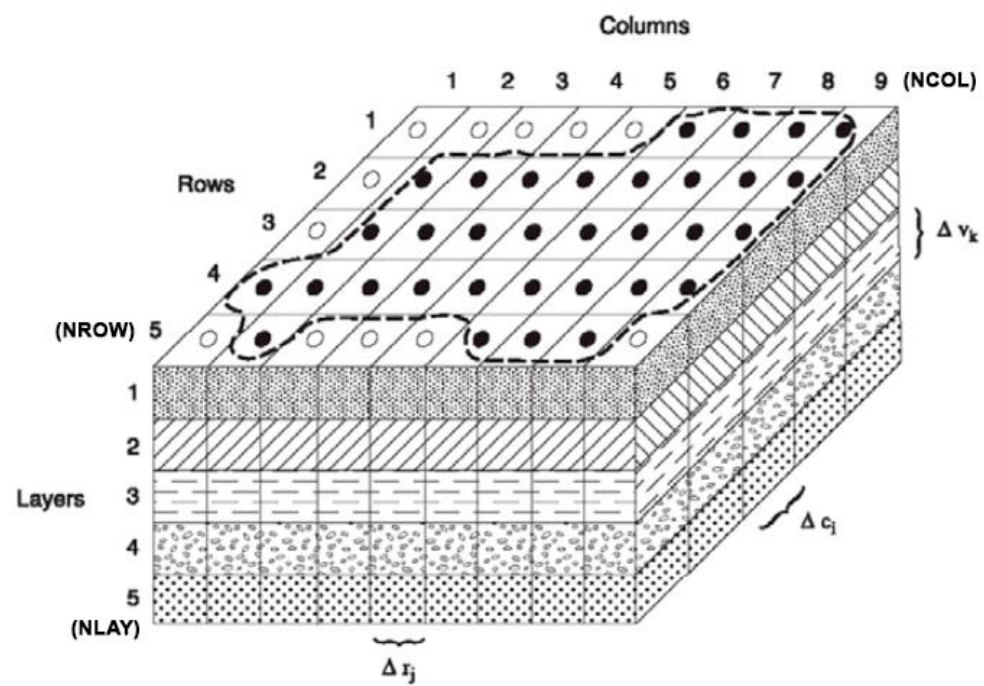

Figure 14 - MODFLOW Discretization System (Modified from Harbaugh, 2005)

Darcy's law is used to quantify flow into each face of each cell, the grid dimensions and hydraulic conductivities are combined into the conductance variables $C R, C C$, and $C V$ for the conductances in the $i, j, k$ directions, relatively. The finite-difference solution for the hydraulic head $\left(h_{i, j, k}^{m}\right)$ at node $i, j, k$ for time $m$ is defined (Equation 3.1.2).

$$
\begin{gathered}
C R_{i, j-\frac{1}{2}, k}\left(h_{i, j-1, k}^{m}-h_{i, j, k}^{m}\right)+C R_{i, j+\frac{1}{2}, k}\left(h_{i, j+1, k}^{m}-h_{i, j, k}^{m}\right)+C C_{i-\frac{1}{2}, j, k}\left(h_{i-1, j, k}^{m}-h_{i, j, k}^{m}\right)+ \\
C C_{i+\frac{1}{2}, j, k}\left(h_{i+1, j, k}^{m}-h_{i, j, k}^{m}\right)+C V_{i, j, k-\frac{1}{2}}\left(h_{i, j, k-1}^{m}-h_{i, j, k}^{m}\right)+C V_{i, j, k-\frac{1}{2}}\left(h_{i, j, k-1}^{m}-h_{i, j, k}^{m}\right)+ \\
P_{i, j, k} h_{i, j, k}^{m}+Q_{i, j, k}=S S_{i, j, k}\left(\Delta r_{j} \Delta c_{i} \Delta v_{k}\right)\left(\frac{h_{i, j, k}^{m}-h_{i, j, k}^{m-1}}{t^{m}-t^{m-1}}\right)
\end{gathered}
$$


The head at the current location and iteration is a function of the head from the previous timestep and the head at adjacent nodes. Time is discretized using a backward-finite difference equation and is considered "implicit" and is described as stable. Other methods, for example solving the temporal derivative using a forward finite-difference approximation, may cause numerical instability and are described as "unconditionally unstable". The newly created system of linear algebraic equations are solved for every timestep and the results from one timestep become the input for the next timestep. The first timestep uses the initial conditions to begin the solution procedure. MODFLOW uses multiple iterations to solve the mathematics for each timestep and converges to an adequate solution. The systems of equations are combined into vector-matrix form (Equation 3.1.3).

$$
A \boldsymbol{h}=\boldsymbol{q}
$$

where the matrix $A$ contains the values of the known coefficients to the heads and $\boldsymbol{q}$ contains the constant terms from the previous timestep and flow input data.

MODFLOW 2005 uses several difference solvers depending on the model application. Some solvers can solve higher-difficulty problems but take a longer amount of time to solve them. Identifying the proper solver is an important component of the model building process. The MODFLOW solvers include the Strongly Implicit Procedure Package (SIP), the Preconditioned ConjugateGradient Package (PCG), the Direct Solver Package (DE4), and the NewtonRaphson formulation (NWT) that integrates the Upstream-Weighting Package (UPW). The UPW package uses an asymmetric matrix instead of a traditionally used symmetric matrix in the Block-Centered Flow (BCF) package. The NWT 
Package is required for the Surface-Water Routing (SFR2) and Seawater Intrusion (SWI2) packages. The effects of variation in convergence criteria on computational timed is addressed later in this study.

\subsection{PEST}

PEST, short for Parameter Estimation, is a model-independent parameter estimation system developed by John Doherty with Watermark Numerical Computing (Doherty, 2016). PEST is an optimization program that calibrates numerical models by assessing the impacts of parameter variation on the ability for the model to reproduce observed data. PEST generates input files for a mathematical model based on "templates", reads model output files based on "instruction" files, and varies parameter values in order to minimize the weighted sum of the square residuals, i.e. $\Phi$ in PEST, where the residuals are the differences between observed data points and the model results (Equation 3.2). PEST utilizes a control file that dictates the optimization parameters, number of optimization iterations allowed, and identifies the number of parameter groups, parameters, template files, instruction files, observations, and observation groups.

$$
\min \Phi=\sum_{i} w_{i}\left(y_{m, i}-y_{o, i}\right)^{2}
$$

where:

$\Phi=$ the sum of the weighted squared residuals

$i=$ an observation counter

$y_{m, i}=$ modeled result at location and time of observation $i$

$y_{o, i}=$ observed data value at location and time of observation $i$

$w_{i}=$ the weight given to the residual at location and time of observation $i$ 
Initial parameter estimates and observation values are included in the control file. The results of the parameter estimation process are recorded in a record file and the residuals are recorded in a residual file for post-processing.

Each PEST optimization iteration begins by calculating the Jacobian (the matrix of first-order partial derivatives). The Jacobian takes the partial derivative observations with respect to parameter values. Computation of the Jacobian requires a model run for each parameter, and requires two runs for each parameter when central derivatives are implemented.

This process consumes the most computational resources, but can benefit from the parallelization process provided by parallel PEST. The Jacobian is used to identify new parameters for the next iteration using iterations varying of Marquardt lambda values. PEST offers a Regularization mode of computation that utilizes Tikhonov regularization that is better suited for solving ill-posed inversion problems. The regularization process implements a second objective that attempts to match estimated parameter values with their original values based on field measurements. The mode of regularization is used in this application because it provides greater decreases in $\Phi$ and less variations in the aquifer inflows and outflows than the normal parameter estimation mode. 
PEST generates output information for each optimization iteration (Figure 15).

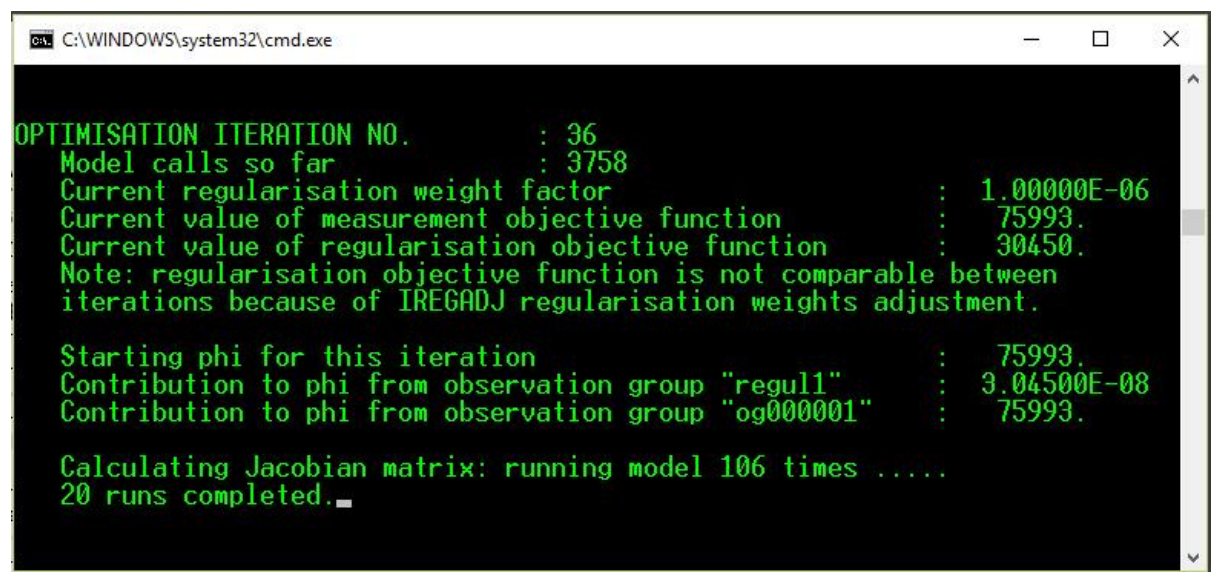

\section{Figure 15 - PEST Run Information}

During each PEST run, PEST provides the optimization iteration number, the total number of model calls thus far, and the starting $\Phi$ value at the beginning of the optimization iteration.

In the groundwater modeling application, the hydraulic conductivities, storativities, and boundary conditions can be implemented as the parameters in PEST. In addition, pilot points can be used to implement hydraulic conductivities and storativities derived from field tests for a network of well systems. PEST then varies the values at the pilot points and interpolates the values in between iteratively to identify the parameter space that best fits the expected hydrograph results. 


\section{Steady State Model Development}

This section describes the methods used to formulate the steady state groundwater model. The materials used to develop the MODFLOW model include the previous literature review, ArcGIS $\AA$, Visual MODFLOW®, and input data to ArcGIS $\circledast$ including land use, soils, geology, stream, precipitation, and well data. The steady state model is used as the building blocks for the transient model described in Section 5 of the thesis.

\subsection{Model Domain Development}

ArcGIS $\AA$ is used to generate the groundwater model domain for the study area (ESRI, 2014). Traditionally, groundwater models are restricted to low-slope areas of watershed basins that contain water-bearing formations. The steep mountains regions are excluded from the model domain and the mountain-front and shallow recharges are integrated into the model as boundary conditions. Focusing on low-slope regions confines the model domain to areas that are likely to have pump test and well data for calibration. The Digital Elevation Model (DEM) is loaded into $\operatorname{ArcGIS} \circledast$ and is used to generate a slope map of the entire watershed (Dollison, R.M., 2010), (Figure 16). 


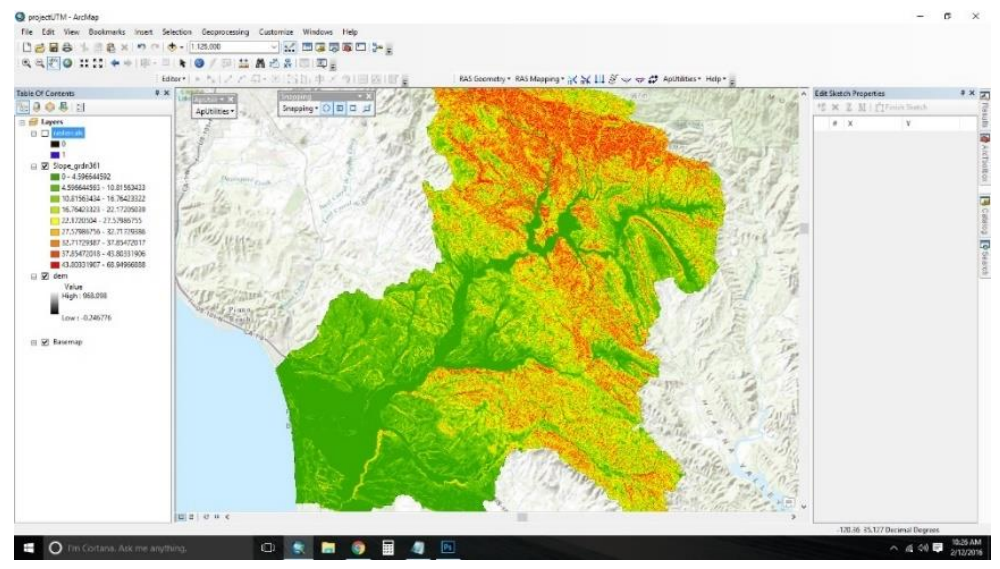

Figure 16 - Slope Map of the Arroyo Grande Creek Watershed

The dark green areas demonstrate locations with gentle slopes and the red areas demonstrate the areas with the steepest slopes. The groundwater model is simplified by removing the steeper slopes from the model. After several iterations of guess and check, the areas with a slope of less than 5 degrees are selected for the groundwater model domain. The distributed polygons are joined together to generate a shapefile for the NCMA area and the Arroyo Grande Valley up to the dam (Figure 17).

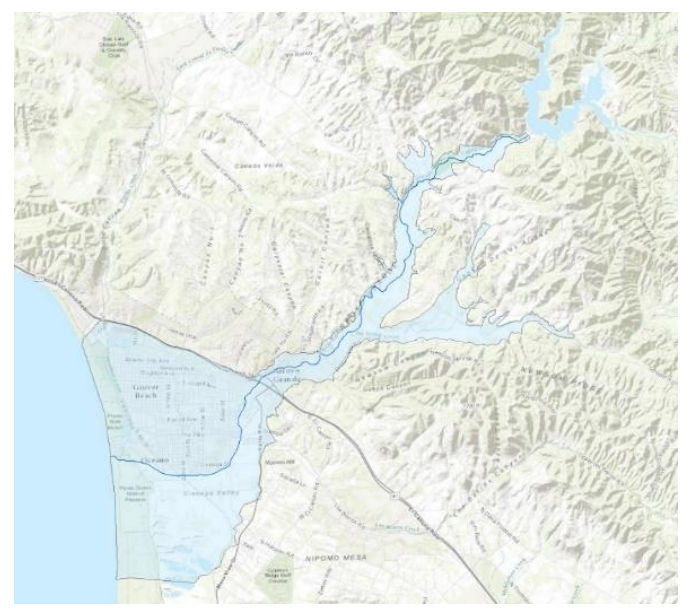

Figure 17 - Arroyo Grande Valley and Tri-Cities Watershed Model Domain 
After discussion with local geologists Tim Cleath and Spencer Harris, the Arroyo Grande Valley component of the model was removed (Cleath-Harris Geologists, 2/19/2015). The model domain was further reduced to avoid the Nipomo Mesa topography and to ensure that the domain was not in the ocean. Finally, the northern-most component of the domain was removed based on data limitations from the cross section analysis in the following section. The final model domain shapefile is presented (Figure 18).

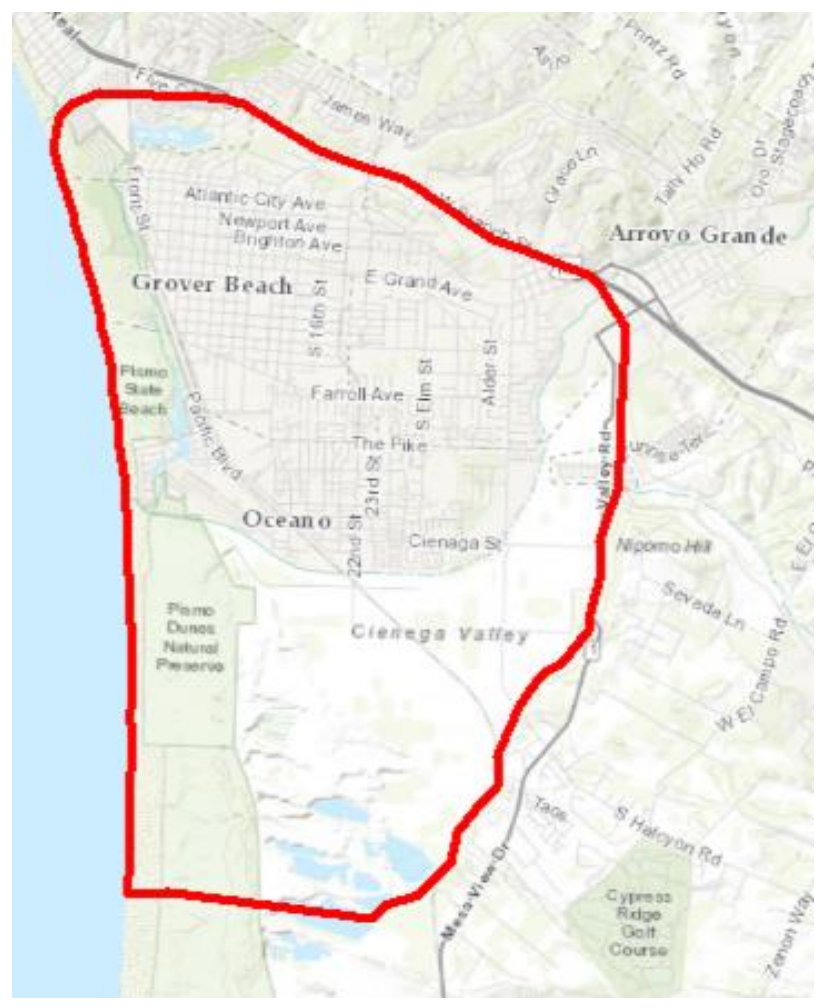

Figure 18 - Finalized NCMA Groundwater Model Domain

The final model domain includes areas of Pismo Beach, Arroyo Grande, Grover Beach, and Oceano and bounds 7,500 acres (approximately 12 square miles). The Arroyo Grande Creek flows through the model domain from Highway 101 in 
Arroyo Grande to the ocean near Oceano. Meadow Creek and Los Berros creek also enter the study area near the northern and eastern borders, respectively.

\subsection{Layer Development}

ArcGIS $\circledast$ is used to develop raster files from point networks with varying elevations. These raster files are transformed into model surfaces (layer interfaces) in Visual MODFLOW® to spatially represent the different geologic formations. Tim Cleath and Spencer Harris from Cleath-Harris Geologists recommended using three layers for the model (Cleath-Harris Geologists, 2/19/2016). The 2015 Fugro Consultants, Inc. Santa Maria Groundwater Basin Characterization and Planning Activities Study (2015 Fugro Study) provides the following cross sections for the study area: L-L', I-l', and H-H' (Figure 19).

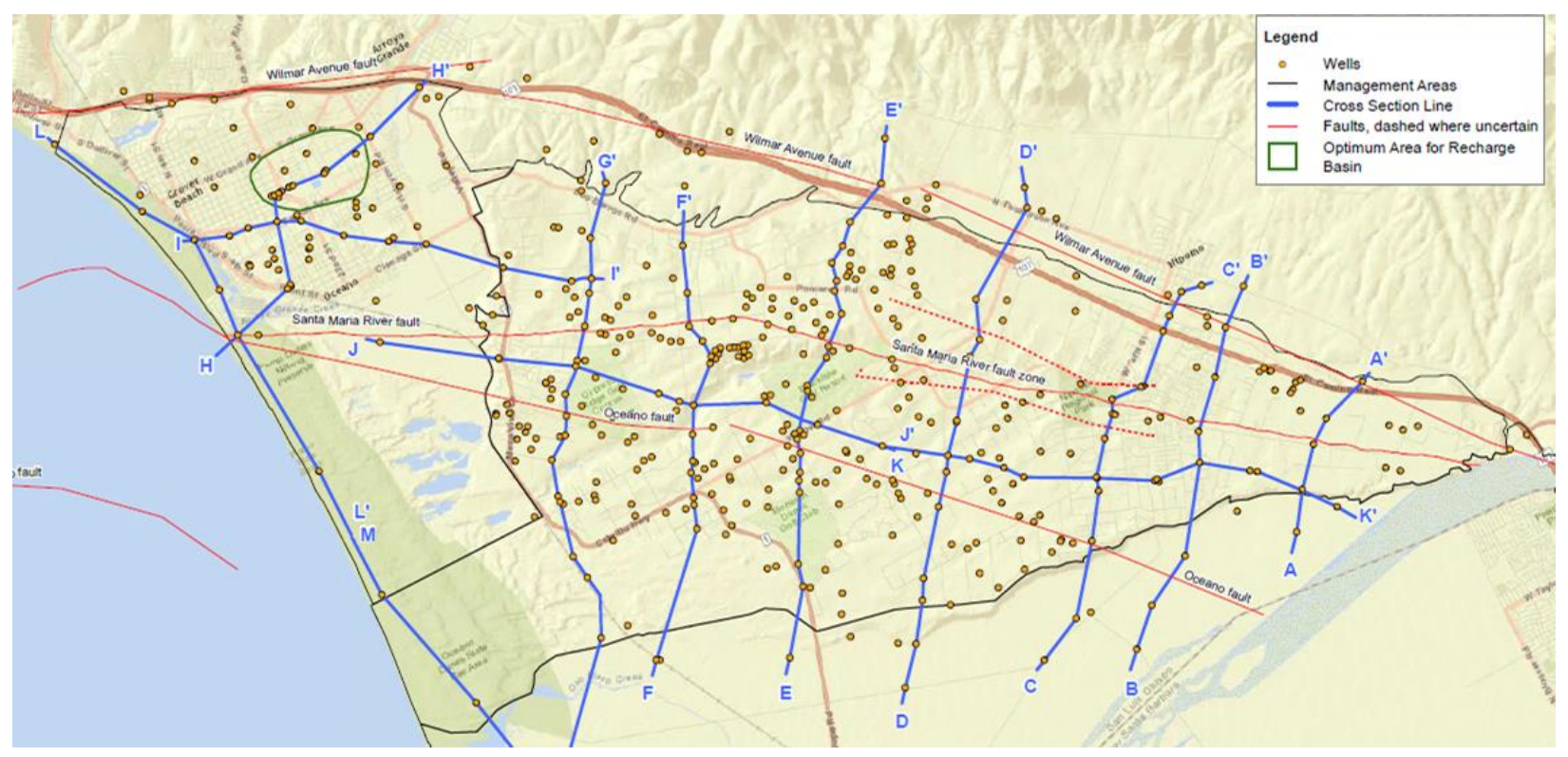

Figure 19 - Cross Section Map of the Santa Maria Groundwater Basin

(Fugro Consultants, Inc., 2014) 
Fugro Consultants, Inc. developed cross-sections based on well log data used in the development of the Santa Maria Basin Characterization study and on DWR reports and geologic logs. Cross-section L-L' parallels the coast, cross-section II' intersects both $\mathrm{H}-\mathrm{H}$ ' and L-L' and is cut across the Tri-Cities Mesa from Northwest to Southeast towards the Nipomo mesa, and cross-section $\mathrm{H}-\mathrm{H}^{\prime}$ is cut from west to east and ends at the bottom of the Arroyo Grande Valley at Highway 101. The cross-sections provided by Fugro Consultants, Inc. demonstrate the layers of the aquifer system at each well intersecting the cross section lines on the map (Figure 20).

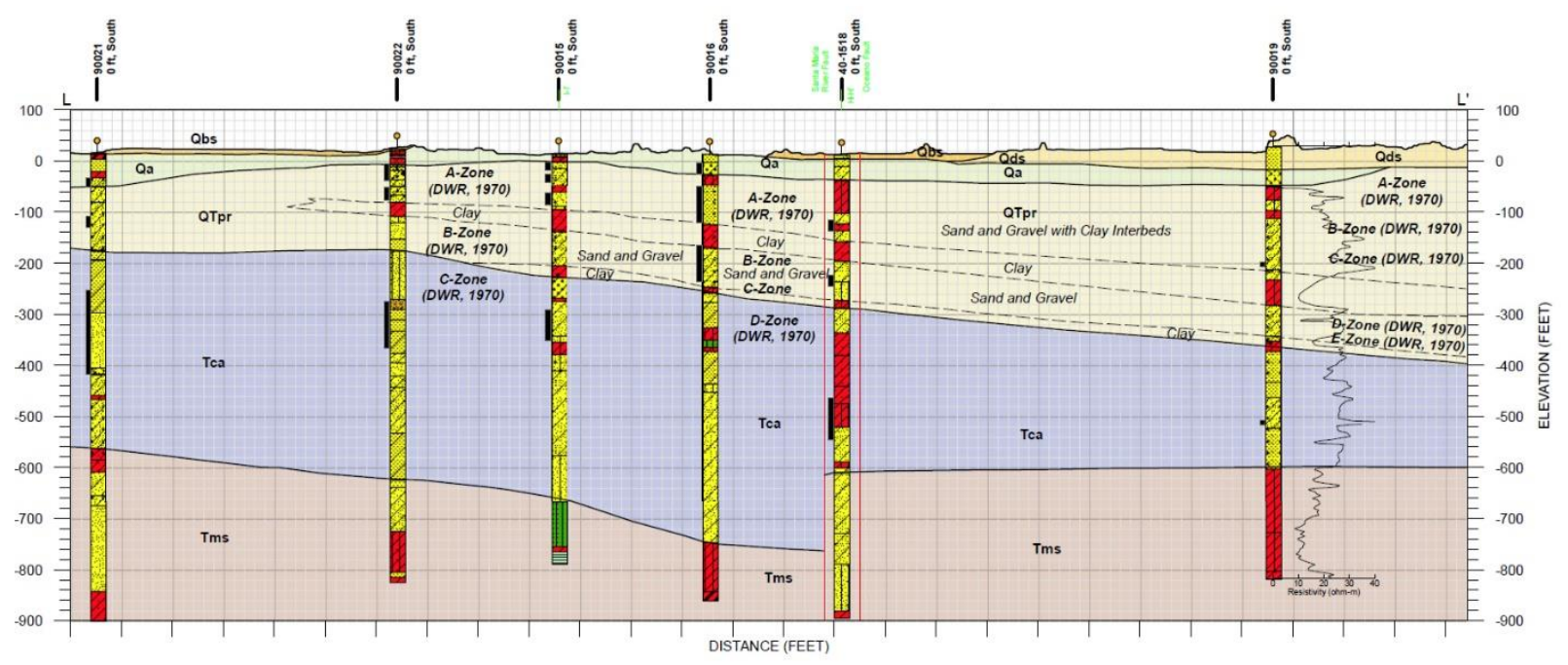

Figure 20 - L-L' Cross Section

Microsoft $\AA$ Excel and Adobe ${ }^{\circledR}$ Photoshop $\AA$ are used to create tabular data for layer elevations at each well for the three cross sections. Using Photoshop $\AA$, gridlines are set at the bottom of the alluvium and dune sand layer, at the bottom of the Paso Robles Formation layer, and at the bottom of the Careaga or Pismo Formation. The depths to each geologic interface are estimated from the gridline 
on the vertical axis to an approximate accuracy of 3 feet. The values are entered into Excel for implementation into the GIS attribute table for the point layer. Based on the data points, Layer 1 is developed between the ground surface and the bottom of the sand or alluvium layer, Layer 2 is developed between the bottom surface of Layer 1 and the bottom of the Paso Robles Formation, and Layer 3 is developed between the bottom of the Paso Robles Formation and the top of the bedrock layer. Layer 1 is assumed to be comprised of three individual components of alluvium, dune sands, and the Pismo Formation, Layer 2 is assumed to contain the characteristics of the Paso Robles Formation, and Layer 3 is assumed to have the aquifer properties of the Careaga Formation.

For implementation into ArcGIS®, a screenshot of the zoomed-in image of the aerial cross-section map is imported into Photoshop ${ }^{\circledR}$, rotated, and then exported to ArcGIS® for georeferencing. The points on each cross-section are added using a point feature class and elevations are added using the DEM. Then the layer elevations are added in the attribute data table for the point feature class (Figure 21). 


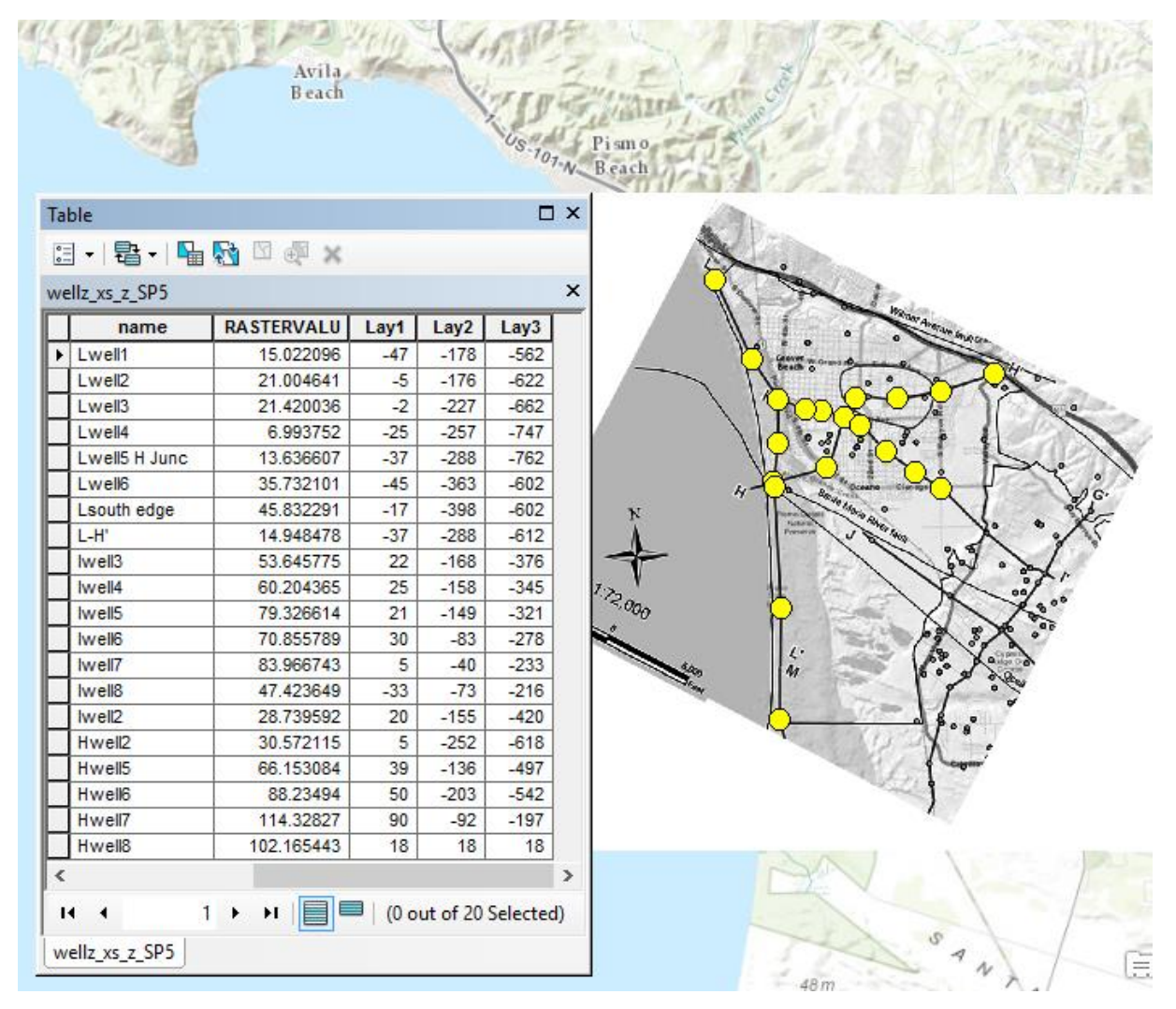

Figure 21 - Ground Surface and Layer Attribute Data

Raster surfaces are generated for each of the layers using the Kriging Raster Interpolation tool in ArcGIS $\AA^{\text {. The }}$. The spherical semivariogram model is used with 12 points in the search radius settings parameter. The kriging formula is described (ESRI Resource Center, 2016, Equation 4.2.1),

$$
\hat{Z}\left(s_{0}\right)=\sum_{i} \lambda_{i} Z\left(s_{i}\right)
$$

where:

$$
\begin{aligned}
Z\left(s_{i}\right)= & \text { the measured value at the } i \text { th location } \\
\lambda_{i}= & \text { a weight for the measured value at the } i \text { th location based } \\
& \text { on the distance between the measured points and the } \\
& \text { spatial variability of the measured points. }
\end{aligned}
$$

Each layer is generated through the Kriging process and visualized as a contour plot (Figure 22). 


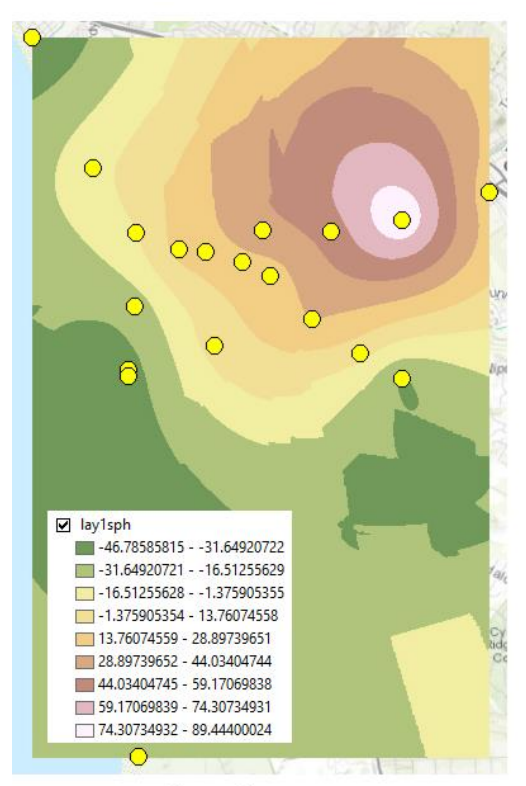

Layer 1

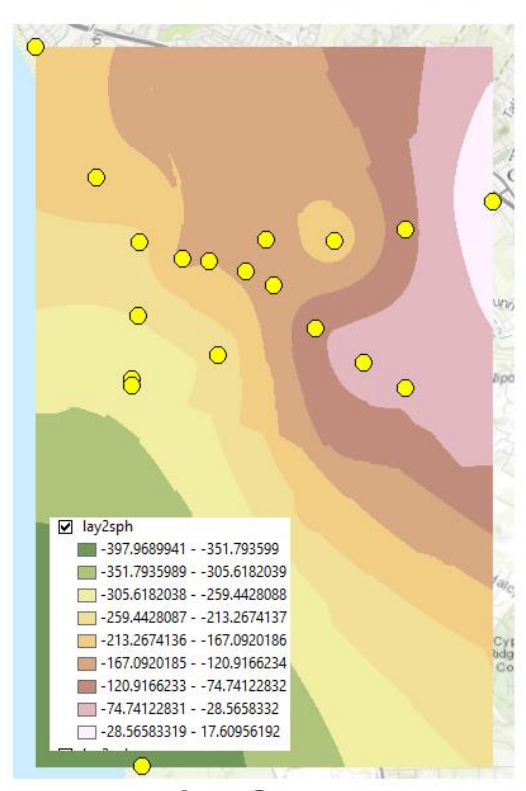

Layer 2

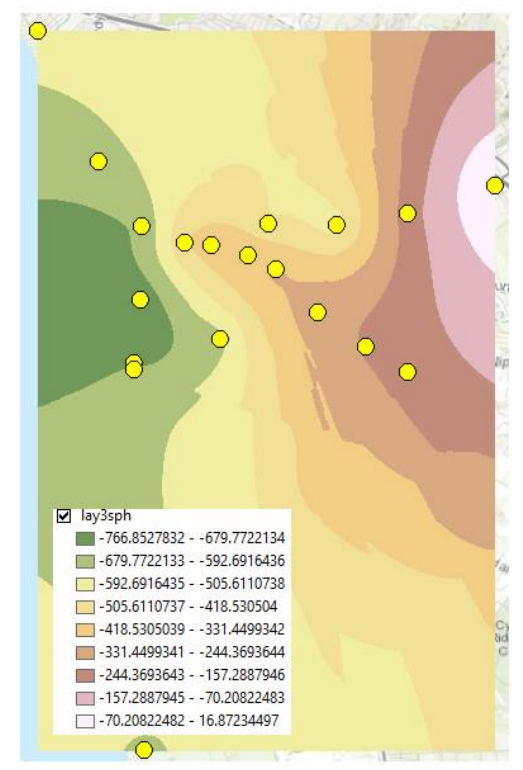

Layer 3

\section{Figure 22 - Kriging Interpolation Results for Layer Development}

The raster surfaces are clipped to the model domain and exported as ASCII .txt files for implementation in Visual MODFLOW®. The State Plane coordinate system is used to ensure that the dimensions in the raster files and Visual MODFLOW® are in feet to properly match the depth data provided in the 2015 Fugro Study. The elevation raster is clipped to match the dimensions of the interpolated layer rasters and is imported by Visual MODFLOW®. The northwest corner of the model domain is removed due to the limited area of the interpolated surfaces. The surfaces are loaded into Visual MODFLOW® and visualized in 3 dimensions (Figure 23). The layers are exaggerated by 15 times to magnify the vertical variations. The deep grooves in the left hand side of the bottom layer surface represent the fault from cross-section L-L' at the junction with the $\mathrm{H}-\mathrm{H}^{\prime}$ cross-section. 
The DEM for the land surface is obtained from the USGS National Map Viewer (Dollison, R.M., 2010). The land surface raster is clipped to match the same dimensions as the layer rasters using the Clip Raster on the Raster Domain polyline developed from the layer raster shape.

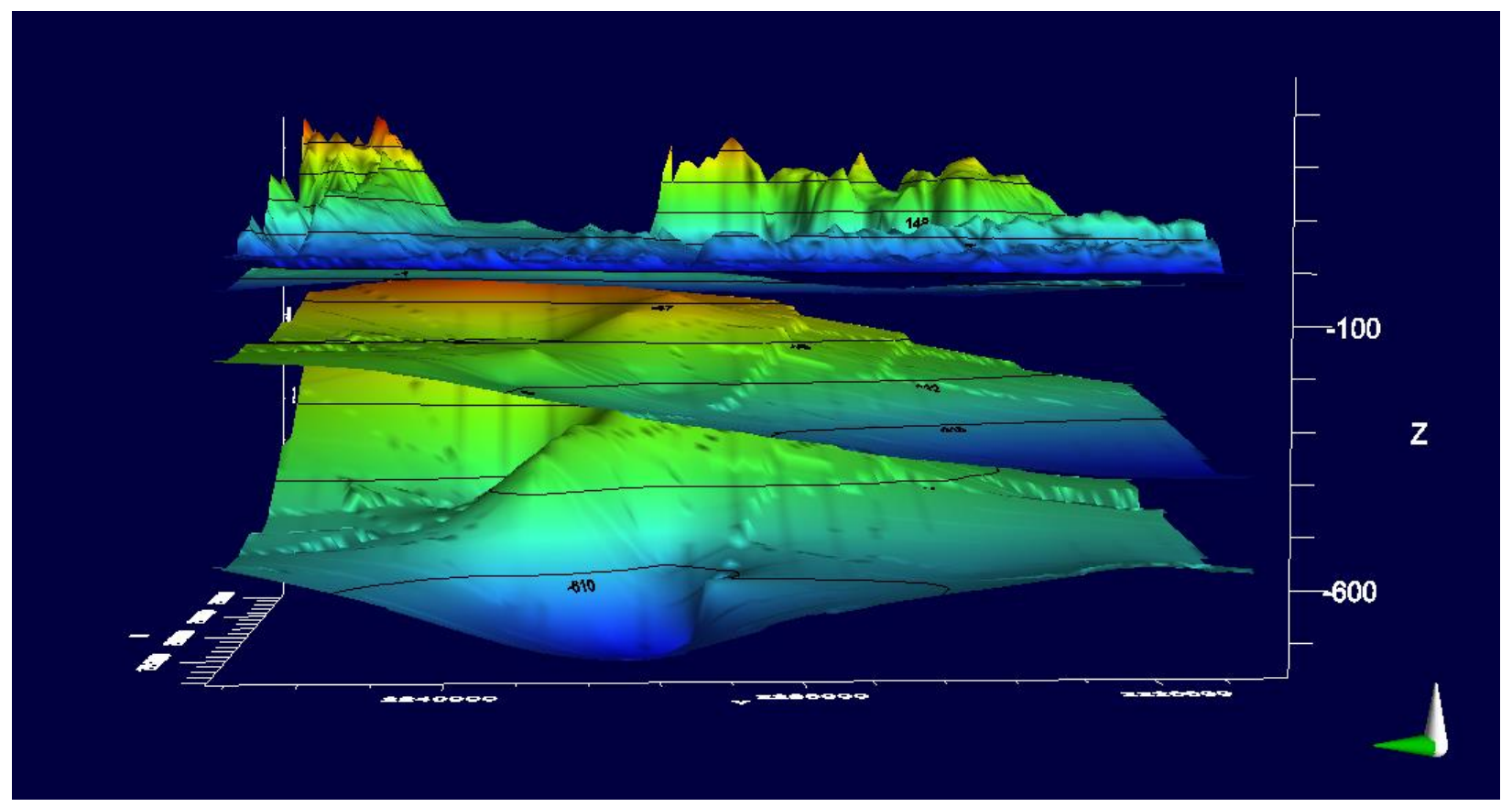

Figure 23 - Raster Surfaces in Visual MODFLOW® Conceptual Model 3D

\section{Viewer (West to East)}

The land surface, Layer 1, Layer 2, and Layer 3 are set as the $1^{\text {st }}, 2^{\text {nd }}, 3^{\text {rd }}$, and $4^{\text {th }}$ horizons in the Visual MODFLOW® conceptual model building process. The land surface horizon is defined as an erosional surface, Layer 1 and Layer 2 are described as conformable surfaces, and Layer 3 is described as a base surface. Previous attempts involved clipping the surface shapes to the model boundary polygon in ArcGIS® generated vertical distortion during horizon development (Figure 24). 


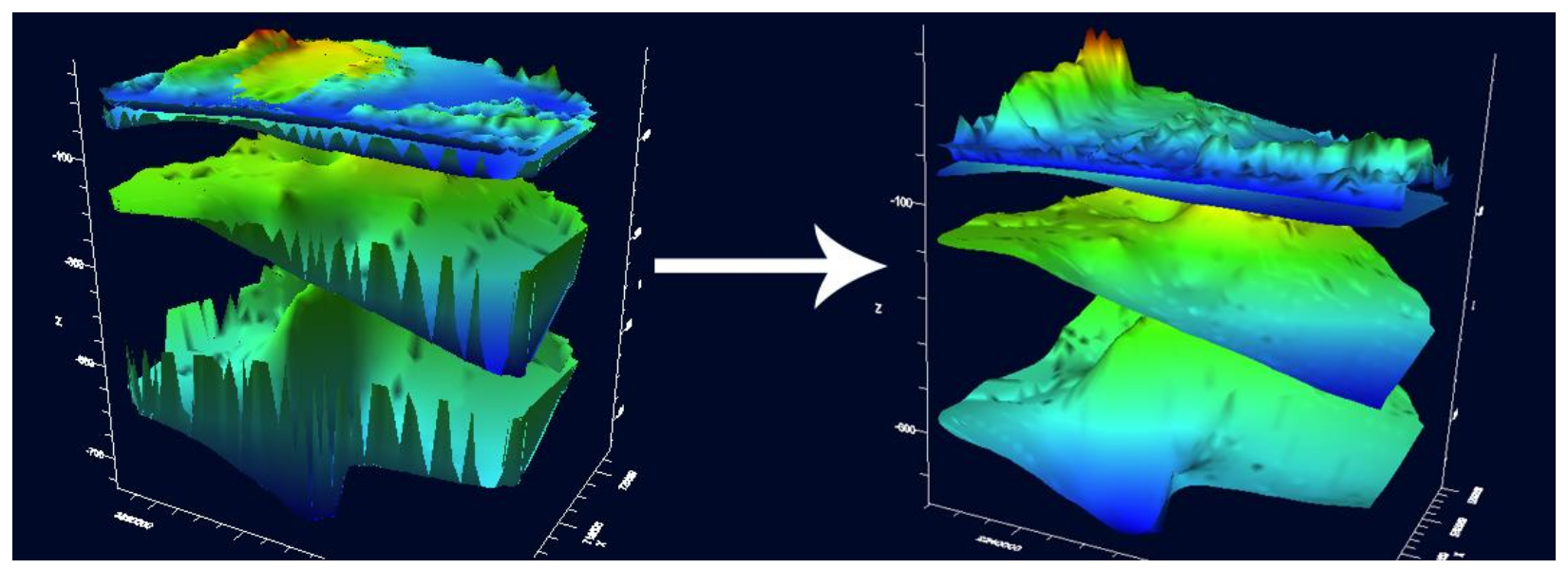

Figure 24 - Removal of Vertical Distortion by Clipping in Visual MODFLOW®

Importing the surfaces large rectangles and using the model boundary polygon to clip the surfaces in Visual MODFLOW® removed the vertical distortion on the edges of the surfaces.

\subsection{Geology Development}

Geologic information is obtained from the County of San Luis Obispo website (SLO County, 2015). The data includes several types of dune sands that are aggregated and stream terrace deposits that are aggregated with the alluvium subcomponents (Figure 25). 


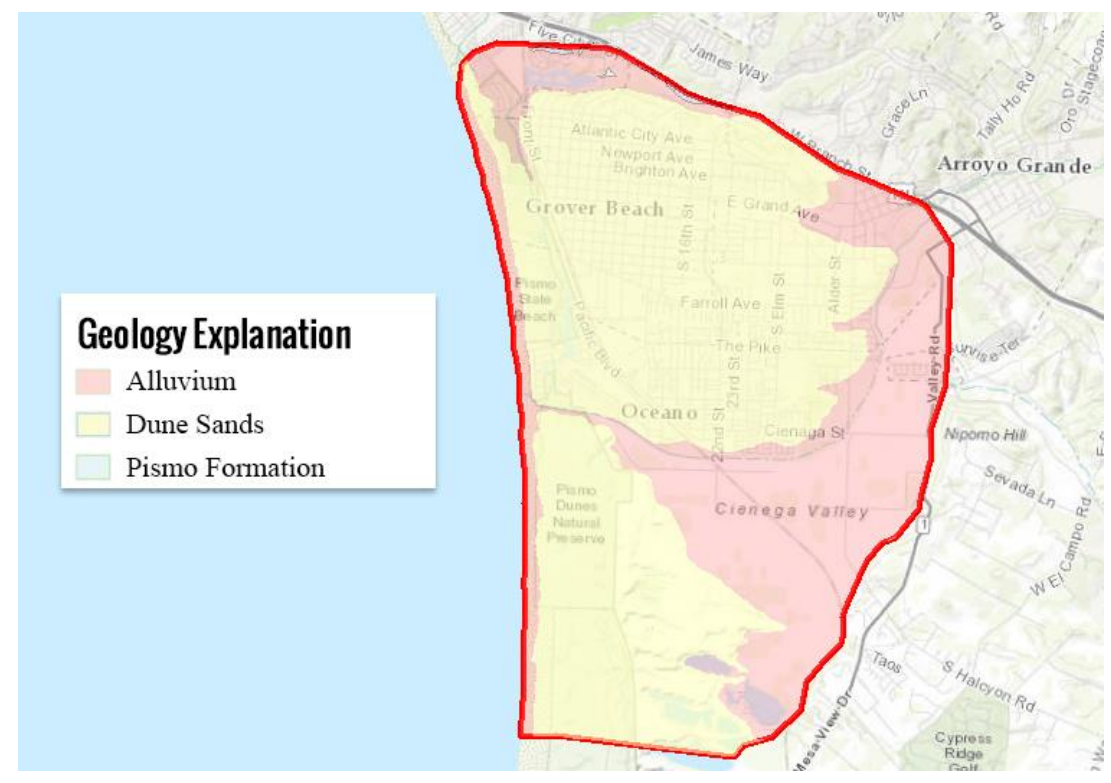

Figure 25 - Aggregated Surface Geology

The aggregated shapefiles are used to develop geologic variations in the first layer of the groundwater model. The dune sands are partitioned throughout the model domain beneath Grover Beach, parts of Oceano, and in the southern region of the groundwater model. The alluvium deposits are distributed in the foothills to the mountainous regions and below the beach sands. The Pismo Formation is distributed along the northern-border of the model domain. The second and third layers are assumed to be homogenous and include the Paso Robles Formation and the Careaga and Pismo formations, respectively. The alluvium, dune sand, and Pismo Formation hydraulic conductivities are integrated with Visual MODFLOW® property zones and added to Zone 1. Hydraulic conductivities defined for each zone range from 46.8 feet per day to 6.7 feet per day (Table 5). 
Table 5 - Initial Hydraulic Conductivities for Each Zone

\begin{tabular}{|l|c|c|c|}
\hline Zone and Geology Type & $\mathrm{Kx}(\mathrm{ft} / \mathrm{d})$ & $\mathrm{Ky}(\mathrm{ft} / \mathrm{d})$ & $\mathrm{Kz}(\mathrm{ft} / \mathrm{d})$ \\
\hline Zone 1 - Alluvium & 27 & 27 & 2.7 \\
\hline Zone 1 - Dune Sands & 47 & 47 & 4.7 \\
\hline Zone 1 - Pismo Formation & 7 & 7 & 0.7 \\
\hline Zone 2 - Paso Robles Formation & 13 & 13 & 1.3 \\
\hline Zone 3 - Careaga/Pismo Formations & 6.7 & 6.7 & 6.7 \\
\hline
\end{tabular}

The vertical hydraulic conductivity is assumed to be one-tenth of the horizontal hydraulic conductivities (USGS, 1982).

\subsection{Boundary Condition Development}

The boundary conditions are generated in ArcGIS® based on the information provided in the 2007 Todd Groundwater study, and a geologic shapefile provided by San Luis Obispo County (SLO County, 2015). Three types of boundary conditions are defined: deep recharge from the Nipomo Mesa, shallow recharge from alluvium layers from Meadow Creek, Arroyo Grande Creek, and Berros Creek, and outflow to the ocean along the coast (Figure 26). 


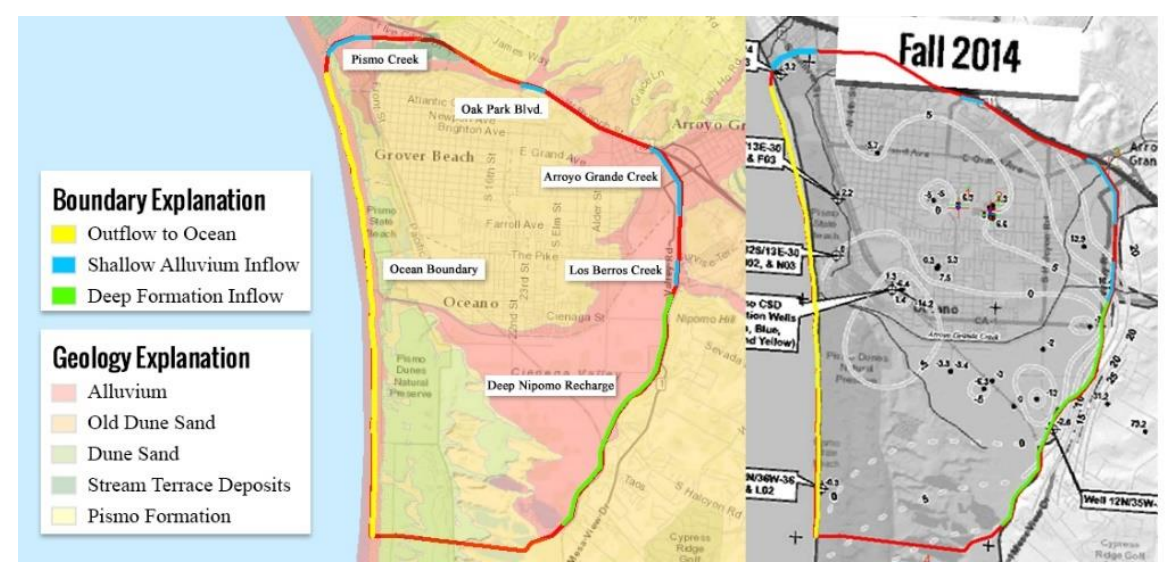

Figure 26 - Boundary Condition Development

The alluvial and mountain-front recharge boundary conditions are developed as Dirichlet constant head boundaries and are parameterized to match hydraulic gradient profiles in the annual NCMA reports. The boundary conditions represented by the red lines in Figure 26 are assumed to be impermeable zero Neumann conditions. The ocean boundary is defined as a Cauchy type boundary condition and is integrated into the MODFLOW model using the General Head Boundary (GHB) package. The 2014 fall hydraulic head contours are georeferenced in ArcGIS $\AA$ to aid in the development of the boundary conditions. The initial constant hydraulic head conditions for the boundary conditions are tabulated (Table 6). The initial assumed boundary conditions created boundary inflow and outflow values that best fit hydraulic contours from the 2011-2014 NCMA Annual Reports. 
Table 6 - Assumed Boundary Condition Values

\begin{tabular}{|l|c|}
\hline Boundary Name & Constant Head (ft) \\
\hline Pismo Creek & 5 \\
\hline Oak Park Blvd. & 15 \\
\hline Arroyo Grande Creek & 18 \\
\hline Los Berros Creek (0-2) & $8-15$ \\
\hline Ocean Boundary & 0 \\
\hline Deep Nipomo Recharge & 12 \\
\hline
\end{tabular}

The Pismo Creek, Oak Park Blvd., Ocean Boundary, Los Berros Creek, and Arroyo Grande Creek constant head Dirichlet boundary conditions are applied on the top of the simulation model domain in Visual MODFLOW®. The Deep Nipomo Recharge boundary condition is applied to the surface of the Layer 2 and Layer 3 interface. The Los Berros Creek boundary condition is defined as 5 feet at the southern start point and 20 feet for the northern end point and is linearly interpolated for the intermediate components of the boundary.

\subsection{Stream Development}

The stream is digitized in ArcGIS $\AA$ and imported as a shapefile into Visual MODFLOW®. The elevations are integrated using the Arithmetic operation $Z=$ $\operatorname{surface}(x, y)$. 


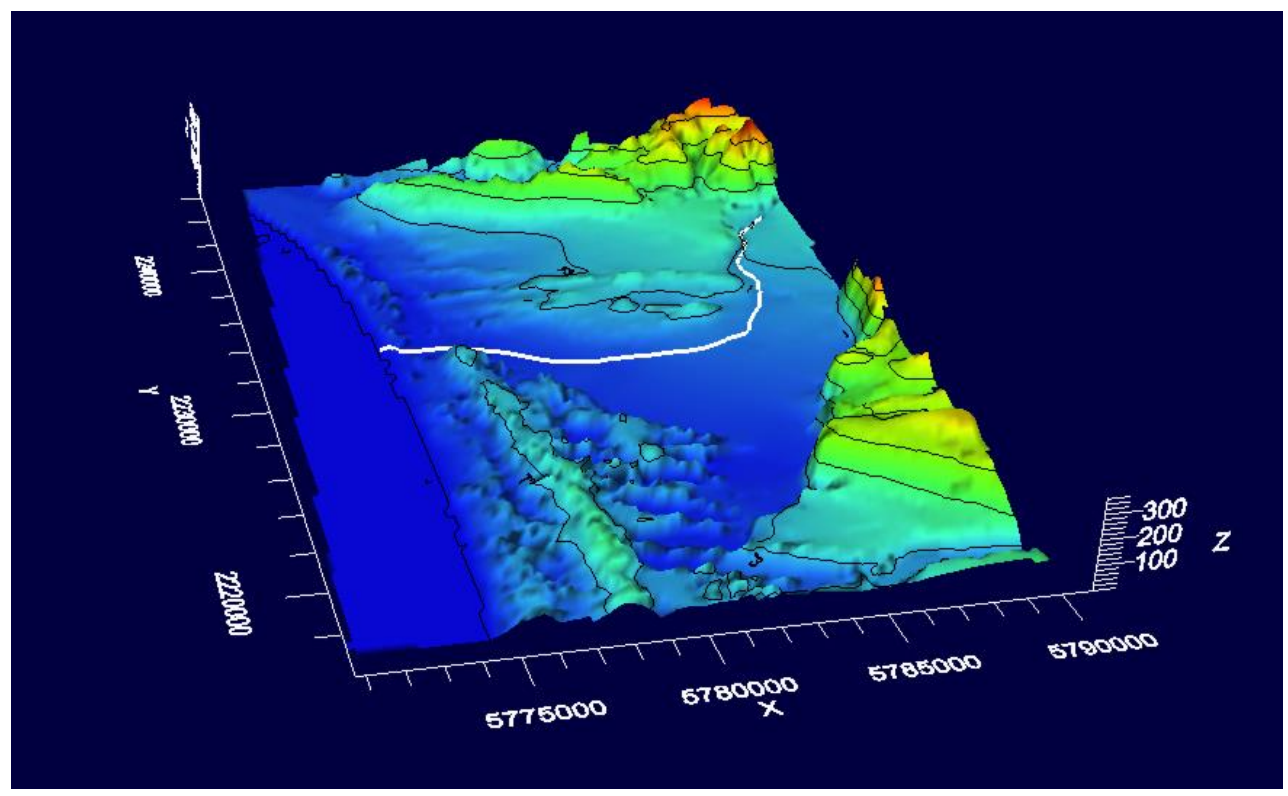

Figure 27 - Stream Implementation in Visual MODFLOW®

The stream is integrated into Visual MODFLOW® using the River boundary condition. Arroyo Grande Creek is added as a boundary condition and the leakance term is parameterized in order to match hydraulic gradient distributions from the 2014 NCMA Annual Monitoring Report. The DEM is increased using Raster Math by 0.2 feet to provide a surface for the river stage. The river stage is uniform for the entire stream for both steady state and transient model applications.

\subsection{Recharge Development}

The infiltration of precipitation is a function of soil type, land use, and many other factors. For this application, it is assumed that the NRCS Curve Number method will provide adequate values of initial abstraction and infiltration rates based on curve number and soil type. This method is similar to the method used in the 2007 Todd Engineers study. Other important factors, including slope, are ignored using this method. The final result for the infiltration rate based on the land 
and soil use is assumed to be greater than the actual amount due to horizontal migration to the stream and evaporation from the soil.

Soil data is obtained from the NRCS Web Soil Survey website (NRCS, 2016). The Microsoft $\AA^{A}$ Access Database contained in the NRCS download is used to import the soil data into the database (Figure 28).

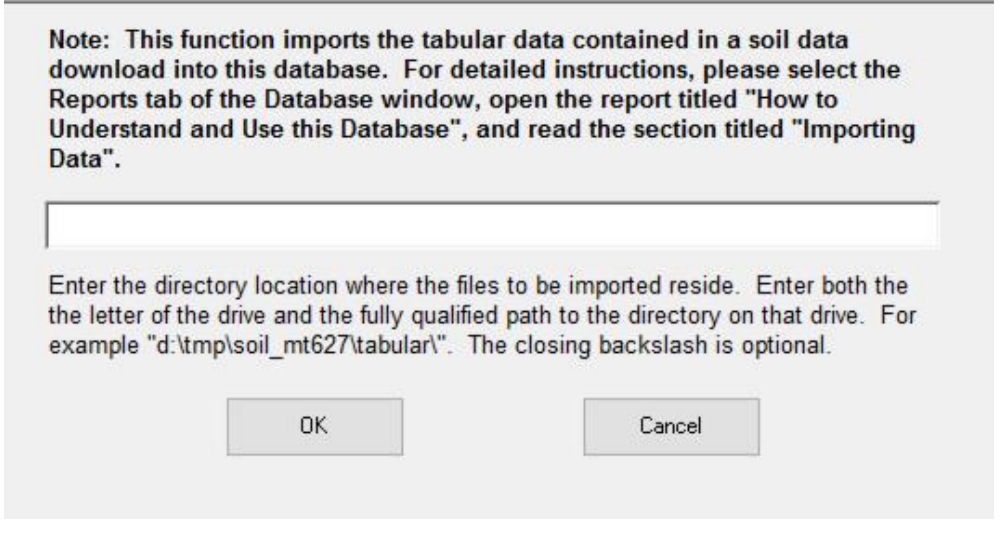

Figure 28 - Soil Database Import Form

The soil data is integrated with the shapefile using the component table from the Access Database. The shapefile for the spatial variation in soil type is added to ArcGIS $\AA$ in addition to the tabular data. The component table is joined to the soil data shapefile using the MUKEY values as a link. All values except for the hydgrp (NRCS Soil Type A, B, C, or D), runoff, and soil general descriptors (basin floors, hills, mountains, beaches, and dunes) are deleted from the attribute table. The null values are filled using similar runoff and soil description values to generate a complete list of soil types.

The land use data is obtained as a .TIFF file from the USGS National Map Viewer (Dollison, R.M., 2010). The .TIFF file is converted to a polygon shape using 
the Raster to Polygon tool after projection and clipping. The land use names are applied to a new field based on the integer value due to removal from the conversion process. The land use and soil data are merged. Values that do not overlap contain -1 in the FID field and are removed. The land use and NRCS soil type features are demonstrated (Figure 29).

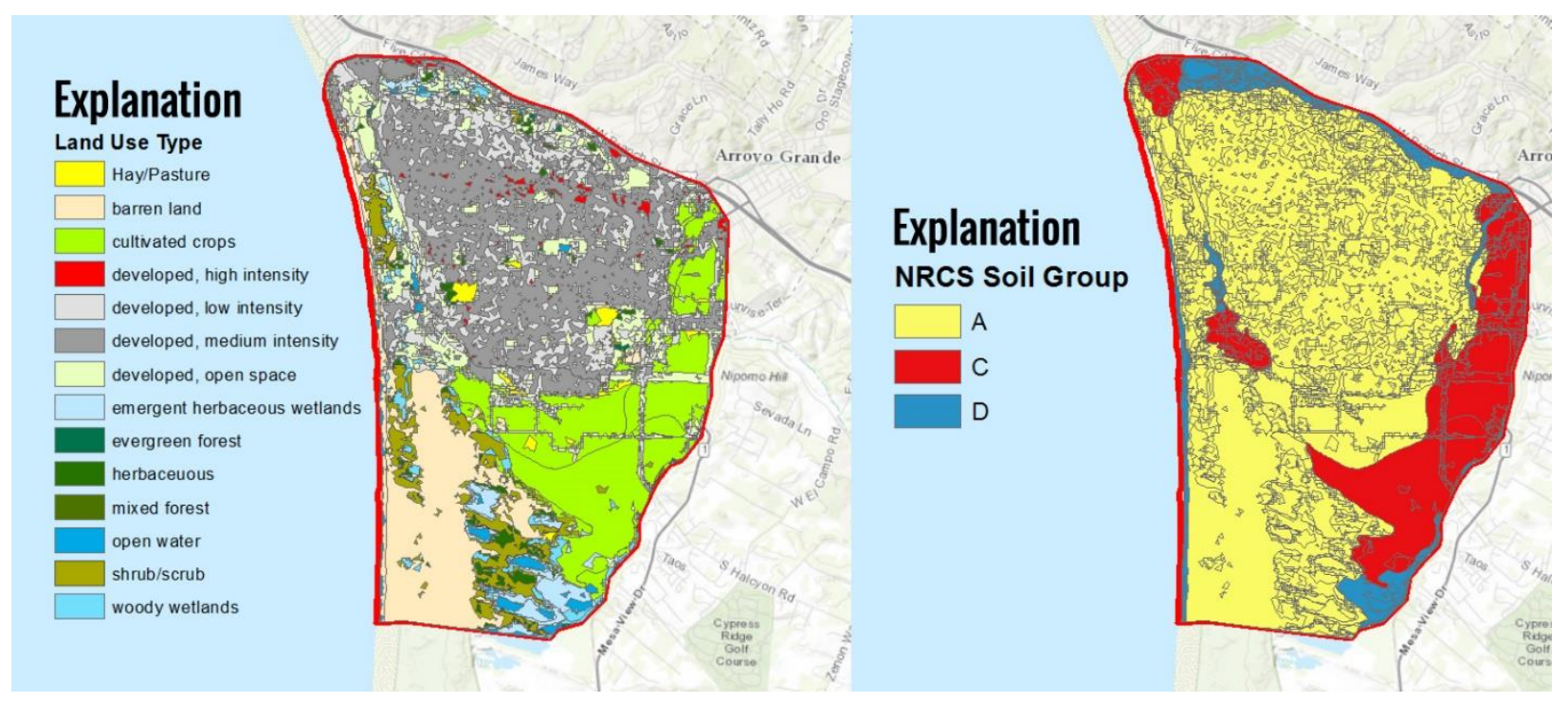

Figure 29 - Land Use and Soil Group Demonstration

Curve numbers are developed using a VBA code relating the land use type to NRCS curve number land use descriptions. The assumed NRCS descriptions linked with the USGS provided land use descriptions is tabulated (Table 7). 
Table 7 - Curve Number Linkages (Muleta, 2015)

\begin{tabular}{|l|l|l|l|l|l|}
\hline USGS Land Use Description & $\begin{array}{l}\text { Assumed NRCS Land Use } \\
\text { Description }\end{array}$ & A & B & C & D \\
\hline Hay/Pasture & Non-cultivated Pasture Fair & 49 & 69 & 79 & 84 \\
\hline Barren Land & Assumption & 40 & 40 & 40 & 40 \\
\hline Cultivated Crops & Cultivated Ag. Land Row Crop Straight & 67 & 78 & 85 & 89 \\
\hline Developed, High Intensity & Paved parking lots, roofs, driveways & 98 & 98 & 98 & 98 \\
\hline Developed, Low Intensity & Fully developed urban areas, Fair & 49 & 69 & 79 & 84 \\
\hline Developed, Medium Intensity & Commercial and Business Areas & 89 & 92 & 94 & 95 \\
\hline Developed, Open Space & Fully developed urban areas, good & 39 & 61 & 74 & 80 \\
\hline Emergent Herbaceous Wetlands & Assumption & 95 & 95 & 95 & 95 \\
\hline Evergreen Forest & Forestland - Evergreen & 44 & 65 & 76 & 82 \\
\hline Herbaceous & Fair Herbaceous & 60 & 71 & 80 & 89 \\
\hline Mixed Forest & Woods Fair & 36 & 60 & 73 & 79 \\
\hline Open Water & Assumption & 95 & 95 & 95 & 95 \\
\hline Shrub/Scrub & Forestland - Brush Poor & 48 & 67 & 77 & 83 \\
\hline Woody Wetlands & Woods Poor & 66 & 77 & 83 \\
\hline
\end{tabular}

The open water and emergent herbaceous wetlands were assumed to have a curve number value of 95 . The sand is expected to quickly infiltrate water and is assumed to have a curve number of 40 . The curve number is converted to an infiltration rate based on the precipitation level and making the assumption that the initial abstraction is equal to one-fifth of the potential maximum soil moisture retention. 
The equation relating the continuing abstraction to the curve number is demonstrated (Eqn 4.5.1).

$$
F_{a}=\frac{\left(P-I_{a}\right)}{\left(1+\frac{0.2\left(P-I_{a}\right)}{I_{a}}\right)}
$$

The derivation for the equation is provided in Appendix 2. The curve number spatial distribution is demonstrated (Figure 30).

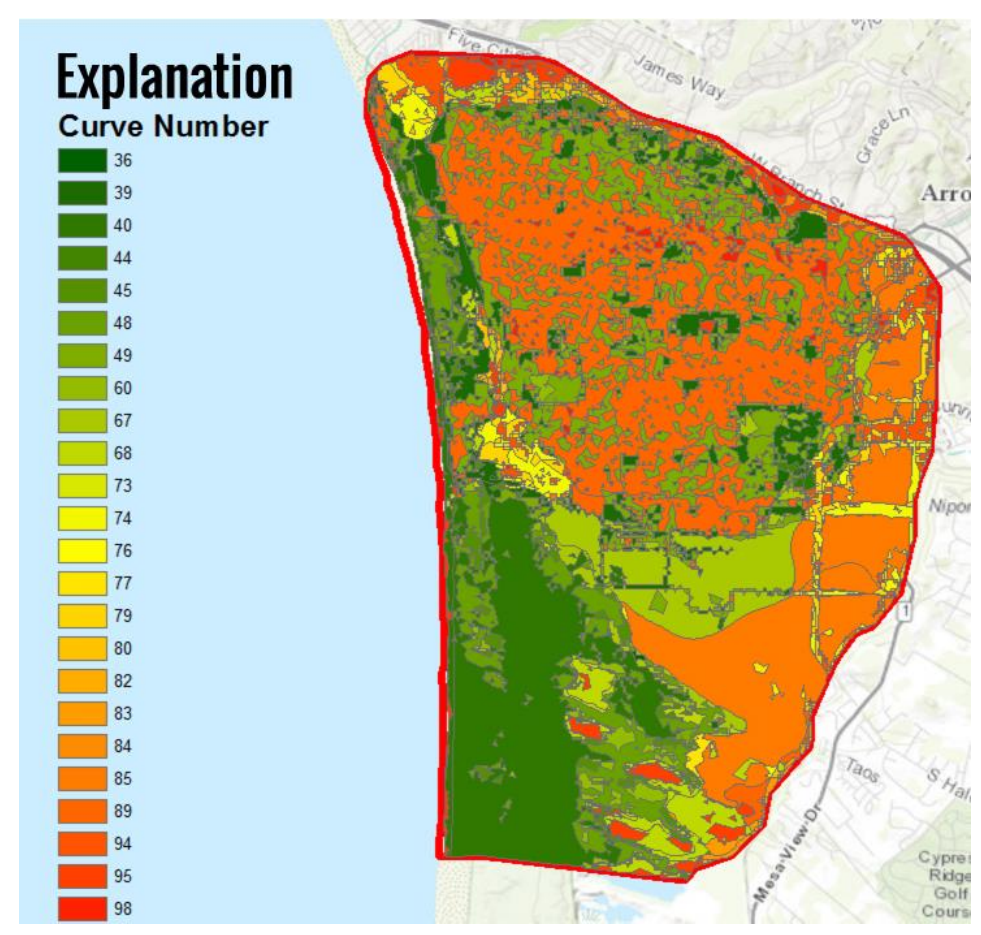

Figure 30 - Curve Number Distribution in Model Domain

Recharge is expected to occur along the coast and in the central and southcentral regions of the model domain. Sparse recharge exists throughout the largely urban dominated northern region.

The complexity of the recharge shapefile caused Visual MODFLOW® to crash upon import. The shapefile is divided into six components and imported one- 
at-a-time, but the complexity of variation in the infiltration rate per polygon caused Visual MODFLOW® to be unable to save. The six components are divided into bins based on curve number. The curve numbers are aggregated for each component based on the weighted average of the total polygon area for each curve number and aggregate curve numbers are established. In addition, import of recharge values from a shapefile was determined to use a significantly greater amount of computation than usage of a constant value and caused a longer save time. The infiltration rates based on a steady state annual precipitation of 16 inches are tabulated (Table 8).

\section{Table 8 - Infiltration Rates for Aggregated Infiltration Zones}

\begin{tabular}{|c|c|c|c|c|}
\hline $\mathbf{C N}$ & $\mathbf{S}$ & la (in/year) & Fa (in/year) & Fa (in/day) \\
\hline 40.09 & 14.9 & 3.0 & 7.0 & 0.019 \\
\hline 48.78 & 10.5 & 2.1 & 6.0 & 0.016 \\
\hline 60.00 & 6.7 & 1.3 & 4.6 & 0.013 \\
\hline 70.03 & 4.3 & 0.9 & 3.3 & 0.009 \\
\hline 83.85 & 1.9 & 0.4 & 1.7 & 0.005 \\
\hline 90.08 & 1.1 & 0.2 & 1.0 & 0.003 \\
\hline
\end{tabular}

The aggregated infiltration shapefiles were imported into Visual MODFLOW ${ }$ and the infiltration rates were manually added (Figure 31). 


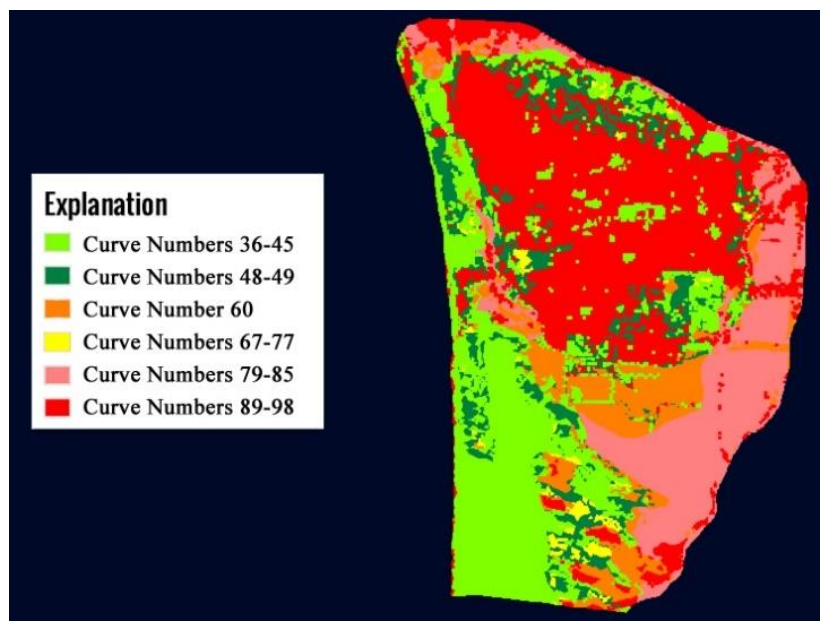

Figure 31 - Aggregate Infiltration Zones

The initial abstraction height was converted into feet and incorporated as the ponding depth during the boundary condition definition. The conceptual model to numerical model conversion process is affected most principally by infiltration shapefile conversion.

In addition to surface recharge from varying types of land use and soil type, infiltration also enters the model domain through percolation beneath lakes, ponds, and infiltration basins. These are integrated into the groundwater model using the LAK package and a Hydrography shapefile provided by the USGS National Map Viewer (Dollison, R.M., 2010). Careful inspection of the hydrography polygons is important to distinguish land use type changes over time (Figure 32).

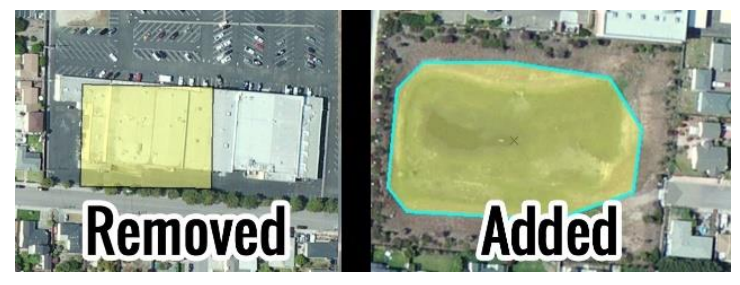

Figure 32 - Infiltration Pond Development and Validation 
The infiltration pond locations were validated using the Todd Engineers 2007 Water Balance Study. The lakes in the southern and northern regions in the study area were not included in the analysis conducted by Todd Engineers due to limited data and were removed from the infiltration basin analysis for the purpose of this report (Figure 33).

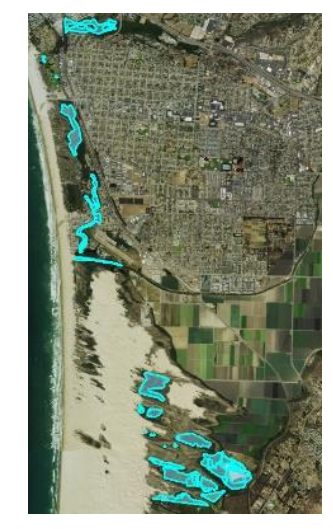

Figure 33 - Lakes Removed from Infiltration Basin Analysis

According to the Todd Engineers Study (2007), the lakes in the southern region are described by some previous reports as potential sources of outflows of the system, as they may be fed by groundwater. The area of the infiltration ponds is determined to be 9.61 acres using ArcGIS $\AA_{\text {. }}$. The leakance term used in the LAK package is determined based on the average monthly infiltration volume from the Todd Engineers study, assuming a depth of 3 feet for all ponds, and the total area of the infiltration ponds. Lake leakance budget terms generated from MODFLOW did not contribute the amount of infiltration that was expected.

\subsection{Well Field Development}

Well data was provided in an ArcGIS® shapefile by Shane Taylor, the Utilities Manager at AGPW. Six wells are located in the study area and pertinent 
attribute data included in the shapefile contains the well name, casing depth, and well capacity (Figure 34).

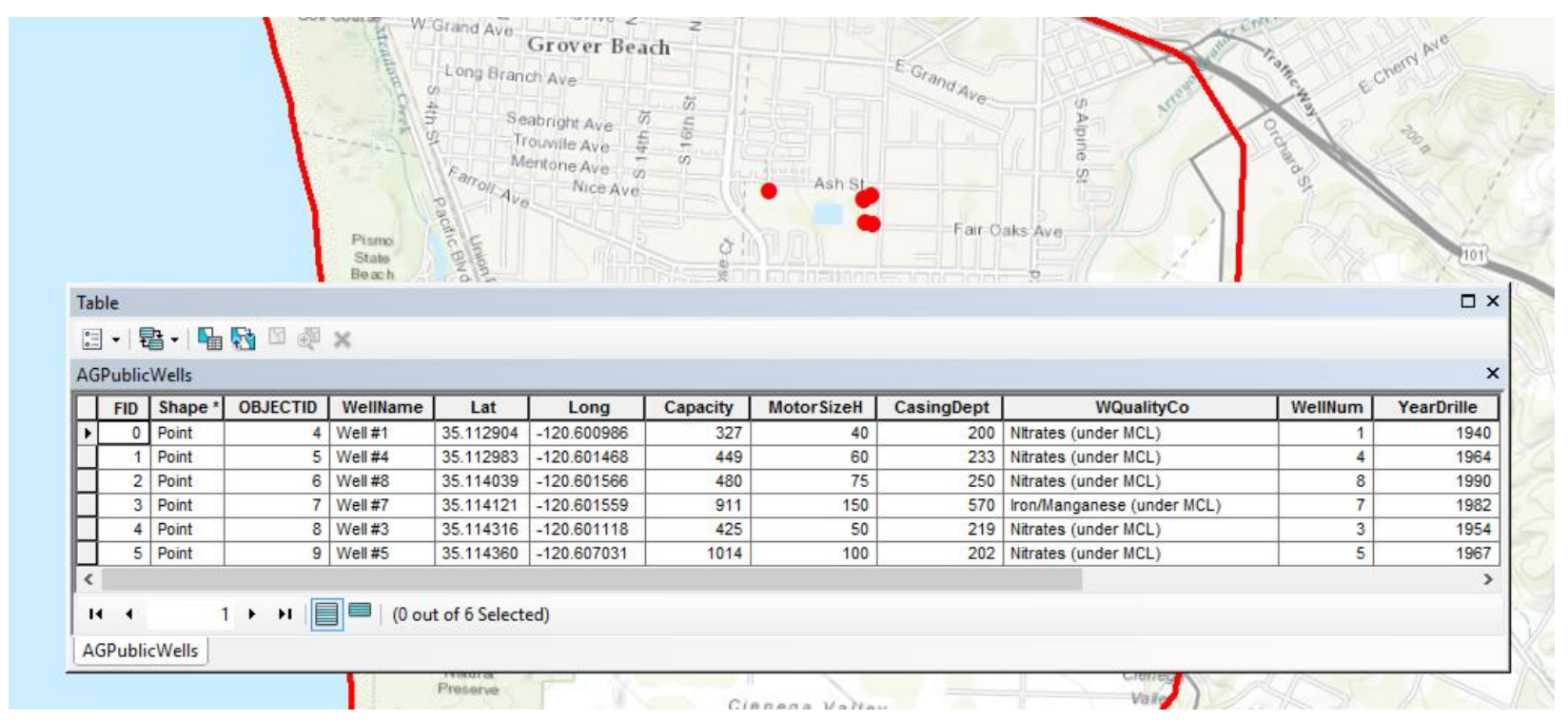

Figure 34 - Arroyo Grande City Well Field and Attribute Data

The shapefile is imported into Visual MODFLOW® as point data. It is assumed that the well screens are 10 feet and that the pumping schedules are steady state. Actual pumping rates and well screen intervals are implemented in the transient development section. The Oceano and Grover Beach well locations are identified by georeferencing the 2014 NCMA Annual Monitoring Report image of well locations and gradient contours to the model domain in ArcGIS®. Shapefile layers are edited to include wells for Grover Beach, Oceano, and an additional well in the Arroyo Grande City limits (Figure 35). 


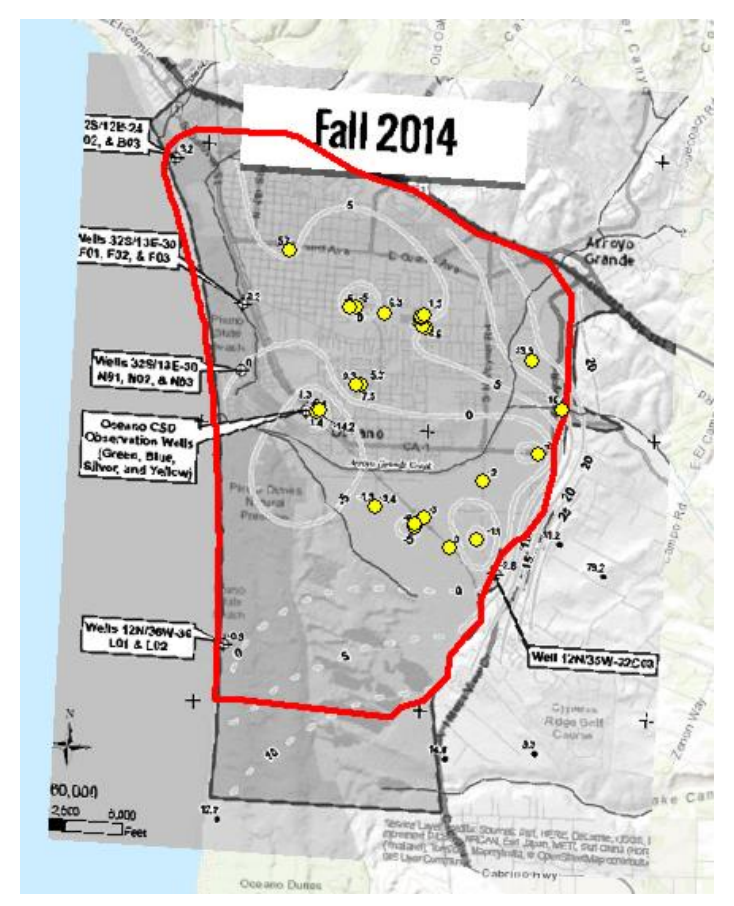

Figure 35 - Georeferenced Well Locations

Pumping rates are estimated in order to develop drawdown that is consistent with the 2014 NCMA Annual Monitoring Report. The guess and check method is used until the drawdowns in the wells match the historical data (Figure 36).

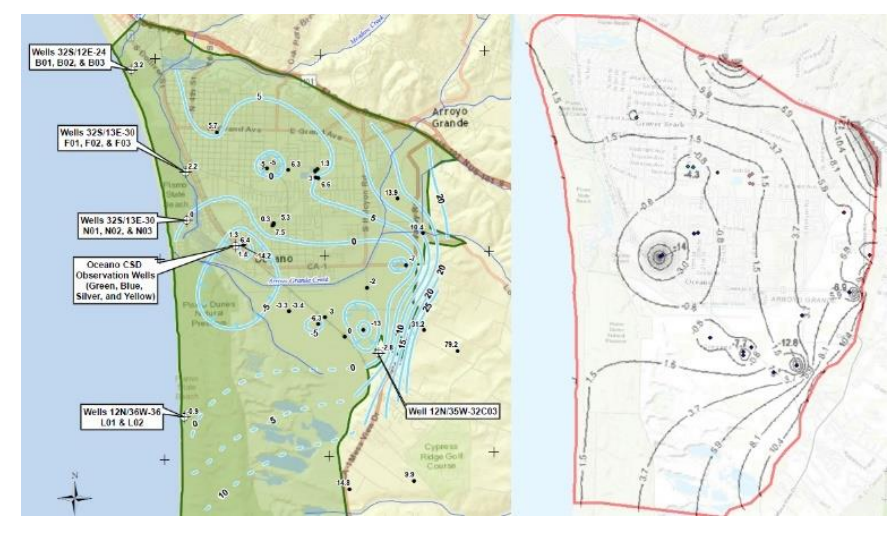

Figure 36 - Matching Simulated Drawdowns to Historical Drawdown Data 
Pump information was obtained from Tony Marraccino at OCSD, Shane Taylor AGPW, and from Greg Ray and Keith MacGregor at the GBPW (Table 9).

Table 9 - Municipal Pump Data

\begin{tabular}{|c|c|c|c|c|}
\hline Authority & Pump \# & Flow Rate (GPM) & Depth (ft) & Screen Interval (ft) \\
\hline OCSD & 4 & 325 & 200 & $114-128$ \\
\hline OCSD & 6 & 325 & 607 & $305-596$ \\
\hline OCSD & 8 & 950 & 525 & $380-520$ \\
\hline AGPW & 1 & 300 & 230 & $100-230$ \\
\hline AGPW & 3 & 400 & 233 & $100-219$ \\
\hline AGPW & 4 & 450 & 250 & $92-232$ \\
\hline AGPW & 5 & 950 & 220 & $75-200$ \\
\hline AGPW & 7 & 850 & 570 & $290-570$ \\
\hline AGPW & 8 & 350 & 240 & $137-231$ \\
\hline GBPW & 1 & 620 & 178 & $132-178$ \\
\hline GBPW & 2 & 560 & 180 & $126-180$ \\
\hline GBPW & 3 & 730 & 178 & $78-178$ \\
\hline GBPW & 4 & 700 & 549 & $481-549$ \\
\hline & & & & \\
\hline
\end{tabular}

The wells pumping the largest amount of water had the greatest depths and are assumed to be pumping out of the Careaga Formation. Several pumps that had been included in the original steady state development were discovered to be out of commission and were removed from the groundwater model. In addition to the flow rate, depth, and screen interval information, monthly extraction in acrefeet and monthly depth to water data was provided going back to 2008 to aid in transient model development and calibration. 


\subsubsection{Spatial Discretization Analysis}

The spatial discretization defines the number of rows and columns in each layer of a groundwater model. The $x$ and $y$ spatial discretization values $(\Delta x, \Delta y)$ are arguably among the most important parameters of a mathematical model. As was previously described, coarse models complete model runs quickly but average over important model characteristics and yield inaccurate data, and models with excessively high resolution consume enormous computational resources. To further complicate the issue, transient models run the model for every timestep, and parameter estimation optimization methods require thousands of model runs to identify parameters that create solutions that best fit historical data. This section describes the steps taken to identify the optimal discretization for the NCMA groundwater model.

At the beginning of the discretization analysis, an equal number of rows and columns are used to generate varying grid sizes. The values of $\Delta x$ and $\Delta y$ are not equal in length because the model domain is 1.44 times taller than it is wide. A deformed grid is used for the vertical $(\Delta z)$ discretization to maintain the layer elevation profiles (Figure 37).

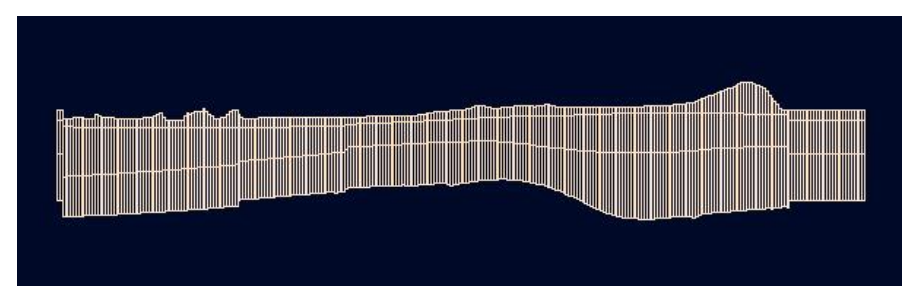

Figure 37 - 300x300 Deformed Grid in Vertical $(\Delta z)$ Discretization 
Benefits from using deformed grids include using a smaller number of layers and efficient model redevelopment. The downside of using deformed grids is potential pinching of layers in convergence areas and the associated model instability. Using uniform grids requires more attention to detail during development and is more computationally demanding (Schlumberger, 2016). In Figure 37, the discontinuous left and right components of the cross section are defined as null values and are not included in the simulation domain.

The effects of variation in the spatial discretization is addressed by comparing variations in well drawdown values and hydraulic contouring from previous studies to the results of the steady state model. Wells used in the discretization analysis include four wells in Oceano and one well from Grover and Arroyo Grande (Figure 38).

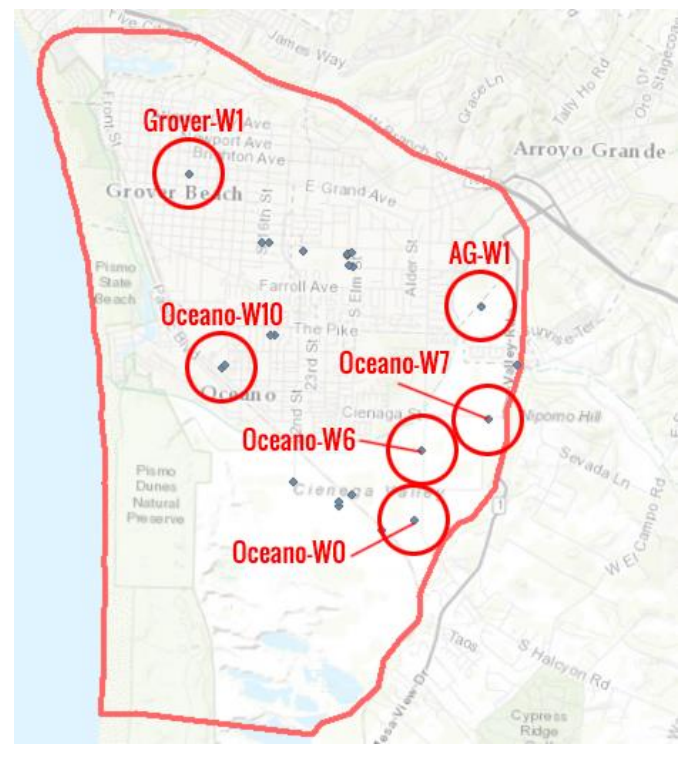

Figure 38 - Wells Used in Discretization Analysis 
The drawdown in heavily impacted wells increases as the number of cells increases. This is a result of the method used by the WEL package to distribute the pumping out over the horizontal cell face. As the cell face area decreases, the pumping occurs in a more localized area and generates a greater drawdown.

Discretizations ranging from 30 rows and 30 columns $(30 \times 30)$ to $200 \times 200$ columns are used to assess variability in head levels in wells, stream effects, and hydraulic contouring to assess the variability of the resolution. The results began to converge to a similar number in most wells as the discretization increased from $180 \times 180$ to $200 \times 200$ (Table 10 ).

\section{Table 10 - Discretization Analysis Results in Well Heads}

\begin{tabular}{|c|c|c|c|c|c|c|}
\hline \multirow{2}{*}{ Discretization } & \multicolumn{7}{|c|}{ Layer 2 Well Heads (ft) } \\
\cline { 2 - 7 } & Oceano-W10 & Oceano-W0 & Oceano-W7 & Oceano-W6 & Grover-W2 & AG-W1 \\
\hline $30 \times 30$ & -8.9 & 3.0 & 6.5 & 7.5 & 1.8 & 11.5 \\
\hline $50 \times 50$ & -9.9 & -8.0 & 5.5 & 1.9 & 1.0 & 9.5 \\
\hline $100 \times 100$ & -12.8 & -12.2 & 4.2 & -6.0 & 0.9 & 3.9 \\
\hline $140 \times 140$ & -14.0 & -14.3 & 3.9 & -8.8 & 0.9 & 7.7 \\
\hline $180 \times 180$ & -15.1 & -15.9 & 3.6 & -11.0 & 0.7 & 8.1 \\
\hline $200 \times 200$ & -15.2 & -16.6 & 3.6 & -11.6 & 0.7 & 9.2 \\
\hline
\end{tabular}

The percent change in hydraulic head from one resolution to the next is plotted to demonstrate the convergence to a solution (Figure 39). Outliers demonstrating a percent change greater than $100 \%$ were eliminated from the 
plotting process and were replaced with an average between the two adjacent points.

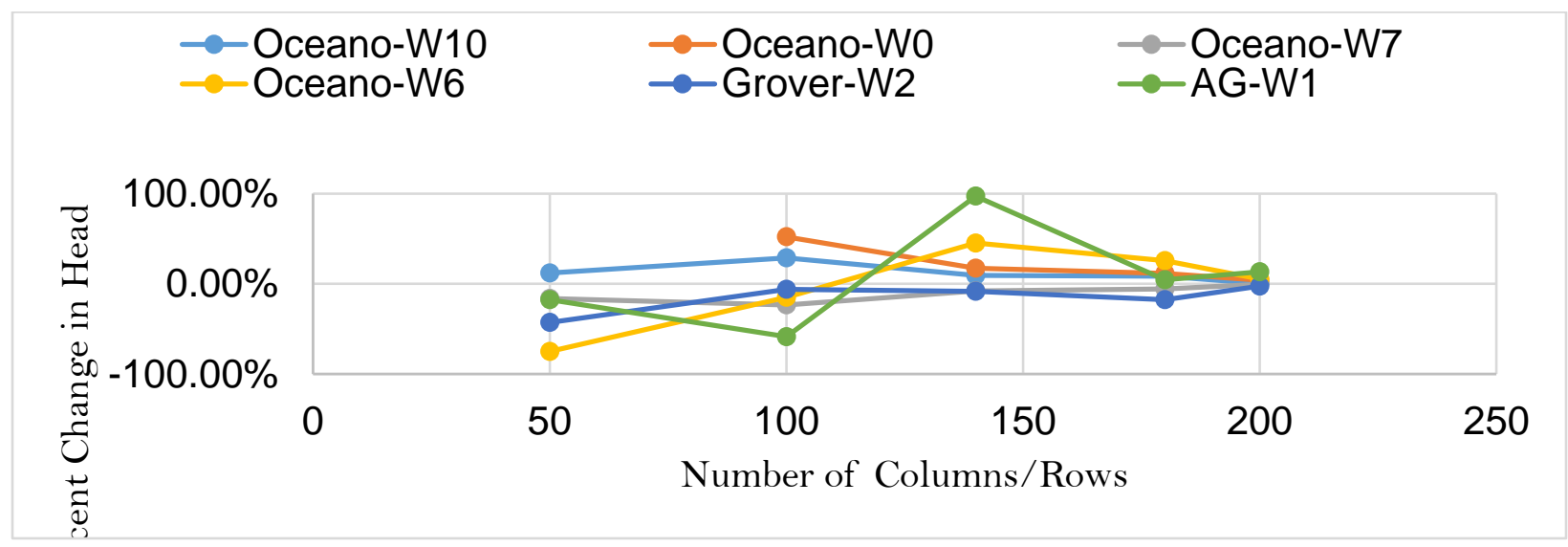

Figure 39 - Percent Change in Well Head Levels from Previous Iteration

Moderate convergence occurred at the discretization of $200 \times 200$ with a percent change in heads of less than $6 \%$ in Oceano wells, less than $3 \%$ in the Arroyo Grande well, and $14 \%$ in Arroyo Grande farm well close to the river. The computational time increased by an average of $182 \%$ during each iteration of discretization increase (Figure 40). 


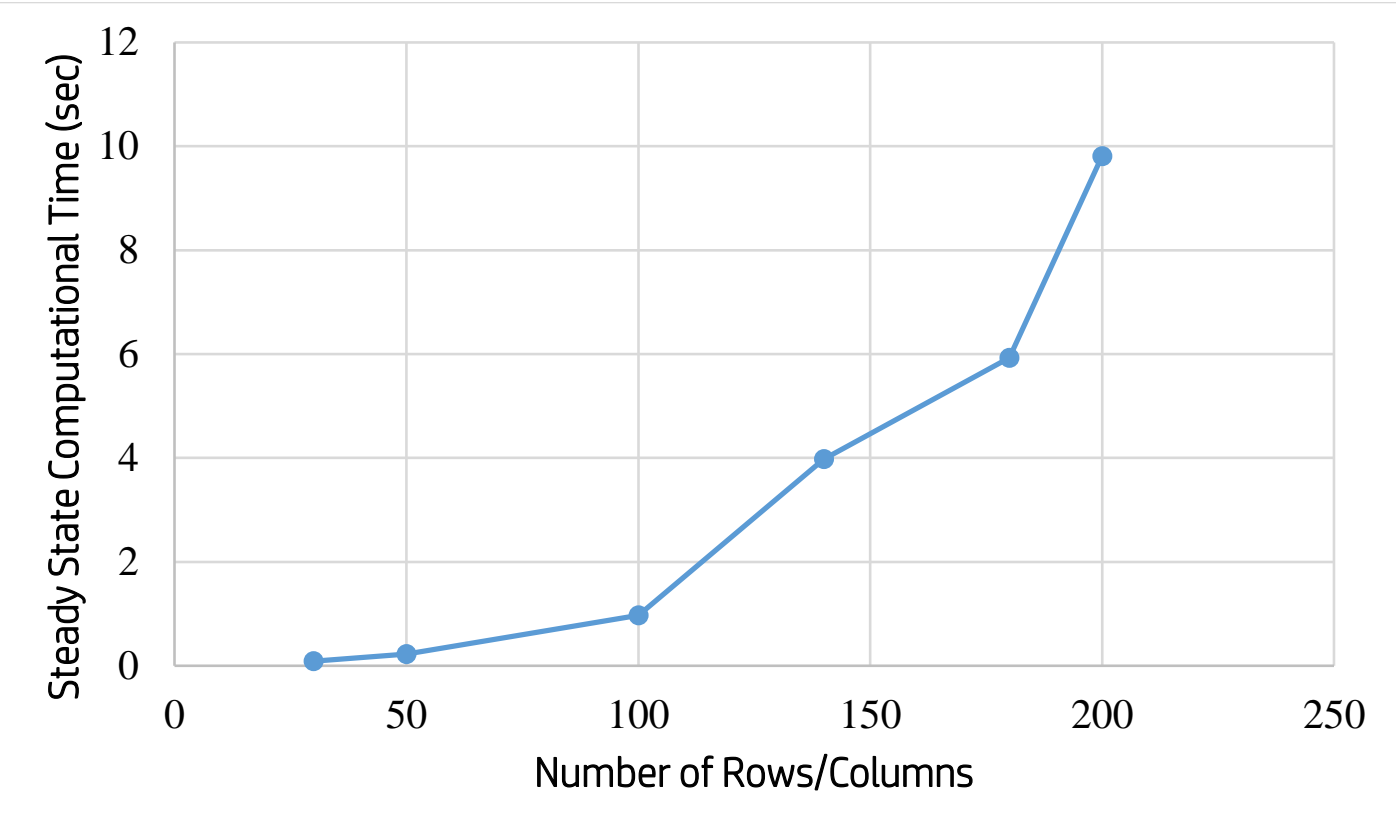

Figure 40 - Computational Time for Increasing Discretizations

Increasing the discretization greater than 200 columns and 200 rows caused the conversion process from the conceptual model to numerical model to run longer than 8 hours. Hydraulic contours for varying discretizations demonstrate the variability in model accuracy (Figure 41 and Figure 42). 


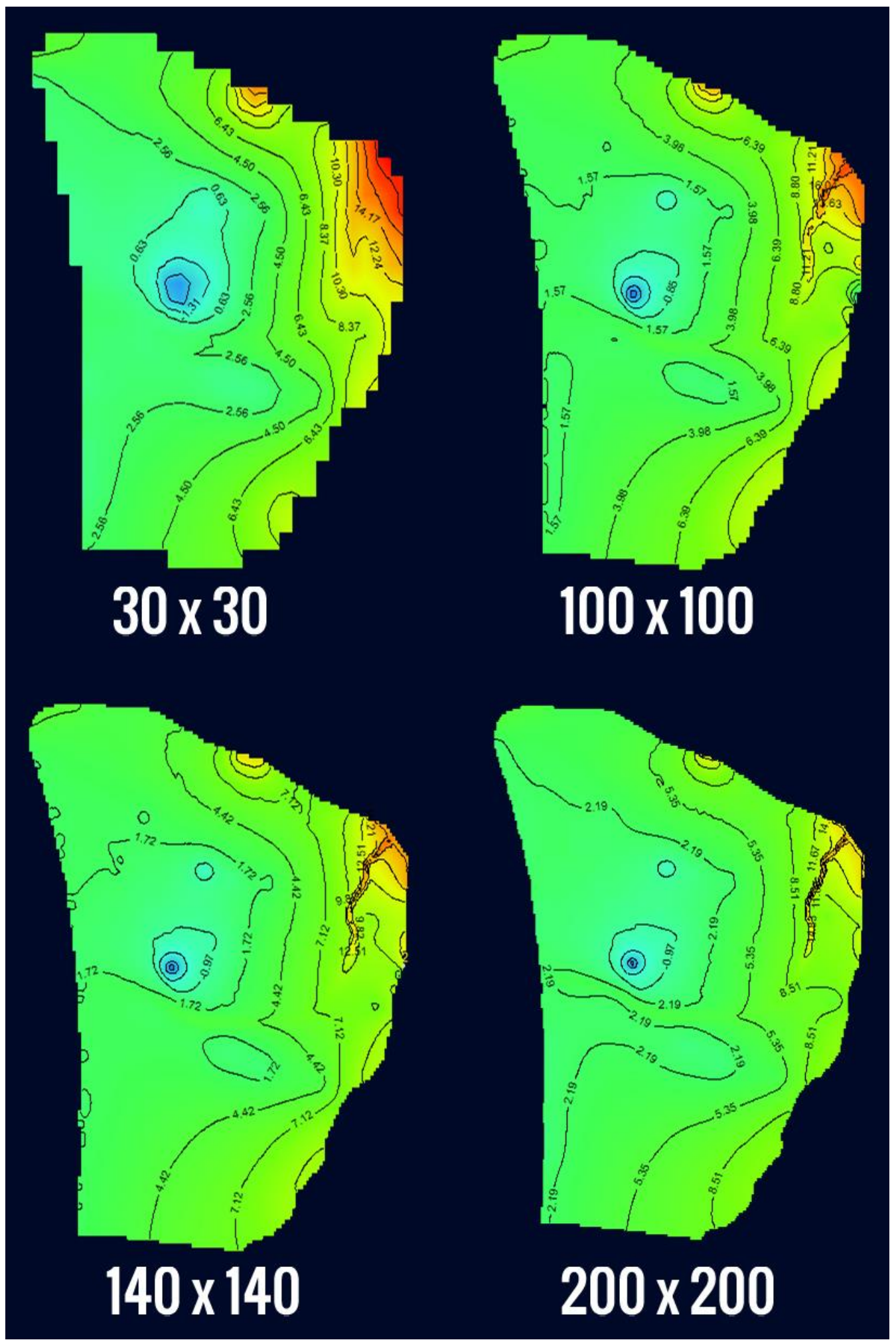

Figure 41 - Layer 1 Variations in Hydraulic Contours from Variation in Discretization 


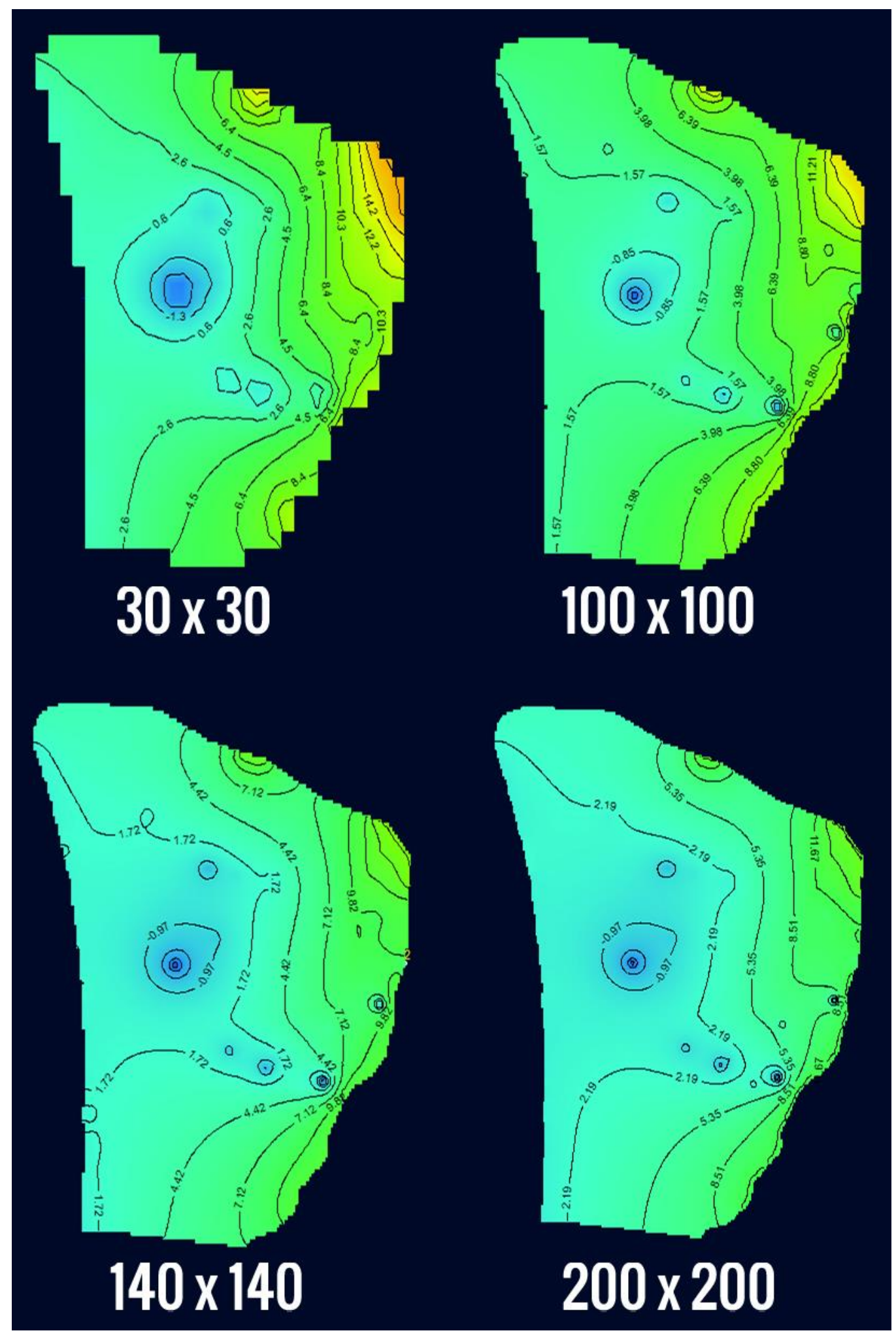

Figure 42 - Layer 2 Variations in Hydraulic Contours 
The variations in contour and head levels in wells between the $180 \times 180$ and $200 \times 200$ discretizations were within the tenth of a foot for most of the wells. The variations between $140 \times 140$ and $180 \times 180$ were within a foot for most wells, with some wells demonstrating drawdown variation of 1.6 feet. The discretization of $202 \times 140$ is selected to provide more nodes than the $140 \times 140$ discretization, but the computational efficiency of an equivalent discretization of $168 \times 168$. The rows are selected to generate square shaped cells of $127 \times 127$ feet.

\subsubsection{Steady State Calibration}

The steady state boundary conditions are calibrated to averaged well heads from the 2011-2014 NCMA Annual Monitoring Reports. Previous reports did not include head data in the hydraulic contouring plots. The well data demonstrates declines in hydraulic head over time for Arroyo Grande, Grover Beach, Oceano, and the farms (Figure 43, Figure 44, Figure 45, and Figure 46).

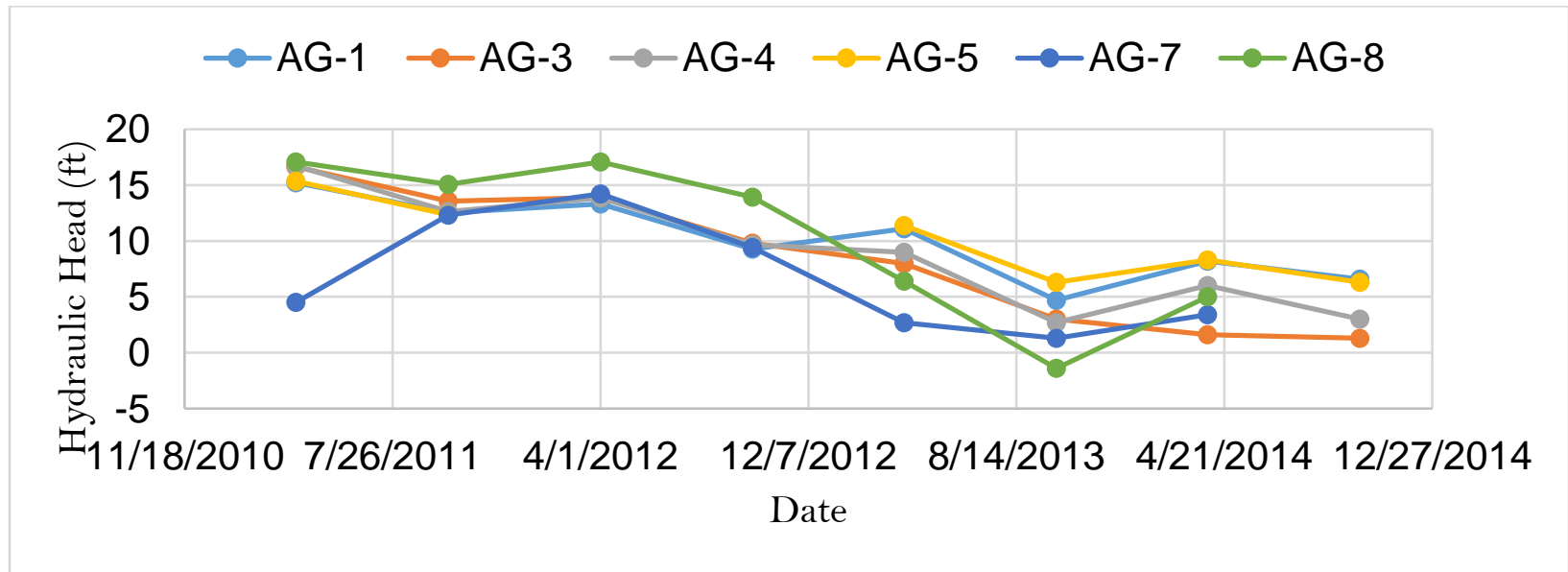

Figure 43 - Arroyo Grande City Well Hydrographs from NCMA 


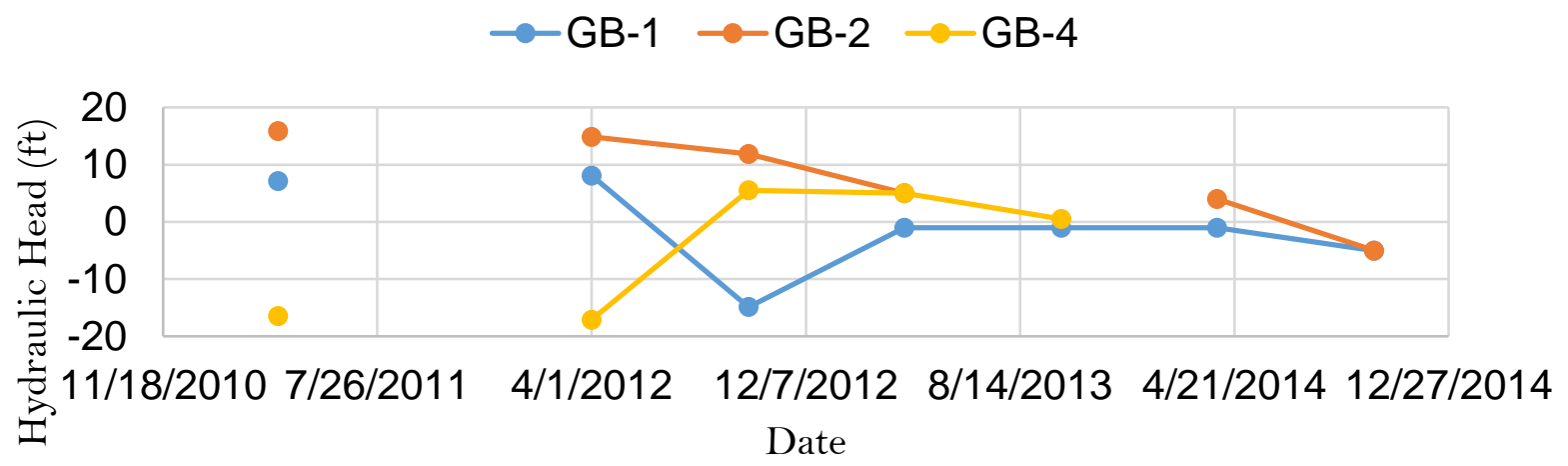

Figure 44 - Grover Beach Hydrographs from NCMA

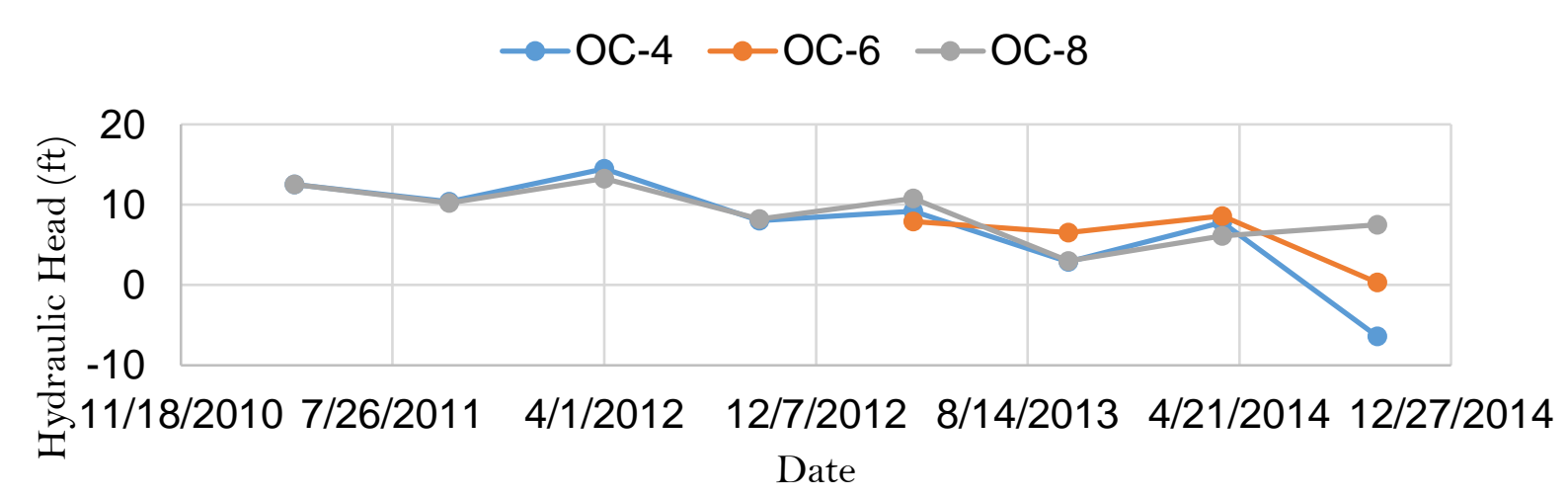

Figure 45 - Oceano Hydrographs from NCMA

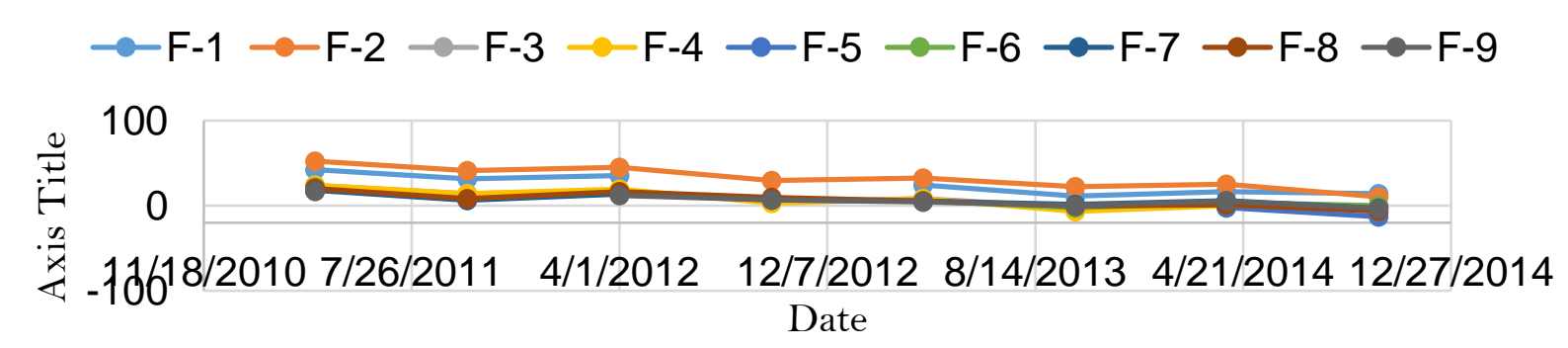

Figure 46 - Farm Well Hydrographs from NCMA

All wells demonstrate decreases in hydraulic head over the $2011-2015$ drought period. The variation in head data for the southeast farm wells exceeded 
30 feet during the drought period. The averaged value over the period with data is used to calibrate the boundary conditions of the steady state model.

The sum of the square residuals value $(\phi)$ decreases as the Dirichlet boundary conditions are increased. Increasing the Arroyo Creek boundary condition from 18 to 28 feet caused an $8 \%$ reduction in $\phi$. The new $\phi$ value was then reduced by $32 \%$ after increasing the Los Berros boundary conditions by 20 feet. Subsequently, increasing the Deep Nipomo boundary condition by 10 feet generated a reduction in $\phi$ of $53 \%$, increasing Oak Park boundary by 10 feet generated a reduction in $\phi$ of $13 \%$, increasing the Pismo Creek boundary condition by 5 feet caused a $1 \%$ decrease in $\phi$, and increasing the Deep Nipomo boundary condition an additional by 5 feet decreased the $\phi$ value by another $19 \%$. During this calibration process, the $\phi$ value decreased $80 \%$ from 2480 feet $^{2}$ to 505 feet $^{2}$. The new boundary conditions versus the initially assumed boundary conditions are tabulated (Table 11).

Table 11 - Calibrated Boundary Conditions

\begin{tabular}{|l|c|c|}
\hline Boundary Name & Old Constant Head (ft) & New Constant Head (ft) \\
\hline Pismo Creek & 5 & 10 \\
\hline Oak Park Blvd. & 15 & 25 \\
\hline Arroyo Grande Creek & 18 & 28 \\
\hline Los Berros Creek (0-2) & $5-15$ & $25-35$ \\
\hline Ocean Boundary & 0 & 0 \\
\hline Deep Nipomo Recharge & 12 & 28 \\
\hline
\end{tabular}


The initial guesses for the boundary conditions were based on the 2014 NCMA Annual Monitoring Reports and did not provide an average for years with higher hydraulic heads in the earlier stages of the 2011-2015 drought. The density of saltwater is not accounted for in the ocean boundary condition and should be implemented in further groundwater model development. The differences in simulated hydraulic heads and observed averaged hydraulic heads is demonstrated for the original and calibrated boundary conditions is demonstrated (Figure 47).

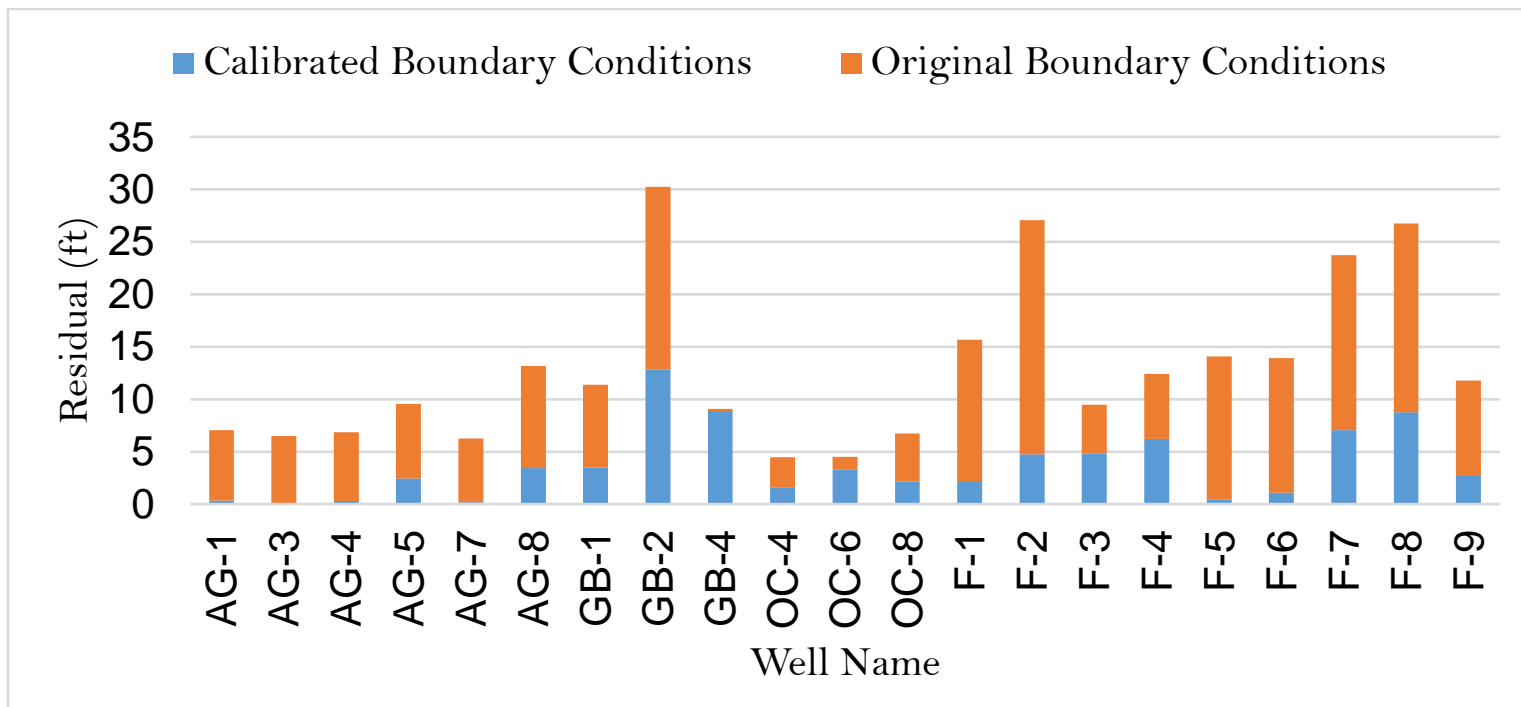

Figure 47 - Hydraulic Head Residuals in Wells for Steady State Simulation and Averaged Well Data

Significant improvements are made in the majority of the Arroyo Grande wells, but the well GB-2 and GB-4 wells had residuals of 12.8 and 8.7 feet, respectively, after the steady state boundary calibration process. 


\subsubsection{Calibration to Todd Engineers 2007 Water Balance Study Results}

The river leakance and recharge multiplier variables were increased by 4 and 1.2228 respectively to yield budget values within $5 \%$ of the Todd Engineers numbers (Table 12). The Dirichlet boundary conditions providing inflow to the model are within $6 \%$ of values estimated by the Todd Engineers study. Utilization of the GHB package for the ocean boundary condition yielded numbers within $7 \%$ of predicted values. The $17 \%$ reduction in pumping between the averaged pumping values since 2008 and the Todd Engineers 2004 report is expected because of the utilization of Lopez Lake reservoir water instead of pumping wells in recent years. 
Table 12 - Modeled Steady State Budget Values Comparison

\begin{tabular}{|c|c|c|c|c|c|c|c|}
\hline & \multicolumn{4}{|c|}{ Inflow (AFM) } & \multicolumn{3}{|c|}{ Outflow (AFM) } \\
\hline & $\begin{array}{c}\text { CONSTANT } \\
\text { HEAD }\end{array}$ & $\begin{array}{c}\text { RIVER } \\
\text { LEAKAGE }\end{array}$ & RECHARGE & $\begin{array}{c}\text { CONSTANT } \\
\text { HEAD }\end{array}$ & WELLS & $\begin{array}{c}\text { RIVER } \\
\text { LEAKAGE }\end{array}$ & \\
\hline Model & 307 & 176 & 215 & 230 & 387 & 2 & \\
\hline $\begin{array}{c}\text { Previous } \\
\text { Study }\end{array}$ & 289 & 168 & 227 & 247 & 466 & 1 & \\
\hline $\begin{array}{c}\% \\
\text { Change }\end{array}$ & $6 \%$ & $5 \%$ & $-5 \%$ & $-7 \%$ & $-17 \%$ & $121 \%$ & \\
\hline & & & Total In & 699 & & Total Out & 699 \\
\hline
\end{tabular}

Implementation of pump data obtained after the steady state model development demonstrated a reduction of $20 \%$ in pumping in the transient model results. The river leakage out term has a residual between the simulated and expected value of within 1 acre-foot, but has a large percentage due to the small value. The spring of 2013 well head levels from the NCMA reports are most similar to the averaged values over the 2011-2014 reporting period. The calibrated steady state results are visually similar to the NCMA 2013 Spring hydraulic contour plots (Figure 48). 

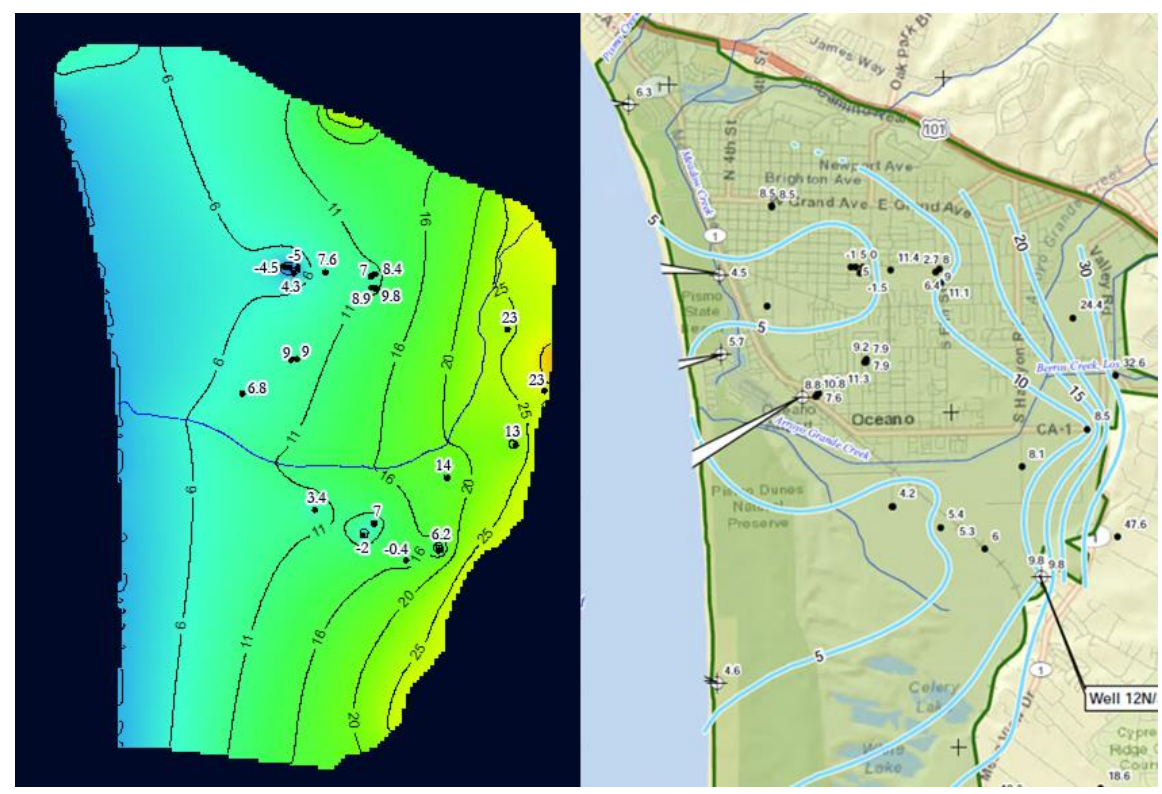

Figure 48 -Steady State Heads Compared to Spring 2013 NCMA Annual Monitoring Report

The simulated values in the farm wells demonstrate the largest discrepancies in the southern region. The farm extraction is partitioned based on drawdown from no-pumping steady state model results using the 275 AFM provided in the Todd Engineers 2007 study. The low hydraulic head in the region southwest of the southern farm wells in the Spring 2013 NCMA contour map is expected to be due to higher hydraulic conductivities in the region. In addition, the steady state model contouring did not take into account monitoring wells and is based on the flow in the model instead of contouring based on well data. 


\section{Transient Model Development}

The transient model is developed in Visual MODFLOW® by adding timeseries data for infiltration, pump flow rates, and well observations to boundary condition functions. In addition, the transient setting is required in the translation step and daily timesteps are multiplied by the number of days per month for each stress period.

\subsection{Transient Data Inputs}

Transient MODFLOW models require streamflow, pumping, hydrograph, infiltration, and boundary condition data to be specified for every timestep. MODFLOW discretizes time using "stress periods". A stress period can be defined using a single timestep, multiple timesteps, or a single timestep with a multiplier. For the NCMA groundwater model, monthly stress periods are used with one timestep per month that is multiplied by the number of days in that month.

Daily streamflow data was provided by Ray Dienzo with SLOCPW. The data is converted to monthly averages for implementation with MODFLOW monthly stress periods. The stage at Arroyo Grande Creek Station \#736 varied from 3.4 feet to 0 feet (Figure 49). 


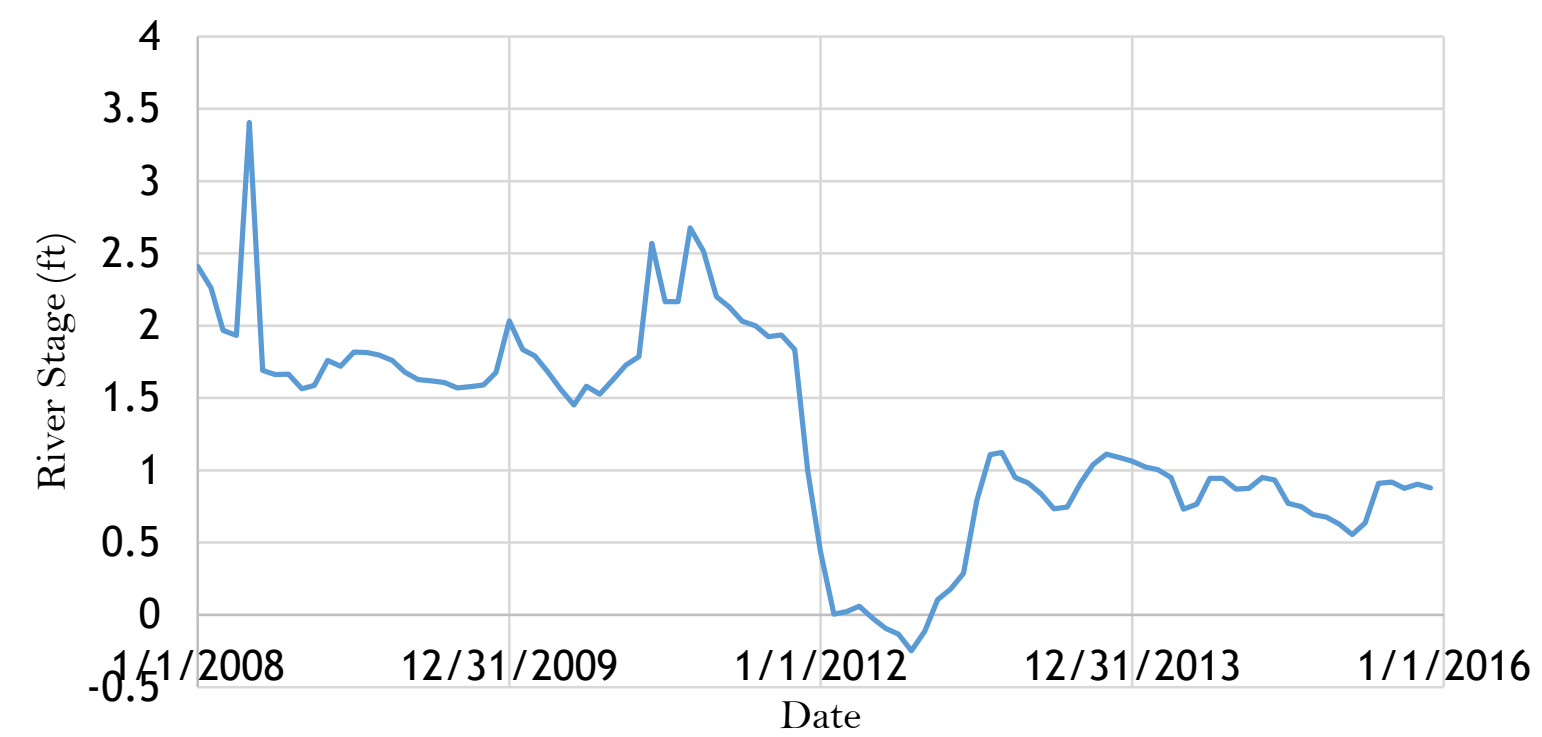

Figure 49 - Arroyo Grande Creek Hydrograph from 1/1/2008 to 12/31/2015 (SLOCPW, 2016)

The approximate streambed bottom elevation is obtained from the SLOCPW website. When the stream is dry, the stage falls below the estimated bottom elevation, and the negative values are replaced with 0 values. Streamflow decreased after 2011 and demonstrates the effects of drought. A transient RIV input file developed from a 0.2 feet surface for the stage is altered using a FORTRAN 95 program to update the stage based on the streamflow data. This program also provides quick updates to stream conductance values for sensitivity analysis without requiring model translation in Visual MODFLOW®. The conductance value is parameterized by minimizing the difference between the annualized average of average monthly river leakance terms from the Todd Engineers 2007 study and the MODFLOW results. The difference between the values was decreased to less than a quarter of one percent. 
Precipitation data was provided by SLOCPW. The precipitation at Oceano Station 795 reached a monthly maximum sum of 9.5 inches in December of 2010 (Figure 50).

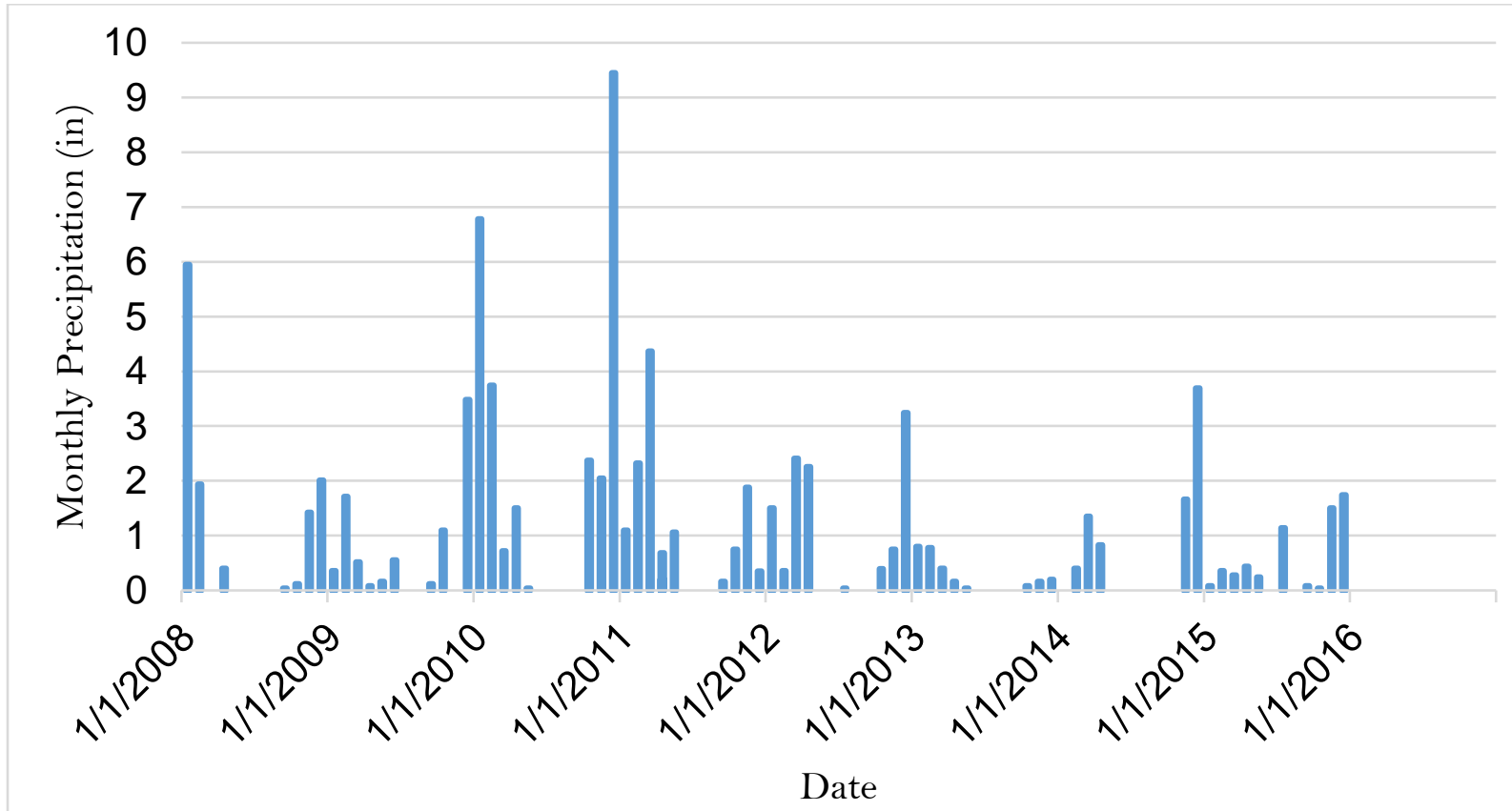

Figure 50 - Monthly Precipitation at Oceano Rain Gauge 795

The precipitation data is converted to infiltration rates using the function described in the steady state model development section in this report. In addition to the infiltration rate, the agriculture, urban, and pond recharge values from the 2007 Todd Engineers Study are added to the infiltration polygons to integrate the varying flows. Separate shapefiles are generated for the urban, agricultural, and pond return flow zones. These areas are subtracted from the other infiltration CN polygons to ensure that there is no superposition of infiltration rates going into Visual MODFLOW®. The Todd Engineers agricultural infiltration of 82.5 acre-feet per month is added to the original infiltration based on precipitation and an 
averaged curve number of 77 . Pond infiltration is added to the pond polygons using the average monthly pond infiltration rates from the 2007 Todd Engineers study. It is assumed that the ponds are dried up after August 2012 based on the difference between model results and AGPW well hydrograph data. Pond infiltration after August 2012 is provided with a 0 value. The urban flow recharge rates are averaged over the urban polygon area and distributed using monthly averages from the 2007 Todd Engineers study. The infiltration rates for the varying 9 infiltration shape areas are integrated with Visual MODFLOW® using the time schedule file type and transient data input system. Infiltration rates are multiplied by a value of 0.9 to decrease the amount of infiltration that reaches the groundwater. The desired average monthly recharge from precipitation (not including return flows) desired was 100 acre-feet, which is scaled by $75 \%$ from the average monthly recharge during the Todd Engineers study period. This value is obtained by comparing the average precipitation in the Todd Engineers study time period of 1986-2004 to the average precipitation in the model time period of 20082015. Multiplication of the infiltration rates by 0.9 provided an average monthly recharge of 97 acre-feet. The average annual total recharge is within $4 \%$ of the desired $75 \%$ of recharge from the 2007 Todd Engineers study.

Monthly flow rates were provided by AGPW, OCSD, and GBPW. These values are demonstrated in addition to estimated farm pumping trends (Figure 51). 


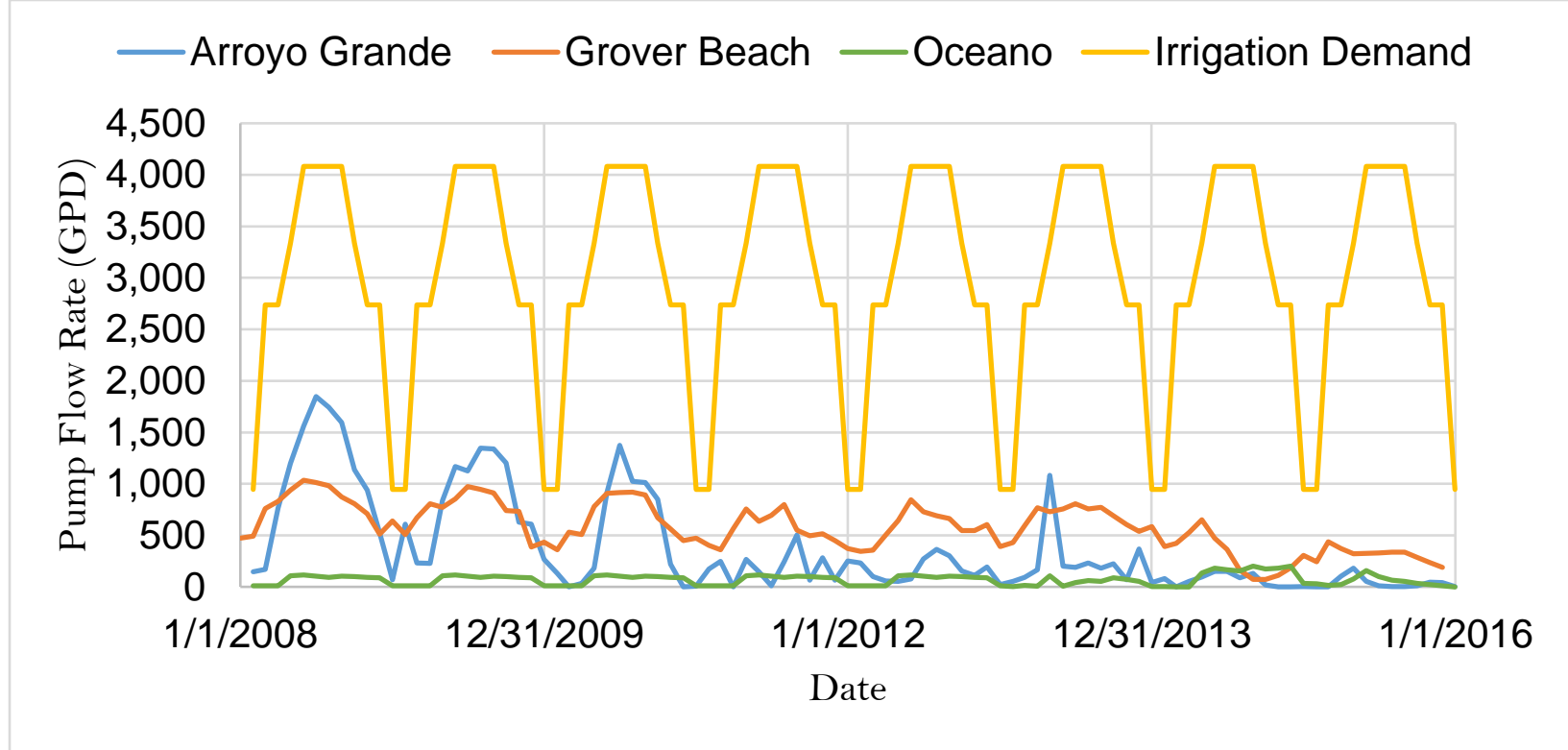

Figure 51 - Extraction Rates (AGPW-, GBPW-, OCSD-, 2016, Todd Engineers, 2007, 2011-2014 NCMA)

Arroyo Grande demonstrates the highest magnitudes of municipal pumping, but pumping rates decrease after 2010. Grover Beach pumping rates are consistent over time and do not decrease until after 2013. Oceano pumping rates remain low except for a peak in 2013 . The decreased pumping rates later in the study time are due to increased Lopez Lake reservoir water usage. The monthly municipal pumping rates are partitioned to the individual wells based on the GPM for each well. It is difficult to evaluate the effects of the inherent error in this assumption because better data is not available at this time, but variations in simulated heads when compared to well hydrographs may provide insight. Monthly logging of flows for each well instead of the entire well field will provide better data for future groundwater model development. 
The irrigation pumping flow rates are partitioned from the 275 acrefeet/month demand using the drawdown in wells based on comparison between the head data from the 2011-2014 NCMA Annual Monitoring Reports to the results from a model of steady state virgin conditions (where no pumping has affected the aquifer system). The constant monthly irrigation rates are multiplied by 0.32 in January and December, multiplied by 0.92 in February, March, October, and November, multiplied by 1.12 in April and September, and are multiplied by 1.37 in May, June, July, and August (Figure 52).

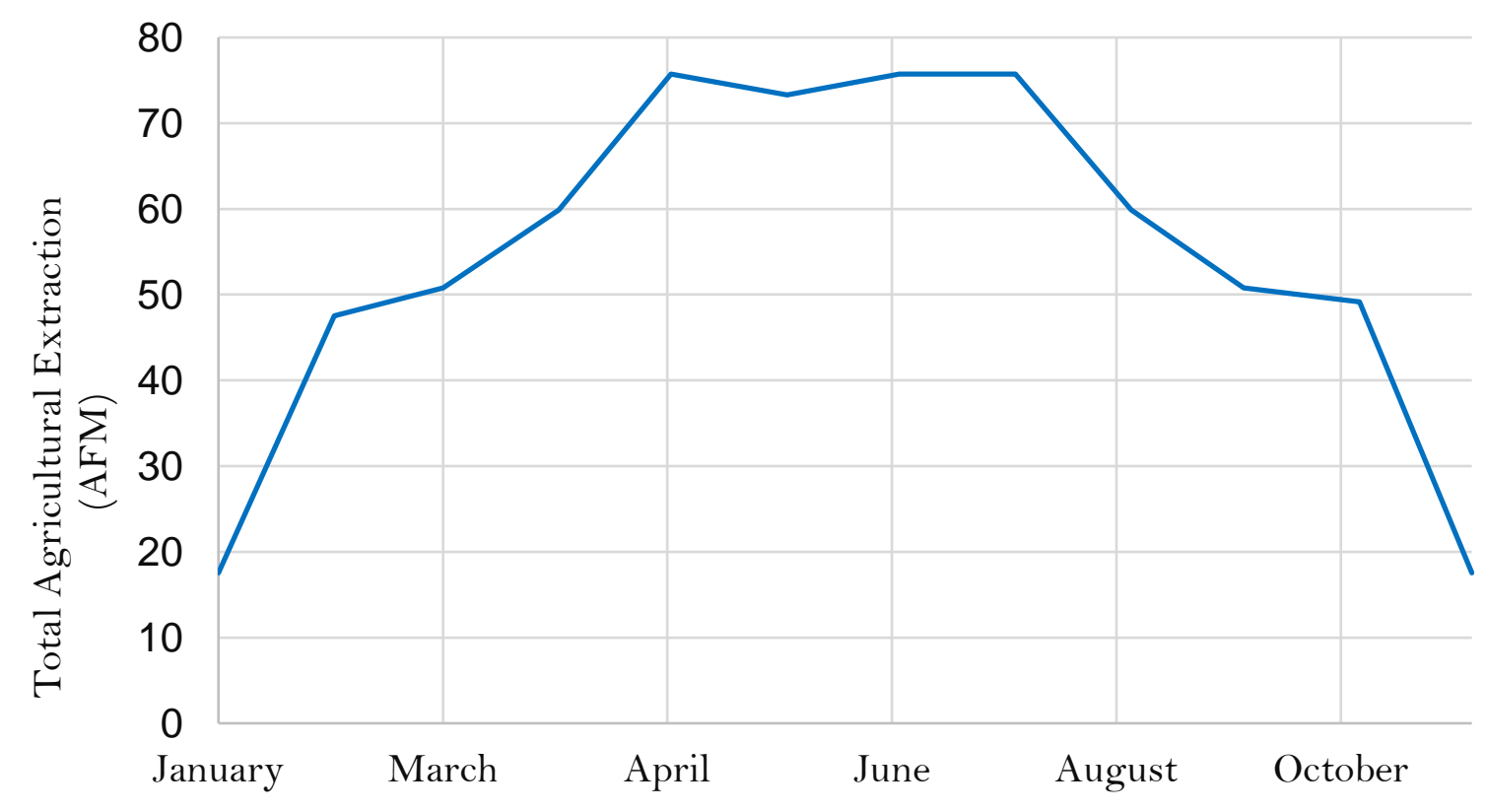

Figure 52 - Farm Well Monthly Extraction Assumptions

This trend provided better hydrograph results than using a multiplier of 2 and 0.5 for the dry and wet seasons, respectively. The multipliers are developed in Excel using initial guesses of $0.2,1$, and 1.35 and the Solver tool. The return flows from agriculture are also distributed using the same pattern to maintain water 
balance. Further evaluation of variations in agricultural pumping over time are not assessed due to temporal limitations.

AGPW and GBPW provided standing water levels for production wells dating back to 2008. Arroyo Grande drawdown values increase dramatically at the beginning of the study period and demonstrate the effects of high extraction rates (Figure 53).

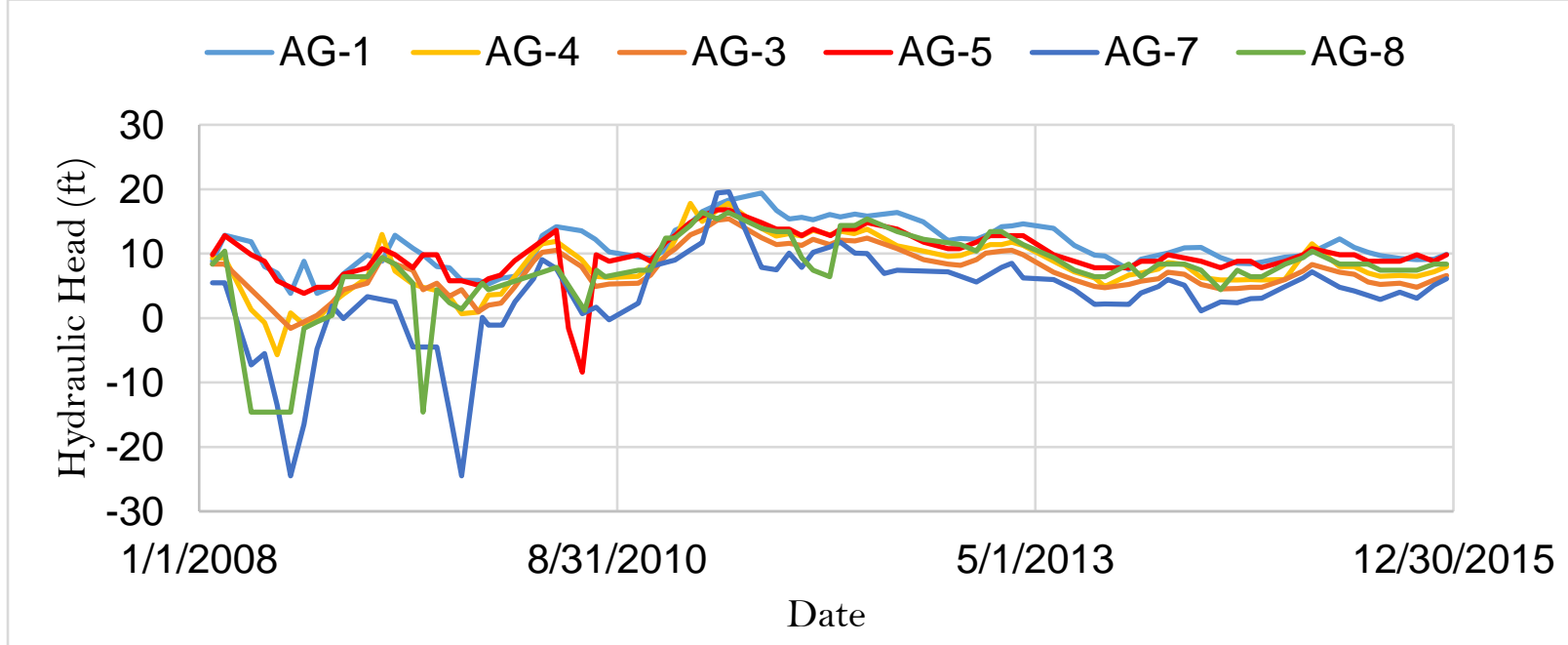

Figure 53 - AGPW Well Standing Water Levels (AGPW, 2016)

Flow rates decreasing after 2011 demonstrate replacing groundwater consumption with Lopez Lake Reservoir water. The standing head values in the Grover Beach public wells trend-sideways with maximum volatility in well GB-4 (Figure 54). 


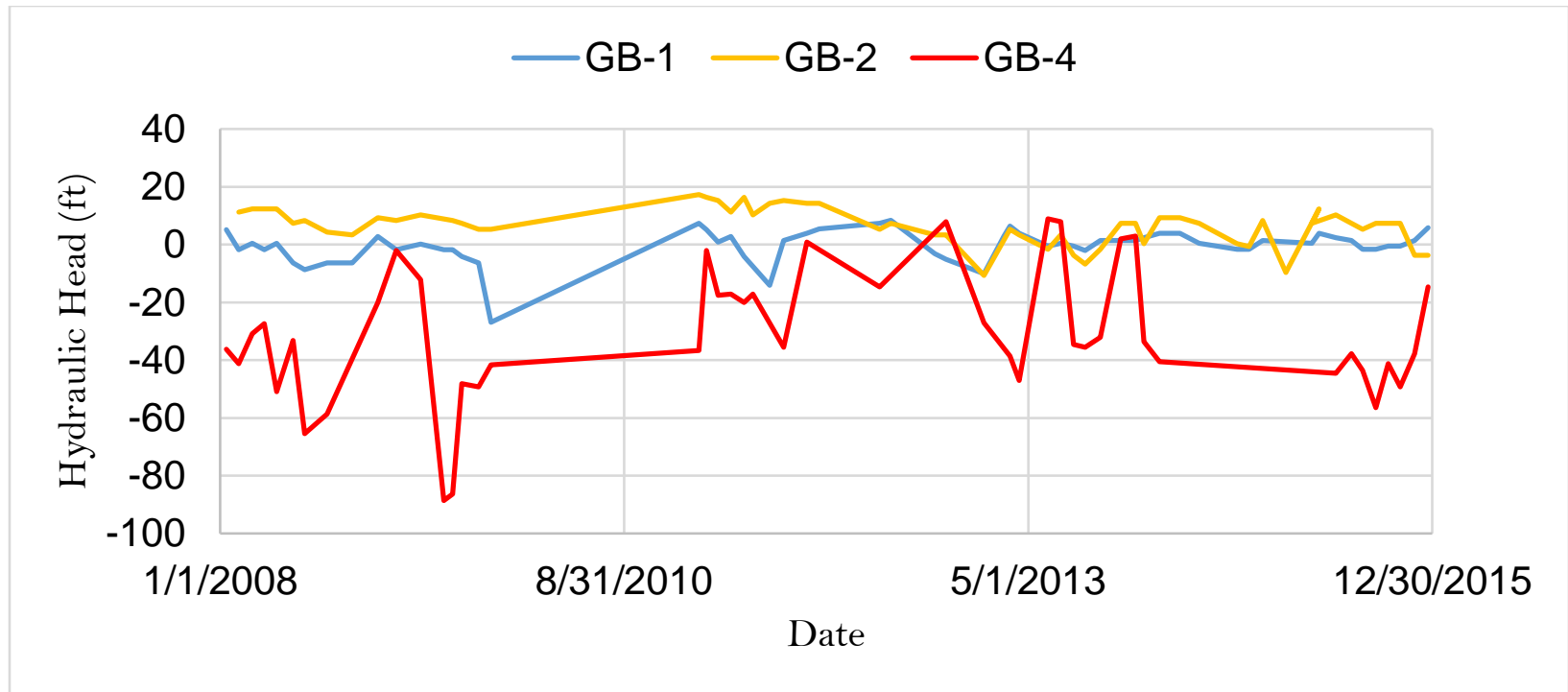

Figure 54 - GBPW Well Standing Water Levels (GBPW, 2016)

The GB-4 well has the deepest screening depth of over 500 feet deep. Lower hydraulic conductivity values in the Careaga Formation contribute to higher volatility in drawdown. Well GB-2 demonstrates the lowest variability due to its decreased GPM capacity.

Farm well data over time was tabulated from the April and October data points from the 2011-2014 NCMA Annual Monitoring Reports. The farm well hydrographs demonstrate decreasing water levels over time (Figure 55). 


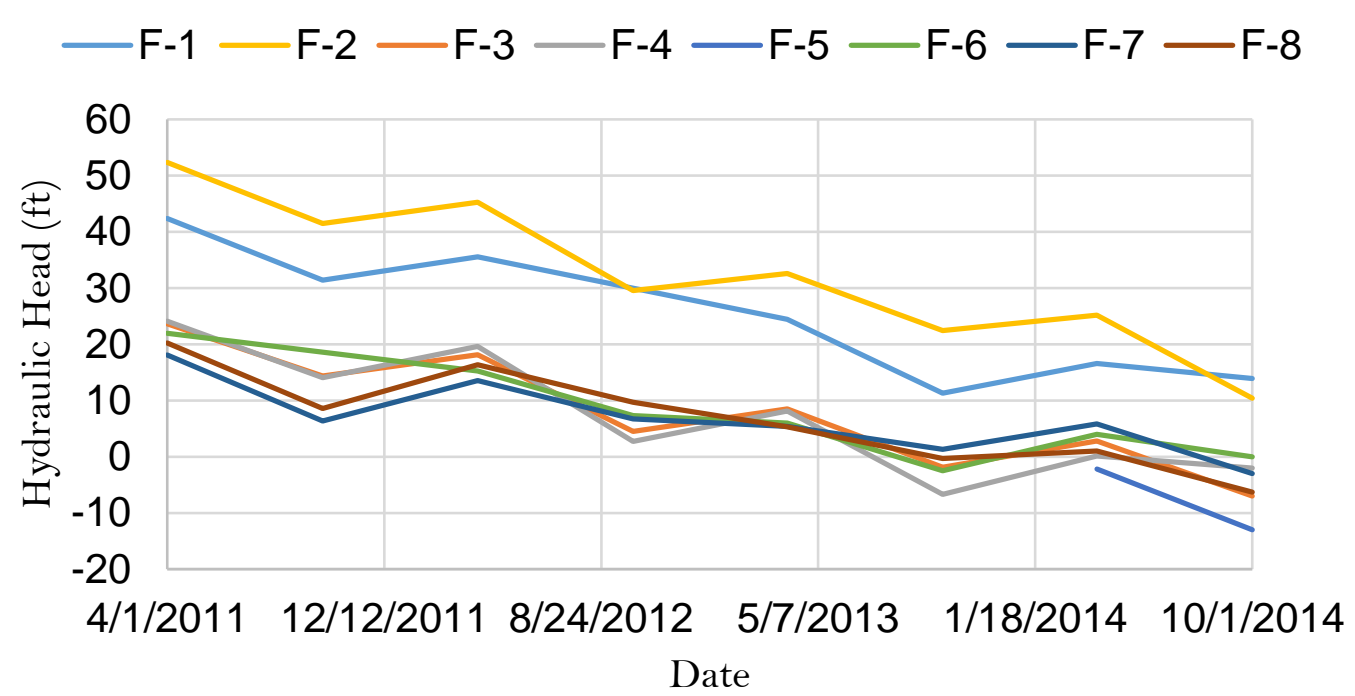

Figure 55 - Farm Well Standing Water Levels

(Fugro Consultants, Inc., 2015)

The effects of assumptions in the farm well characteristics increase model uncertainty. The well depths are assumed to be 150 feet deep and all have a screening interval of 50 feet. Well head data for the agricultural monitoring well 32-C3 was provided (Sorensen, 2016). The well data was provided in 4 minute intervals from 2012 to 2016. A FORTRAN 95 program was constructed to convert the data into monthly averages for implementation in MODFLOW. The well data in 32-C3 decreased over the duration of the study period (Figure 56). 


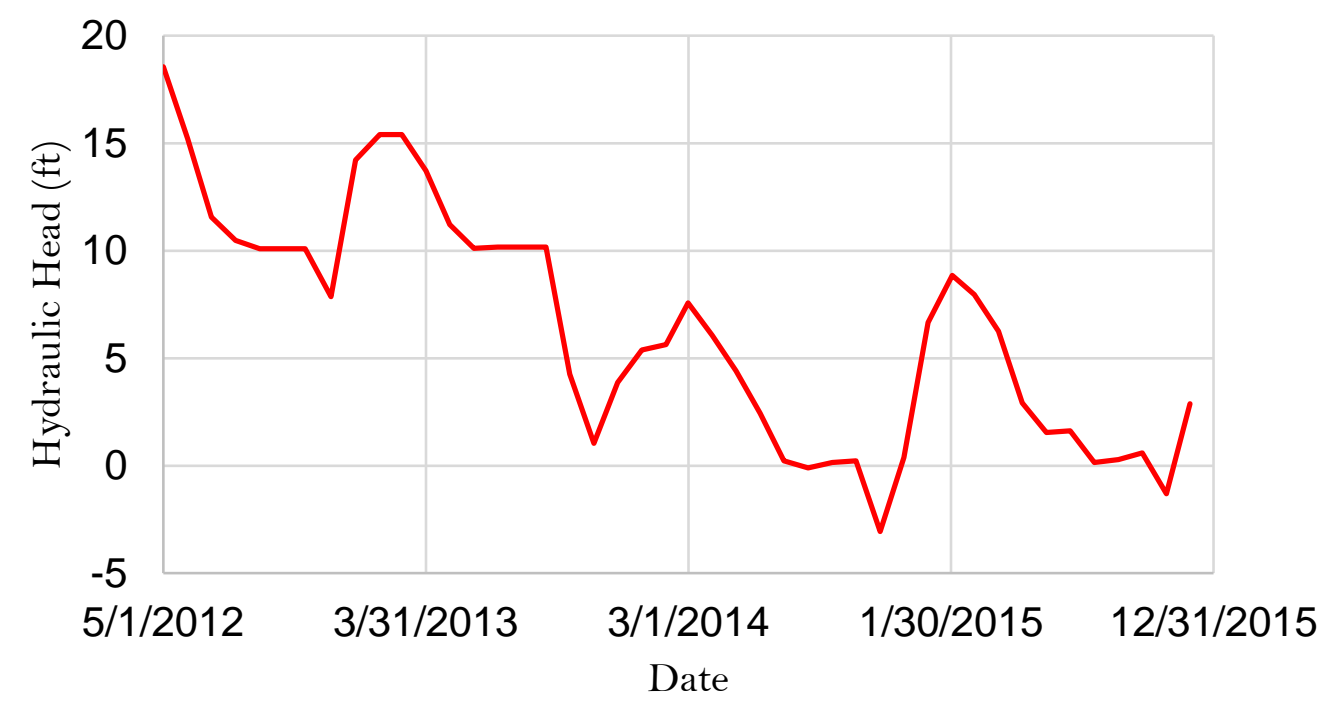

Figure 56 - 32-C3 Agricultural Monitoring Well Hydrograph (Sorensen, 2016)

In addition to gathering standing water levels before turning on municipal pumps, pump drawdown water levels were also measured during extraction. When provided, the pump drawdown levels were averaged with the standing water levels to provide the data point for the well at that time. Additional monitoring well data near pumping epicenters will provide better information for groundwater model calibration and better estimates of storativity and transmissivity.

The initial conditions for the steady state model are transient solutions from averaged pumping on a virgin aquifer system for 3 years. The transition from the initial conditions to transient conditions in the model does not demonstrate any visual variation in the budget rate terms over time. 


\subsection{Transient Model Sensitivity Analysis}

The results of parameter modification are assessed to demonstrate stability of aquifer budget and hydraulic heads values. The effects of variation in stream stage and leakance are demonstrated using the annual average of monthly stream recharge values.

\subsubsection{Stream Leakance Sensitivity Analysis}

Variation in stream stage within 12 inches generated linear variation in the river leakage budget term (Figure 57).

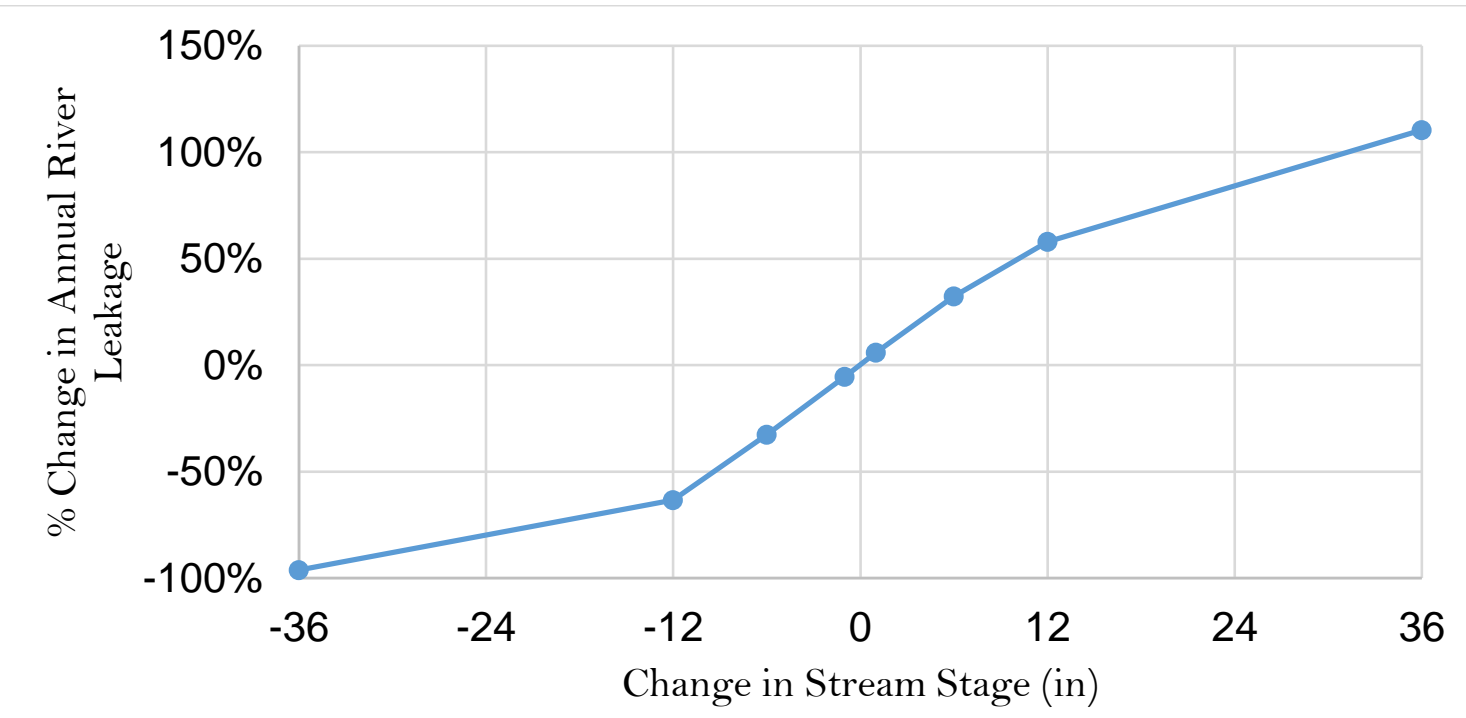

Figure 57 - Changes in River Leakage from Variations in Stream Stage

Increasing the stream stage by 1 inch increased the stream recharge inflow term of 167.7 acre-feet/month by 9.7 acre-feet/month. Decreasing the river stage by 2 feet produced low flow conditions with a river recharge value of 6.7 acrefeet/month. Increasing the stream stage by 3 feet caused an increased stream leakage of 351.6 acre-feet/month. This data can be used to evaluate the trade-off 
between using Lopez Lake Reservoir water versus releasing the water from the dam to increase stream recharge to the aquifer. Increasing stream flows will also benefit steelhead population.

The river leakance term is a function of the streambed conductivity, the stream thickness, and the width of the stream. Increasing the streambed leakance term develops a nonlinear response in river leakage inflow that has a decreasing rate of growth (Figure 58).

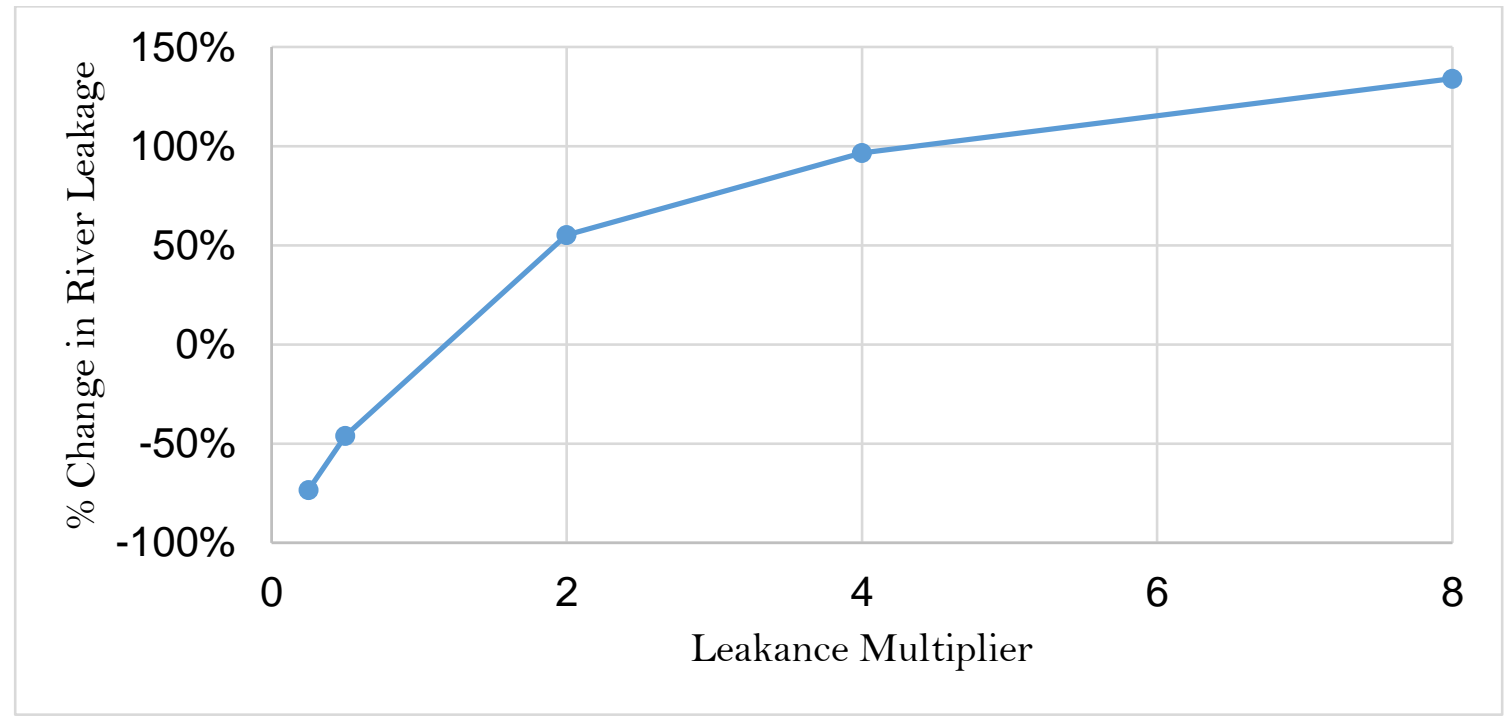

Figure 58 - Changes in River Leakage from Variations in Leakance

Doubling the river leakance terms caused the stream recharge budget term to increase from 167.7 acre-feet/month to 260 acre-feet/month, and multiplying the river leakance terms by 8 caused the stream recharge to increase to 392.8 acrefeet/month. The calibrated leakance value generates an average monthly recharge of 167.7 acre-feet/month which is similar to the Todd Engineers value of 168 acre-feet/month. 


\subsubsection{Boundary Condition Sensitivity Analysis}

The model is run several times with varying constant-head boundary condition values to estimate linear relationships between the constant head values and the aquifer boundary inflows and outflows (Table 13).

\section{Table 13 - Changes in Boundary Budget Values}

\begin{tabular}{|l|c|c|}
\hline Boundary Name & $\Delta$ Inflow (AFY) / $\mathbf{\Delta H e a d}(\mathrm{ft})$ & $\Delta$ Outflow (AFY) / $\mathbf{\Delta H e a d}(\mathrm{ft})$ \\
\hline Deep Nipomo & 73.3 & -22.3 \\
\hline Pismo & 33.7 & 20.7 \\
\hline Oak Park & 22.0 & 1.50 \\
\hline Arroyo Grande Creek & 11.7 & -0.30 \\
\hline Los Berros Creek & 7.90 & 0.10 \\
\hline
\end{tabular}

Variations in the Deep Nipomo constant head boundary generated the greatest variations in the aquifer boundary inflow and boundary outflow budget terms. Variations in the Arroyo Grande Creek and Los Berros Creek constant head values demonstrated the least variation in the boundary budget terms. Variations in constant head values generated linear changes in the boundary inflow terms. The boundary inflow values change over time depending on the magnitude of the other budget terms. During the rainy season, the boundary inflow values decrease because the hydraulic gradient between the internal model domain and the Dirichlet boundary conditions is decreased.

The Deep Nipomo boundary condition is identified as having the greatest contribution to the groundwater model budget. A value of 28 feet is required to 
maintain the same cumulative inflows as the Todd Engineers 2007 study, however a value of 13 feet generates the best fit to well hydrograph data when optimized using PEST.

\subsubsection{Solver Package Sensitivity Analysis}

Two solver packages are assessed for model convergence and run time efficiency. The default solver package in Visual MODFLOW® Flex is the Conjugate Gradient Solver (PCG) package. The package demonstrated excellent water budget percent discrepancy between previous iterations and final solutions (Table 14).

Table 14 - Conjugate Gradient Solver (PCG) Tolerance-Run Time Tradeoffs

\begin{tabular}{|c|c|c|c|}
\hline HCLOSE & Real Time (sec) & Total Time Using 6 CPUs (sec) & \% DISCREPANCY \\
\hline 0.01 & 39.849 & 211.6 & 0.0 \\
\hline 0.1 & 32.256 & 163.2 & 0.0 \\
\hline 0.5 & 27.236 & 139 & 0.0 \\
\hline 1 & 26.752 & 137.6 & 0.0 \\
\hline 2 & 23.466 & 116.5 & 0.0 \\
\hline
\end{tabular}

The HCLOSE parameter demonstrates the tolerance between the head from the previous iteration and the head from the current iteration. The Strongly Implicit Procedure (SIP) package demonstrated faster model run times and greater percent discrepancy between aquifer budget inflows and outflows (Table 15). 
Table 15 - Strongly Implicit Procedure (SIP) Tolerance-Run Time Tradeoffs

\begin{tabular}{|c|c|c|c|}
\hline HCLOSE & Real Time (sec) & Total Time Using 6 CPUs (sec) & \% DISCREPANCY \\
\hline 0.01 & 14.795 & 15.5 & -0.01 \\
\hline 0.1 & 14.561 & 15.1 & 0.04 \\
\hline 0.2 & 11.409 & 12.1 & -0.34 \\
\hline 0.205 & 11.435 & 11.8 & -0.34 \\
\hline 0.22 & 11.449 & 12.0 & -1.5 \\
\hline 0.245 & 11.207 & 11.9 & -1.55 \\
\hline 0.27 & 11.254 & 12.0 & -1.54 \\
\hline 0.35 & 10.987 & 11.6 & -2.7 \\
\hline 0.5 & 10.826 & 11.4 & -4.1 \\
\hline
\end{tabular}

The SIP package demonstrated a decrease of $4.1 \%$ in the accuracy of budgetary inflows and outflows for a HCLOSE value of 0.5 . The decrease of $0.34 \%$ discrepancy in budgetary flow terms is assumed to be tolerable in order to gain the benefit of running the model in 11.4 seconds instead of 40 seconds for optimization purposes. Increases in HCLOSE beyond 0.205 feet caused the percent discrepancy term to increase beyond a tolerance of $1 \%$ in budgetary flow. The value of HCLOSE of 0.205 feet and the SIP solver package is utilized for PEST optimization purposes.

\subsection{Transient Model Calibration}

The groundwater model is calibrated using the PEST parameter estimation process in Visual MODFLOW® Flex. The horizontal hydraulic conductivity values are lognormally transformed to enhance the PEST inversion process. The initial 
value of $\Phi$ is $1.02782 \mathrm{E}+5$. Plotting the calculated head versus the observed head demonstrates the goodness-of-fit for the model prior to hydraulic conductivity calibration (Figure 59).

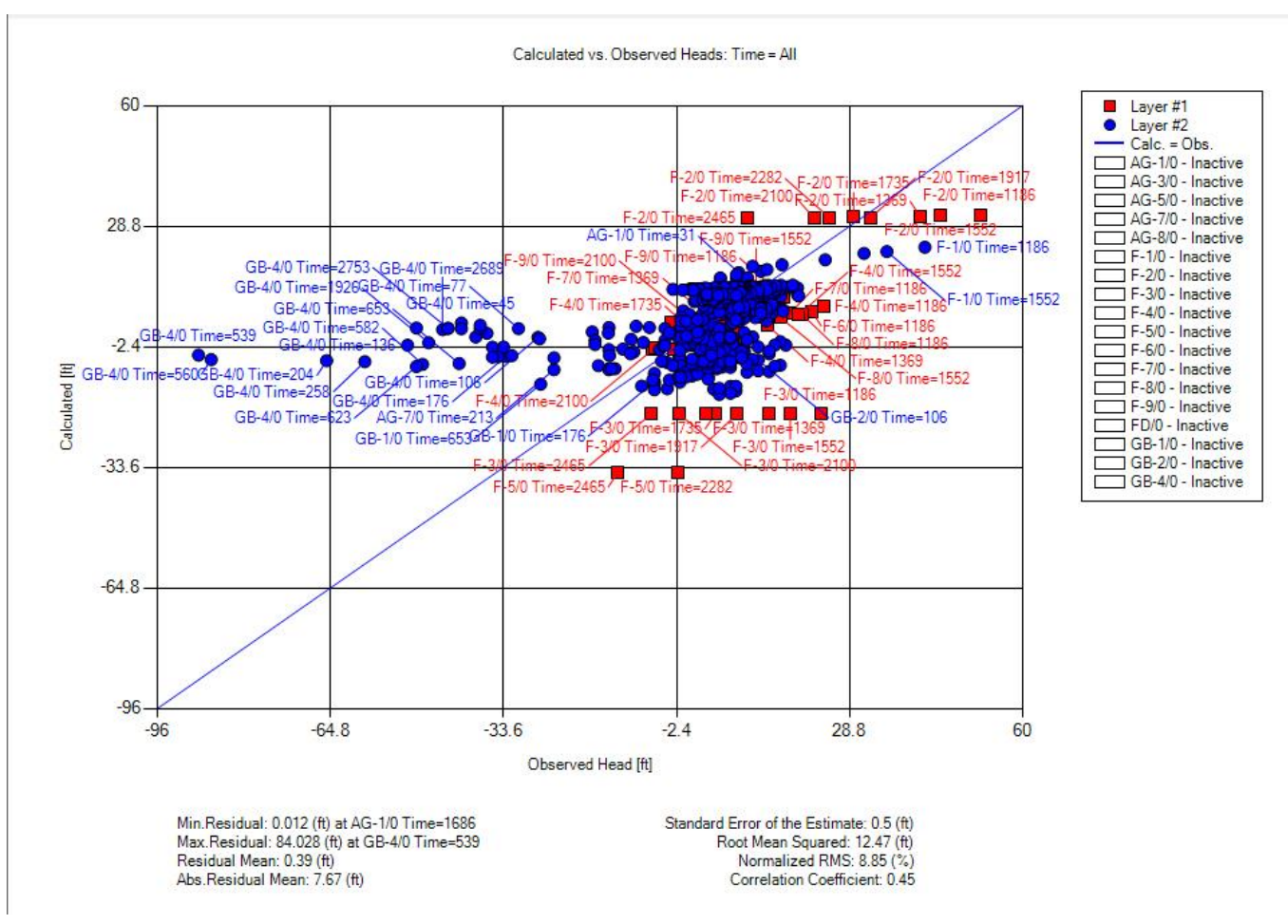

Figure 59 - Pre-Calibration Residual Plots

The points that fall close to the diagonal $1-1$ line represent strong correlation between the observed hydraulic head and the hydraulic head simulated by the model. GBPW observations demonstrate the largest residuals because GBPW wells experience greater drawdown than other wells and because MODFLOW has difficultly perfectly simulating localized drawdown effects. Well hydrograph data included standing water level and pumping water level values. The two values are averaged when pumping water levels are present. Observations that occurred in the same month were removed to provide MODFLOW with a maximum of one 
observation each month. The WEL package in MODFLOW is not capable of matching exactly pumping drawdown levels at a discretization of $247 \times 247$ feet. It is expected that a discretization of $5 \times 5$ feet would provide enhanced results, but the model would require excessive simulation time and is ill-suited for optimization. In addition to this issue, the pump locations are not located in the center of each MODFLOW cell. The observed head data is increased by a factor to compensate for the distance between the center of the MODFLOW node and the actual well location. The maximum distance from the well to the center of a MODFLOW cell is 69 feet, the minimum distance is 9 feet, the mean distance is 47 feet, and the standard deviation is 16 feet. The Thiem equation is used to identify the hydraulic head at the center of the node based aquifer properties and the distance to between the well and the center of the MODFLOW cell (Equation 5.2.1, Modified from Thiem, 1906).

$$
h_{\text {center of cell }}=h_{\mathrm{well}}+\frac{Q}{2 T} \ln \left(\frac{R}{r_{\text {well }}}\right)
$$

where:

$h=$ the hydraulic head (ft)

$Q=$ the pumping rate $\left(\mathrm{ft}^{3} /\right.$ day)

$T=$ the transmissivity of the aquifer ( $\mathrm{ft}^{2} /$ day)

$R=$ the distance between the center of the cell and the well $r_{\text {well }}=$ the radius of the well $(\mathrm{ft})$ 
The transmissivity is estimated using hydraulic conductivity estimates and the layer thicknesses at each well location. Each well had a unique head value added to the well hydrograph data (Table 16).

The $\Phi$ value with the new observations increased $17 \%$ from 102,782 to 120,380 feet $^{2}$. This demonstrates that the boundary condition assumptions based on the steady state model should be revisited. The transmissivity value was calculated by summing the products of the aquifer thicknesses and the hydraulic conductivities. Farm wells F-3, F-4, and F-8 received the largest head additions due to their large extraction rates and low transmissivities. The farm wells have low transmissivities because of the convergence of the layers near the Arroyo Grande Creek inflow (Figure 60).

In Figure 60, the surfaces Layer 1, Layer 2, and Layer 3 represent the bottom of each layer. The Layer 3 surface represents the Franciscan complex bedrock layer and is assumed to be impermeable. 
Table 16 - Compensation for Distance Between Wells and MODFLOW

\begin{tabular}{|c|c|c|c|c|c|c|c|}
\hline WELL & b1 (ft) & b2 (ft) & b3 (ft) & $\mathbf{T}$ (ft ${ }^{2} /$ day) & Q Avg $\left(f^{3} / d\right)$ & $R$ (ft) & Head Added (ft) \\
\hline $\mathrm{F}-1$ & 39 & 79 & 78 & 2,511 & 10,410 & 22 & 2.0 \\
\hline $\mathrm{F}-2$ & 62 & 34 & 81 & 2,482 & 2,002 & 58 & 0.5 \\
\hline F-3 & 72 & 33 & 113 & 2,943 & 73,390 & 61 & 16.3 \\
\hline $\mathrm{F}-4$ & 73 & 45 & 157 & 3,423 & 46,845 & 60 & 8.9 \\
\hline F-6 & 60 & 115 & 199 & 4,328 & 38,036 & 53 & 5.6 \\
\hline F-7 & 53 & 117 & 190 & 4,120 & 43,642 & 21 & 5.1 \\
\hline $\mathrm{F}-8$ & 51 & 131 & 198 & 4,315 & 55,653 & 69 & 8.7 \\
\hline F-9 & 37 & 178 & 235 & 4,861 & 37,235 & 54 & 4.9 \\
\hline AG-1 & 38 & 230 & 312 & 6,079 & 4,473 & 66 & 0.5 \\
\hline AG-3 & 37 & 247 & 338 & 6,462 & 5,964 & 61 & 0.6 \\
\hline AG-4 & 38 & 228 & 313 & 6,068 & 6,710 & 45 & 0.7 \\
\hline AG-5 & 34 & 194 & 332 & 5,668 & 14,165 & 27 & 1.3 \\
\hline AG-7 & 37 & 242 & 335 & 6,374 & 12,674 & 9 & 0.7 \\
\hline AG-8 & 37 & 240 & 333 & 6,346 & 5,219 & 37 & 0.5 \\
\hline GB-1 & 24 & 177 & 318 & 5,097 & 25,040 & 51 & 3.1 \\
\hline GB-2 & 24 & 178 & 328 & 5,180 & 22,616 & 52 & 2.7 \\
\hline GB-4 & 27 & 176 & 323 & 5,196 & 28,271 & 53 & 3.4 \\
\hline
\end{tabular}




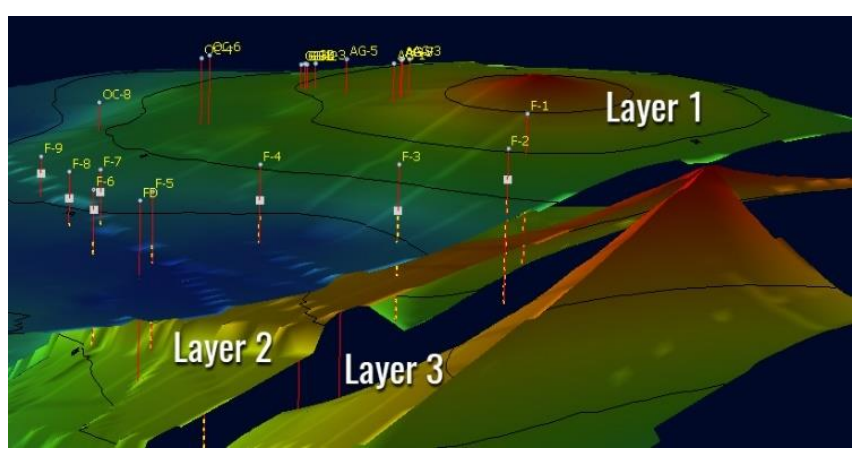

Figure 60 - Layer Thicknesses near North-East Boundary of MODFLOW Model

Holding the boundary conditions constant, the subsurface inflows decreased $22 \%$ during transient simulation when compared to the steady state solution. Prior to calibration, boundary conditions are varied one-at-a-time to decrease $\Phi$ (Figure 61).

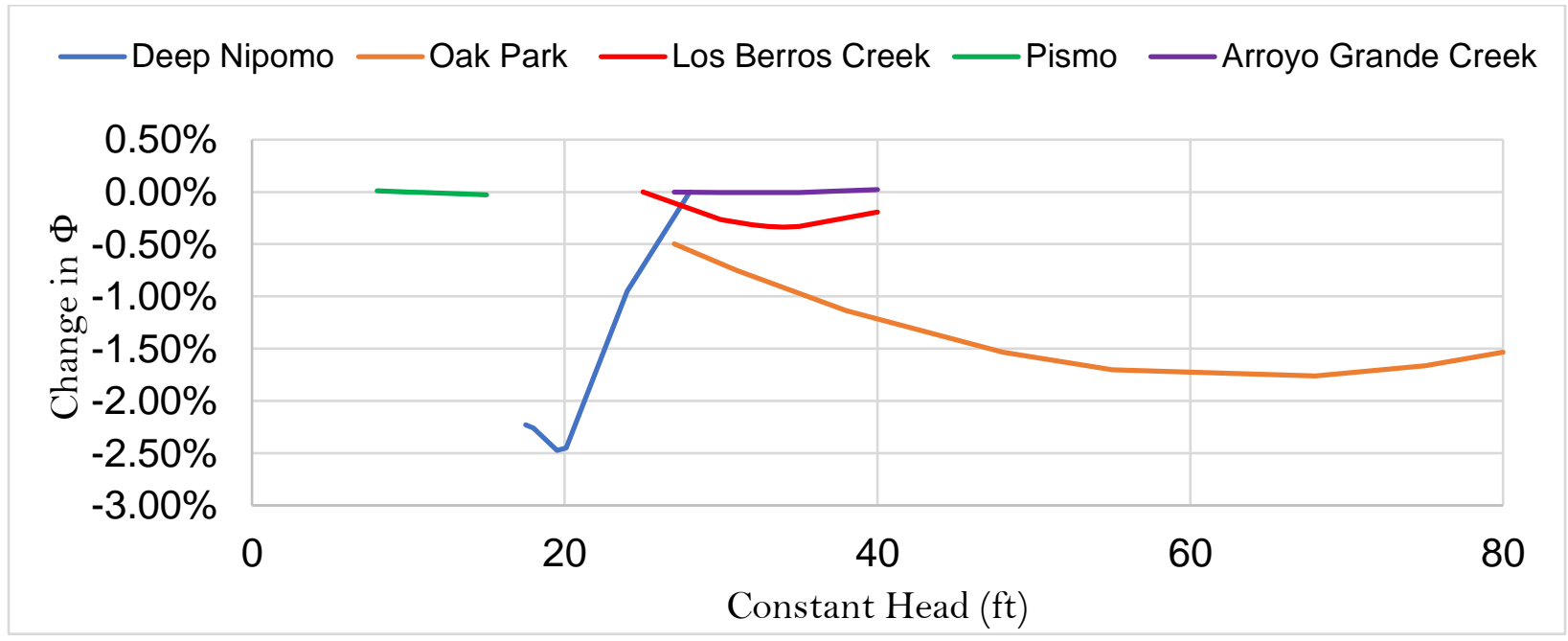

Figure 61 - Percent Change in $\Phi$ from Changes in Dirichlet Head Boundaries 
Variation in the Pismo and Arroyo Grande Creek boundaries did not generate a variation in $\Phi$ more than $0.1 \%$. The Deep Nipomo, Oak Park, and Los Berros Creek boundaries demonstrated the maximum reduction in $\Phi$ at a value of 19.5 feet, 68 feet, and 34 feet, respectively. Reductions in the Deep Nipomo and Arroyo Grande Creek boundary conditions beyond 17.5 feet and 27 feet, respectively, caused the model to crash. The boundary condition values that demonstrated the greatest reduction in $\Phi$ are used as the initial conditions for the calibration process, except for the Oak Park boundary which is provided with a guess of 40 feet. The Oak Park and Los Berros Creek boundary conditions are included as decision variables in the parameter estimation process, but are driven to low values that generate strong divergence in aquifer boundary inflows and outflows. Constant boundary condition values that generate budget inflow terms within 5\% of the Todd Engineers study are used for the calibration process.

Running PEST in the Parameter Estimation mode converges to an "optimal" solution after four PEST iterations and approximately 400 model runs. Regularization mode ran for approximately 20 hours, completed 40 iterations, and executed MODFLOW 4,000 times. The calibrated model provides a higher correlation coefficient than the pre-optimization value (Figure 62). 
Calculated vs. Observed Heads: Time = All
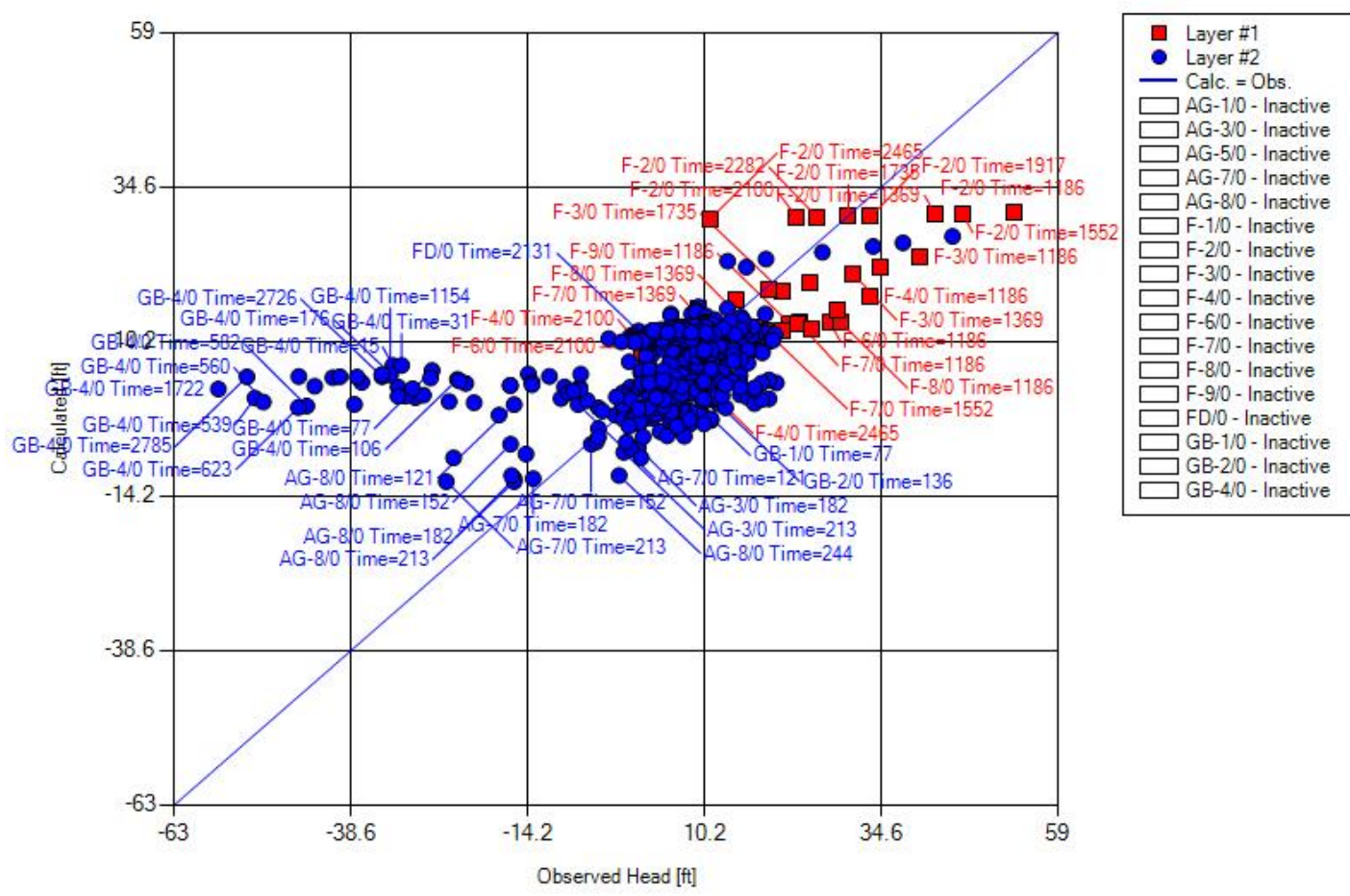

Min.Residual: -0.0081 (ft) at F-8/0 Time $=2282$

Max.Residual: $59.61(\mathrm{ft})$ at GB-4/0 Time $=1722$

Residual Mean: 0.9 (ft)

Abs. Residual Mean: 6.73 (ft)

Figure 62 - Calibrated Simulated/Observed Hydraulic Heads

The ability for the model to generate a linear relationship between predicted and observed heads is fascinating, but the relationships of the underlying physics may be nonlinear due to unconfined flow in Layer 1 . 


\section{Results and Discussion}

The results of the 2007 Todd Engineers study demonstrated annual boundary inflows and outflows to be 3,470 and 2,959 acre-feet, respectively, and that on average $18 \mathrm{AFY}$ is leaving aquifer storage. Similar results for the boundary inflow term can be generated by increasing the boundary condition values beyond the original estimates during the steady state model calibration process. Simulated outflows to the ocean are on average $43 \%$ greater than the values provided in the 2007 Todd Engineers study and the model demonstrates that approximately $373 \mathrm{AFY}$ is leaving aquifer storage (Table 17).

Table 17 - Model Results Compared to 2007 Todd Engineers Study

\begin{tabular}{|l|c|c|c|c|c|c|}
\hline & $\begin{array}{c}\text { BOUNDARY } \\
\text { RECHARGE }\end{array}$ & $\begin{array}{c}\text { RIVER } \\
\text { LEAKAGE }\end{array}$ & $\begin{array}{c}\text { TOTAL } \\
\text { RECHARGE }\end{array}$ & WELLS & $\begin{array}{c}\text { OUTFLOW TO } \\
\text { OCEAN }\end{array}$ & IN-OUT \\
\hline MODEL & 312 & 180 & 219 & 390 & 353 & -373 \\
\hline TODD STUDY & 289 & 168 & 254 & 466 & 247 & -18 \\
\hline$\%$ Change & $8 \%$ & $7 \%$ & $-14 \%$ & $-16 \%$ & $43 \%$ & $1,986 \%$ \\
\hline
\end{tabular}

The values in Table 17 are in AFM for all columns except for the IN-OUT column which has units of AFY. The AFM values have been averaged over the study period to provide concise information delivery. The constant head boundary conditions that are used in the transient calibration process to well data are 30 feet, 7 feet, 31 feet, and 35 feet for the Arroyo Grande Creek, Pismo, Los Berros Creek, and Oak Park boundaries, respectively. The value of $\Phi$ generated from a PEST run using these new boundary conditions and the original estimates for hydraulic conductivity is 103,149 feet $^{2}$. 
Using the PEST regularization mode to provide new estimates for the hydraulic conductivity values and storativity values reduces $\Phi$ by $28 \%$ to 86,926 feet $^{2}$ after 40 optimization iterations and over 4,000 MODFLOW mode. The postcalibration budget results generated a decrease in boundary inflows of $33 \%$ and an increase in boundary discharge of $48 \%$ (Table 18).

Table 18 - K/S Calibrated Model Compared to 2007 Todd Engineers Study

\begin{tabular}{|c|c|c|c|c|c|c|}
\hline & $\begin{array}{c}\text { BOUNDARY } \\
\text { RECHARGE }\end{array}$ & $\begin{array}{c}\text { RIVER } \\
\text { LEAKAGE }\end{array}$ & $\begin{array}{c}\text { TOTAL } \\
\text { RECHARGE }\end{array}$ & WELLS & $\begin{array}{c}\text { OUTFLOW } \\
\text { TO OCEAN }\end{array}$ & IN-OUT \\
\hline MODEL & 194 & 179 & 219 & 389 & 364 & $-1,937$ \\
\hline TODD STUDY & 289 & 168 & 254 & 466 & 247 & -18 \\
\hline$\%$ Change & $-33 \%$ & $7 \%$ & $-14 \%$ & $-16 \%$ & $48 \%$ & $10,721 \%$ \\
\hline
\end{tabular}

Calibration using the hydraulic conductivities and the storativities as the parameters in PEST generated more desirable hydrographs, but created a discrepancy in the in-out term from the previous study of over $10,000 \%$. The large magnitude of almost 2,000 AFY of water leaving storage and flowing to the sea was not expected to be correct from engineering judgement and intuition. Therefore, the Deep Nipomo boundary was also incorporated as a flux condition and parameterized in PEST. Parameterization of the Boundary Condition, in addition to the hydraulic conductivities and the storativities, generated a decrease in $\Phi$ by $20 \%$ to 96,649 feet $^{2}$ from the pre-calibration results. The budget results provided better alignment with the 2007 Todd Engineers study results (Table 19). 
Table 19 - K/S/Boundary Condition Calibrated Model Comparison

\begin{tabular}{|c|c|c|c|c|c|c|}
\hline & $\begin{array}{c}\text { BOUNDARY } \\
\text { RECHARGE }\end{array}$ & $\begin{array}{c}\text { RIVER } \\
\text { LEAKAGE }\end{array}$ & $\begin{array}{c}\text { TOTAL } \\
\text { RECHARGE }\end{array}$ & WELLS & $\begin{array}{c}\text { OUTFLOW } \\
\text { TO OCEAN }\end{array}$ & IN-OUT \\
\hline MODEL & 367 & 179 & 219 & 389 & 395 & -225 \\
\hline TODD STUDY & 289 & 168 & 254 & 466 & 247 & -18 \\
\hline$\%$ Change & $27 \%$ & $7 \%$ & $-14 \%$ & $-16 \%$ & $60 \%$ & $1,158 \%$ \\
\hline
\end{tabular}

The increased flow from the Deep Nipomo Boundary condition and newly calibrated hydraulic conductivity and storativity values provided an increase in the boundary inflows that better represent previous estimates from the 2007 Todd Engineers study. During calibration, bounds were set on the hydraulic conductivities to not exceed 500 feet/day or 1E-6 feet/day, and bounds were set on the storativity values to be between $1 \mathrm{E}-3$ and $1 \mathrm{E}-6$. The optimized hydraulic heads were similar to initial guesses, and the storativity decreased (Table 20).

Table 20 - Optimized Parameter Values

\begin{tabular}{|l|c|c|}
\hline Formation & Initial Value & Optimized Value \\
\hline Layer 1 - Dune Sands & 47 feet/day & 52 feet/day \\
\hline Layer 1 - Alluvium & 24 feet/day & 15 feet/day \\
\hline Layer 1 - Pismo & 13 feet/day & 15 feet/day \\
\hline Layer 2 - Paso Robles & 13 feet/day & 15 feet/day \\
\hline Layer 3 - Careaga & 7 feet/day & 3 feet/day \\
\hline S & 0.001 & $8.00 \mathrm{E}-04$ \\
\hline Boundary Flux & 2,700 feet/day & $2,689.2$ feet $3 /$ day $/$ feet $^{2}$ \\
\hline
\end{tabular}

According to the results of the calibrated model, on average, approximately $225 \mathrm{AFY}$ is leaving aquifer storage. This value is better suited for aquifer management than the "safe" yield, because the total amount of water that remains 
in storage over time is expected to be decreasing due to drought and pumpage. Providing one static number for aquifer management is not representative of reality because the total aquifer storage is not static. Over the study period, the rate of storage flux ranges from a decrease of almost 500 AFM to over 1,5000 AFM demonstrating extreme variability due to climate effects (Figure 63). Decreased extraction is coupled with the drought conditions and the aquifer storage flux is negative for most of 2014 and 2015.

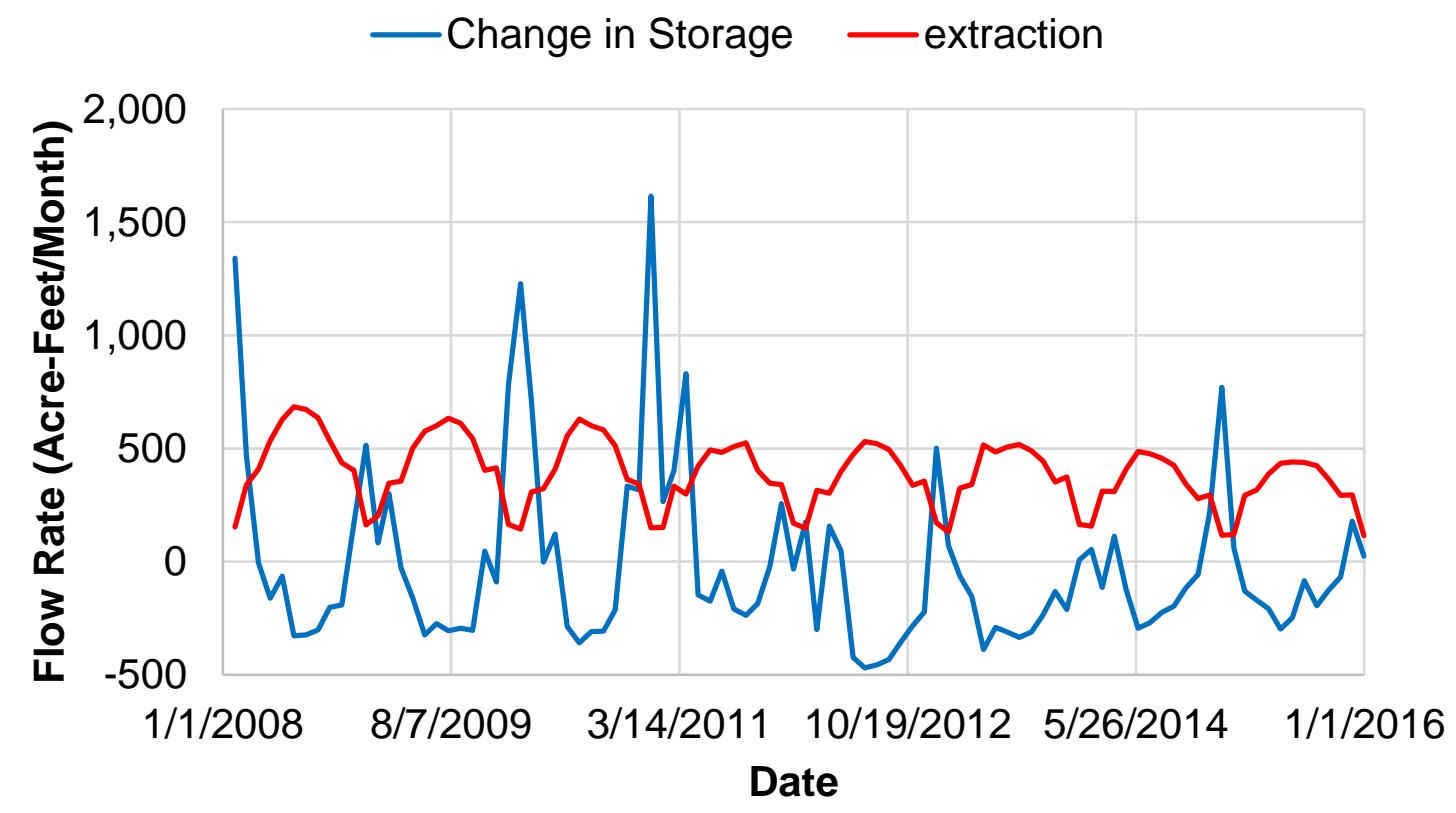

Figure 63 - Storage and Pumping Rates from the Calibrated Groundwater Model

In addition to assessing the rates of flux in and out of aquifer storage, the cumulative aquifer storage chart provides additional insight to long-term aquifer management (Figure 64). 


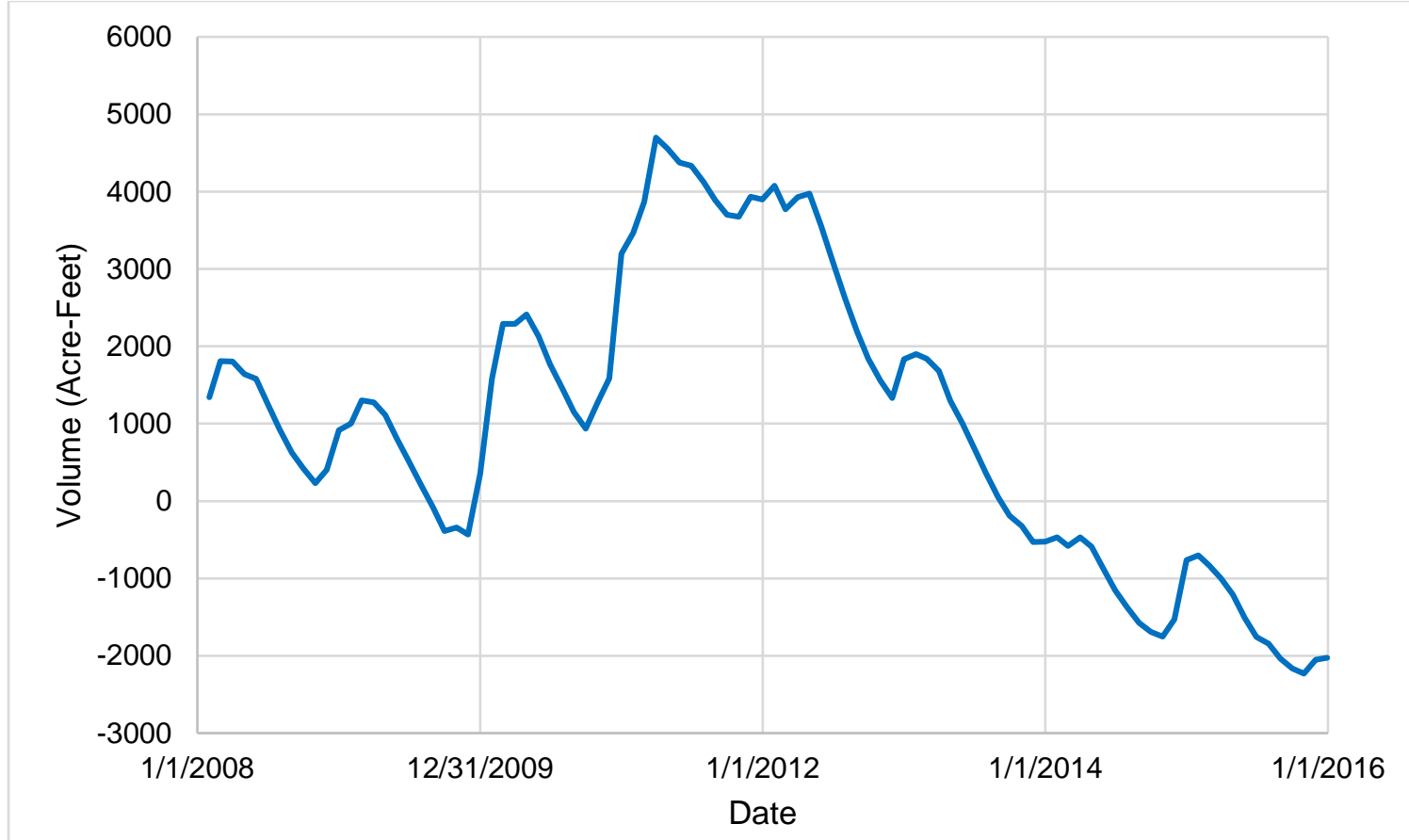

Figure 64 - Cumulated Aquifer Storage During 2008-2015

Sufficient climatic conditions provide adequate inflows to aquifer storage until 2011, when the drought causes the cumulated aquifer storage to decrease. By 2016, approximately 2,000 AF have left storage. When the fluxes of aquifer storage are negative, it can be assumed that the aquifer system is in a state of overdraft and the amount of pumpage is not sustainable. Uncertainty in future climatic conditions should provide additional discomfort in aquifer management.

Well hydrographs comparing the measured heads to the modeled heads demonstrate the validity of the MODFLOW model (Figure 65 - Figure 73). 


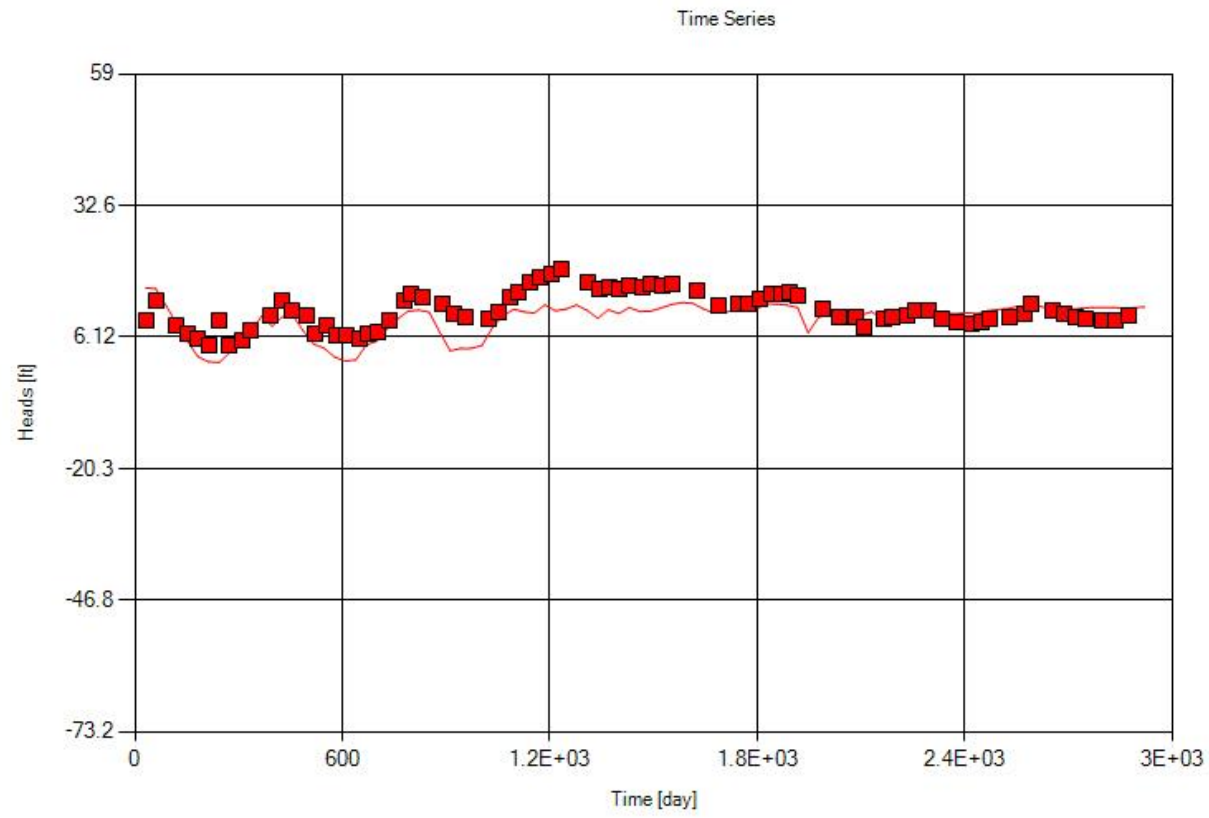

- AG- $1 / 0$ Calc.

Figure 65 - AGPW Pump 1 Well

Time Series

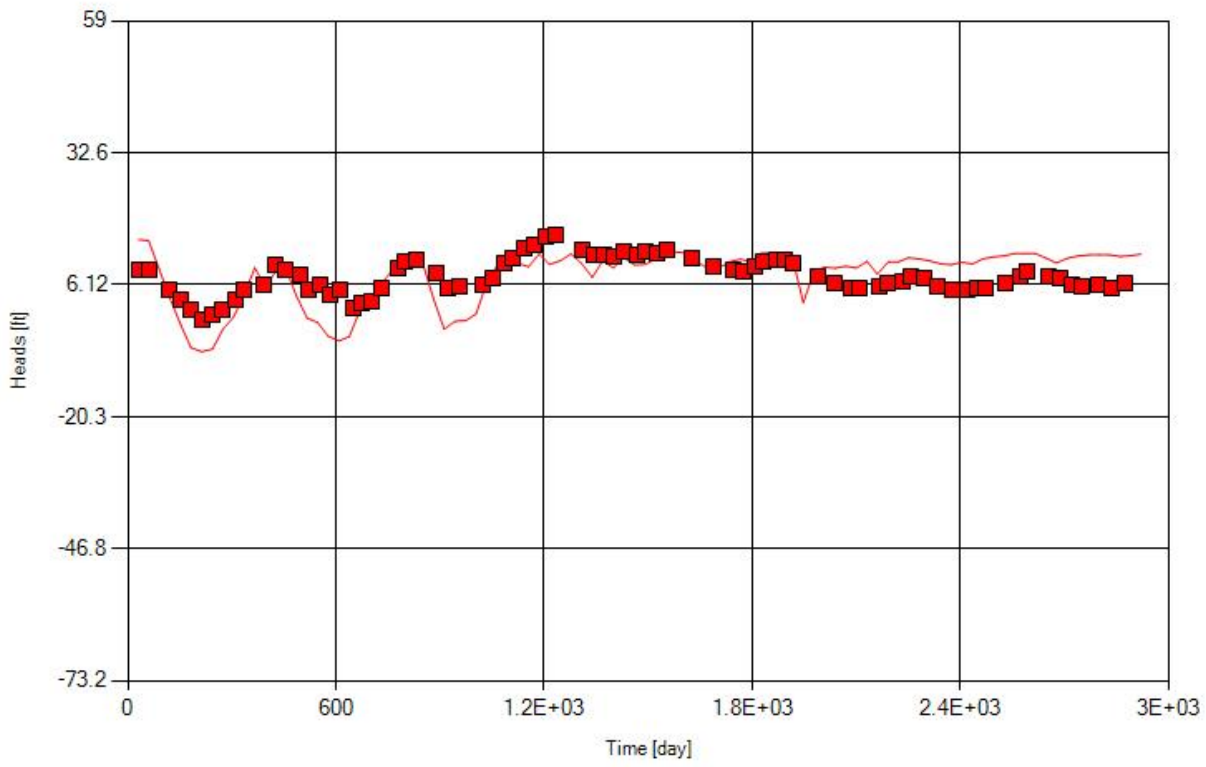

Figure 66 - AGPW Pump 3 Well 
Time Series

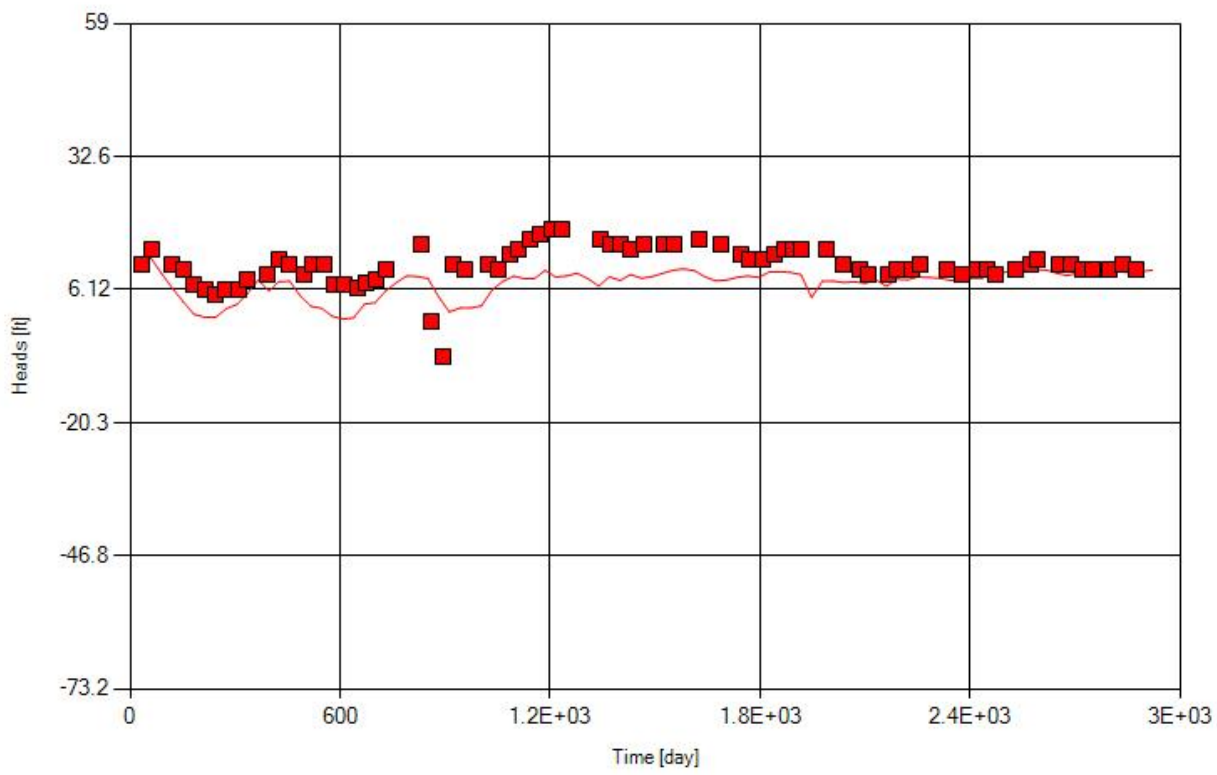

Figure 67 - AGPW Pump 5 Well

Time Series

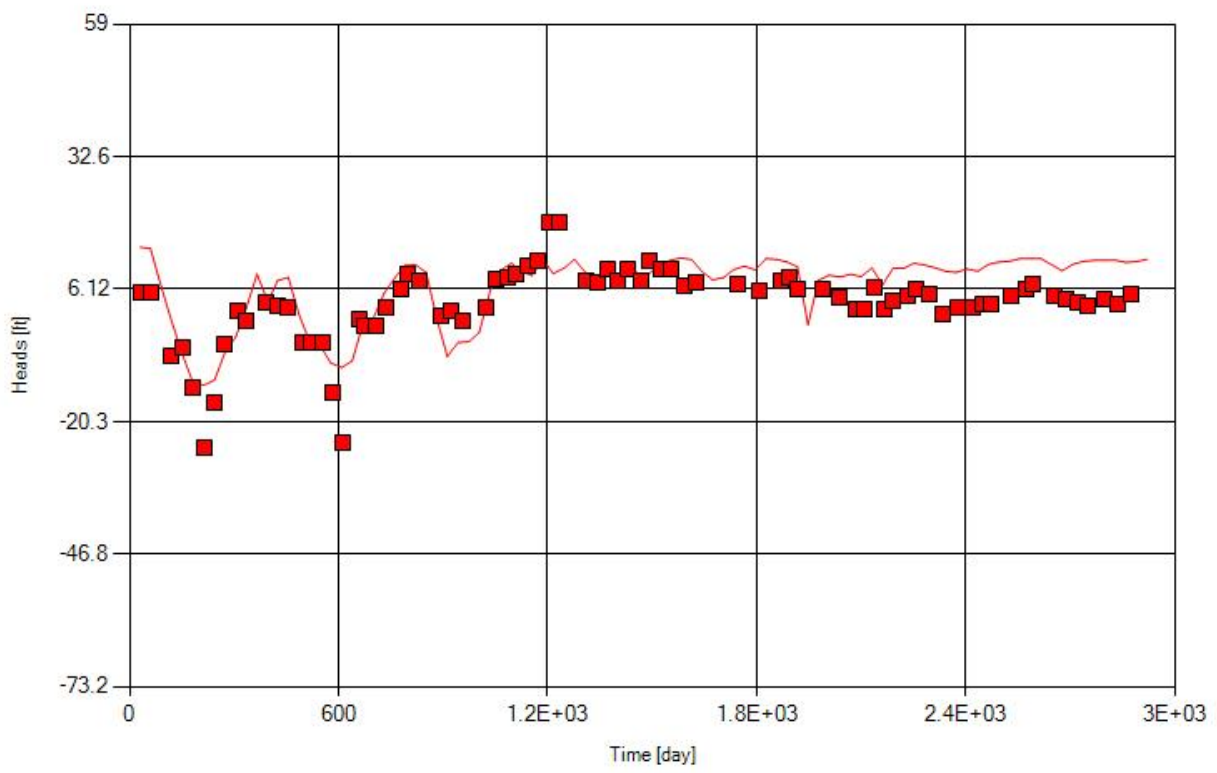

Figure 68 - AGPW Pump 7 Well 


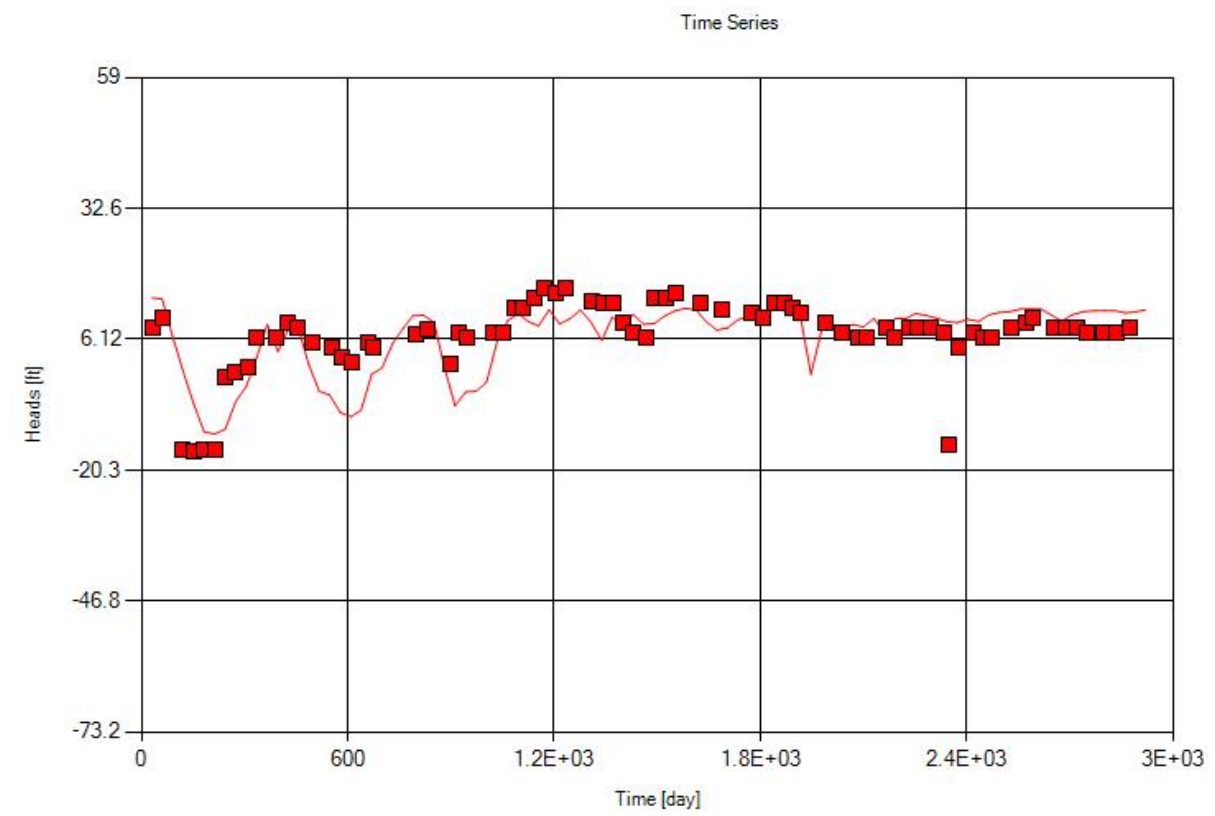

- AG-810 Calc.

Figure 69 - AGPW Pump 8 Well

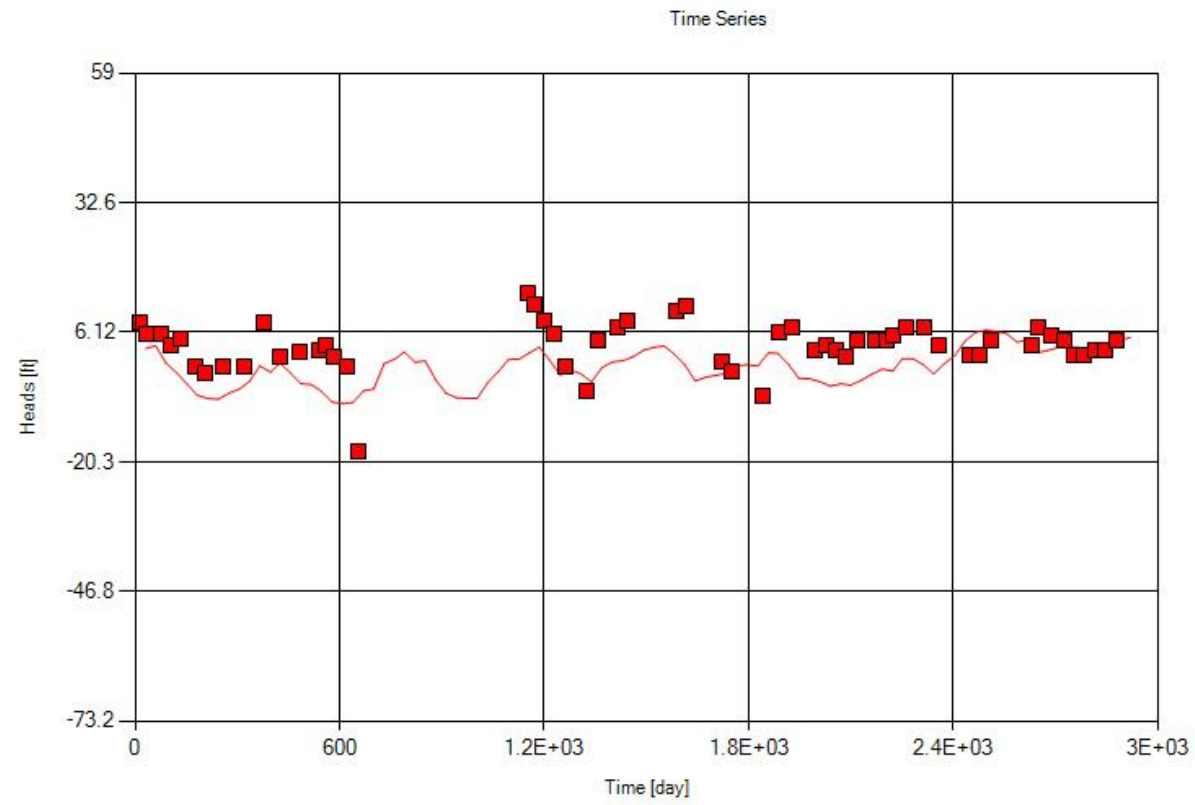

Figure 70 - GBPW Pump 1 
Time Series

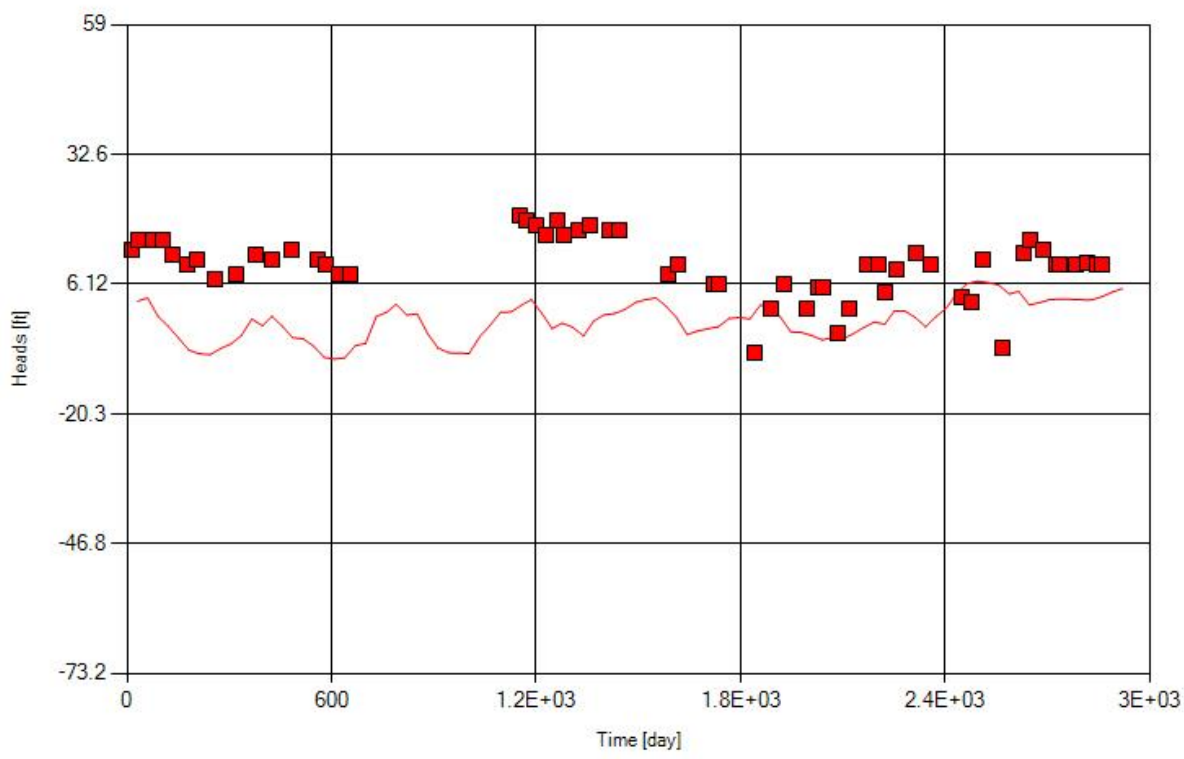

Figure 71 - GBPW Pump 2 Well

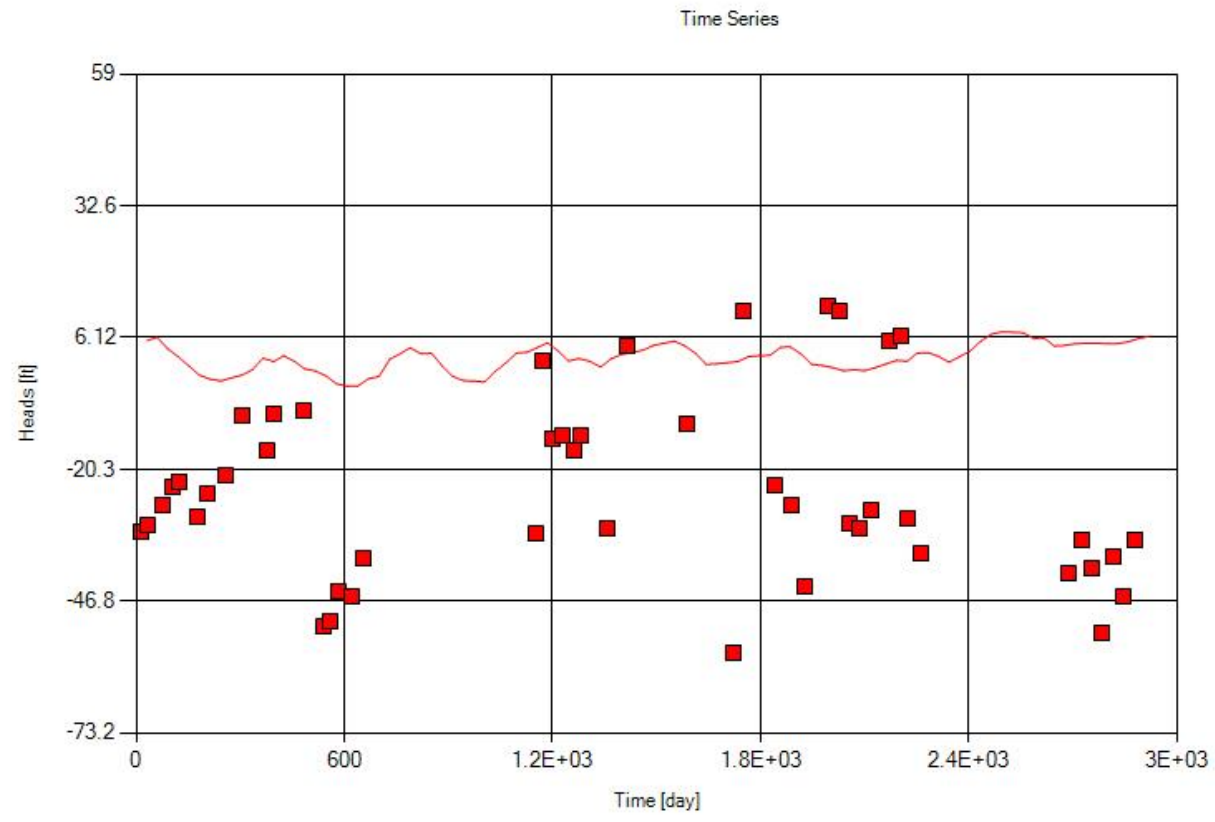

Figure 72 - GBPW Pump 4 Well 


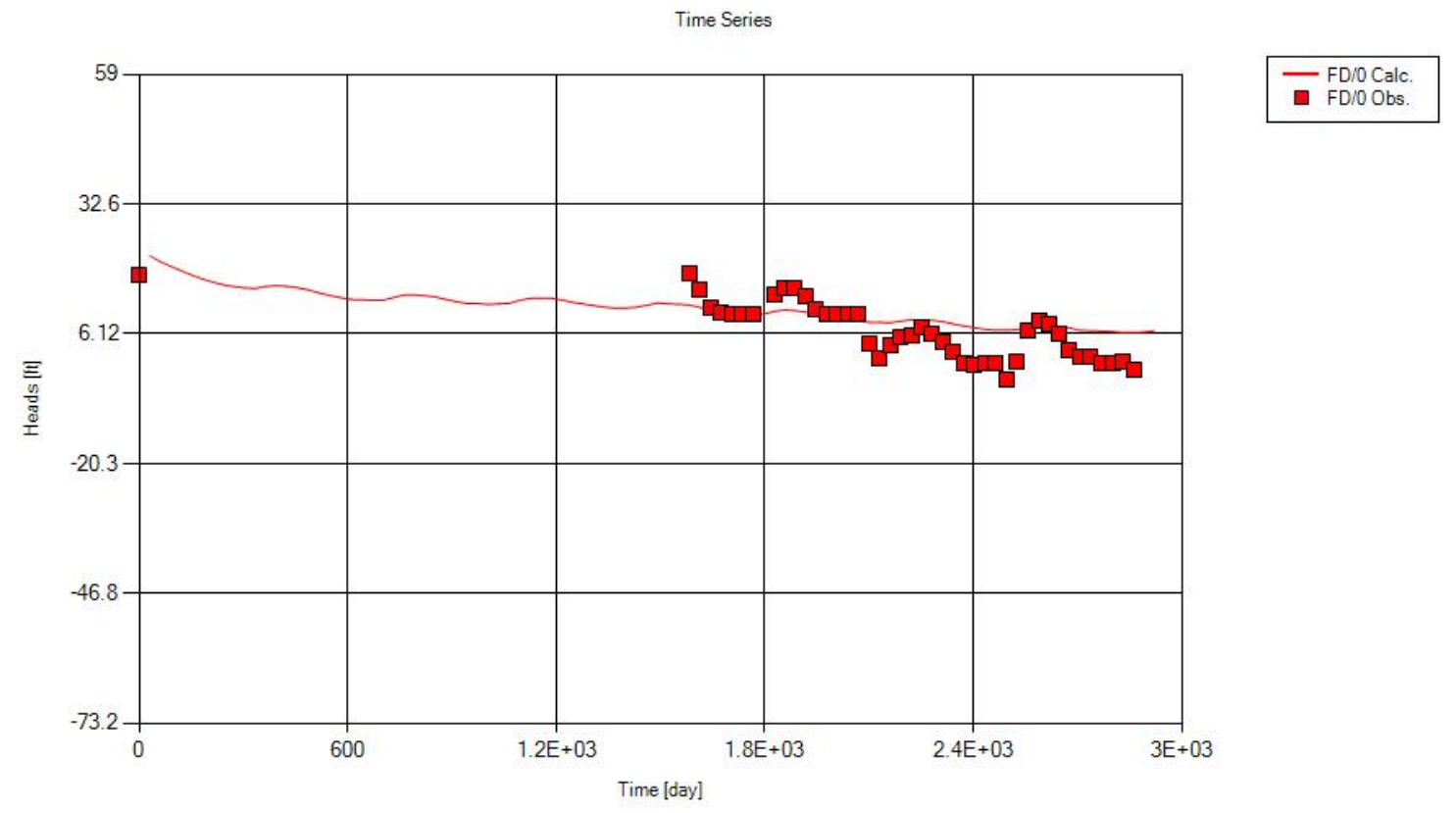

Figure 73 - Farm Monitoring Well

The simulated heads closely match the AGPW hydrographs. The modeled results in the final 2 years of the study period are higher than observed values for AGPW Pump 3 and AGPW Pump 7 wells. The recharge from infiltration ponds was eliminated during the final 2 years of the study period because the ponds were dried up (Taylor, 6/8/2016). The GBPW wells demonstrate increased variability and greater residual values between the measured and observed heads. The well housing GPBW Pump 4 demonstrated drawdown values greater than 50 feet. The measured data may be affected by clogging of well screens, poor construction, and wells may be old and require servicing. 


\section{Future Research}

Initially, future research should continue to enhance the understanding of the relationships between the boundary conditions, the hydraulic conductivities, and the aquifer budget boundary inflow and outflow terms. Once confidence is established for these terms, the presented groundwater model can be used to evaluate the effects of new recharge projects on groundwater flow and budgets over time. Proposed recharge well fields can be developed using the WEL package. Infiltration pond locations and the spatial impacts of additional recharge can be evaluated using the $\mathrm{RCH}$ package and the ZoneBudget system. The NCMA numerical groundwater model can be integrated with the SEAWAT package to estimate the intrusion of the saltwater toe. Climate future scenarios can be implemented into the model to forecast the effects of climate change on the groundwater environment. Future scenarios of increased pumping demand, recharge, sea-level rise, and saltwater intrusion will provide insight into long-term groundwater management.

It is recommended that pump flow data be recorded for each pump instead of the monthly total. Daily extraction data could be used to develop a model with higher temporal resolution. This model can be used to identify the effects of recharge efforts on a daily scale and will provide more accurate results than a model on a monthly timestep. The run time increase is expected to be similar to the results from the temporal sensitivity analysis in the Transient Model Development section. 
During the thesis defense, Pismo Beach municipal pumping wells were identified and are located in the study area. The pump flow rates should be implemented into the study, but they were described as having low flow rates similar to the OCSD. 


\section{Conclusions}

The results of the study have demonstrated that:

- The 2007 Todd Engineers Study subsurface inflows and outflows generate well hydrographs that are above observed data.

- Calibration to well hydrographs generated increased subsurface outflow values and decreased subsurface inflow values.

- It is possible that $\sim 250 \mathrm{AFY}$ is leaving aquifer storage.

- The aquifer budget results are interdependent on the hydraulic conductivity and boundary condition values.

- Calibration to the 2007 Todd Engineers Budget generates a $\Phi$ value based on observed heads of 103,149 feet $^{2}$.

- Regularized parameter estimation of the hydraulic conductivity values decreases $\Phi$ by $27 \%$ to 75,048 feet $^{2}$.

- Regularized hydraulic conductivity calibration generates increases of $23 \%$, $127 \%$, and $12,983 \%$ to $4,267 \mathrm{AFY}, 6,728 \mathrm{AFY}$, and $-2,342 \mathrm{AFY}$ and the boundary outflow term is increased by $127 \%$ in the boundary inflow, boundary outflow, and outflow from storage budget terms, respectively.

- Implementation of additional data will enhance model validity. 


\section{BIBLIOGRAPHY}

Blake, WP (1856) "In Names and Definitions of the Geological Units of California." USGS Bulletin 826, p.51.

Bredehoeft, John, D. Papadopulos, Stephen S. Cooper, H. H. Jr. (1982) “Groundwater: The Water-Budget Myth.” Scientific Basis of WaterResource Management, Studies in Geophysics.

California Department of Public Works, Division of Water Resources (1945) "Memorandum Report On AG Creek, San Luis Obispo County, California: p10-13".

Central Coast Salmon Enhancement (2005). "AG Creek Watershed Management Plan". Coastal San Luis Resource Conservation District. http://www.coastalrcd.org/images/cms/files/Arroyo\%20Grande\% 20Creek\%20Watershed\%20Management\%20Plan\% 20Update\%202009.pdf

Cleath-Harris Geologists (2/19/2016) Personal Communication. San Luis Obispo, CA.

Doherty, John (2016) “PEST - Model-Independent Parameter Estimation - User Manual Part I: PEST, SENSAN, and Global Optimisers - $6^{\text {th }}$ Edition" Watermark Numerical Computing.

Dollison, R.M. (2010) The National Map: New viewer, services, and data download: U.S. Geological Survey Fact Sheet 2010-3055, 2 p. (Also available at http://pubs.usgs.gov/fs/2010/3055/) 
Dvorsky, John (2003). "Steelhead Restoration Planning Project for the Morro Bay Watershed."

DWR (1970) "Preliminary Evaluation of the Water Supply of the AG and Paso Robles Areas."

DWR (1979) "Ground Water in the AG Area: Southern District Report." DWR (1994) "Aerial Geology of the AG- Nipomo Mesa Area - a Map"

DWR (2002) "Water Resources of the AG-Nipomo Mesa Area" State of California Department of Water Resources Southern District.

ESRI (2014). ArcGIS Desktop: Release 10.2.2.3552. Redlands, CA:

Environmental Systems Research Institute.

ESRI Resource Center (2016) "How Kriging Works". ArcGIS Resource Center. http://help.ArcGIS.com/En/ArcGISdesktop/10.0/Help/index.html\# //009z00000076000000.htm

Feigal, K. L., King, R. W (1990) "Geodetic measurement of tectonic deformation in the Santa Maria fold and thrust belt, California." Journal of Geophysical Research, v 95.

Fugro Consultants, Inc. (2014) "Northern Cities Management Area 2013 Annual Monitoring Report." Provided by Water Systems Consulting.

Fugro Consultants, Inc. (2015) "Northern Cities Management Area 2014 Annual Monitoring Report." Provided by Water Systems Consulting. 
Fugro Consultants, Inc. (2015) "Santa Maria Groundwater Basin Characterization and Planning Activities Study - Final Report - Prepared for San Luis Obispo County Flood Control and Water Conservation District". Fugro Job No. 04.62130111 .

Galef, Jeffrey K. (2012) Optimal Groundwater Management with GIS Applications for the Blue Lake Aquifer of Humboldt County, California. 2006 Humboldt State University. Accessed November - December 2012. http://humboldt-dspace.calstate.edu/bitstream/handle /2148/67/Thesis2.pdf?sequence $=1$

GEI Consultants, Inc. (2011) "2010 Annual Monitoring Report Northern Cities Management Area". Provided by Water Systems Consulting.

GEI Consultants, Inc. (2012) "2011 Annual Monitoring Report Northern Cities Management Area". Provided by Water Systems Consulting.

GEI Consultants, Inc. (2013) "2012 Annual Monitoring Report Northern Cities Management Area". Provided by Water Systems Consulting.

Goss, R, and Reed, L (1969) "Geophysical Investigation of the AG below the Lopez Dam and Reservoir, San Luis Obispo County, California" Department of Geological Sciences, University of California, Riverside, Prepared for the San Luis Obispo County Flood Control and Water Conservation District.

Habitat Conservation Plan (HCP) (2004). San Luis Obispo County. 
Hall, C.A., Jr., et al. (1966) "Potassium-argon age of the Obispo formation with Pecten lompocensis Arnold, Coast Ranges, California." Geological Society of America Bulletin, vol 77, p 443-446.

Harbaugh, Arlen W. (2005) "MODFLOW-2005, The U.S. Geological Survey Modular Ground-Water Model—the Ground-Water Flow Process" U.S. Geological Survey.

Hesch, Wayne (2013) "What's On the Menu - 2013 NGWA Summit." Waterloo Hydrogeologic.

http://www.waterloohydrogeologic.com/images/PDFs/ VisualMODFLOWFlex/WayneHesch-NGWA-Summit-2013.pdf

Jin-sheng, Jia, Jing-jie, Yu,Chang-ming, Liu (2002) "Groundwater regime and calculation of yield response in North China Plain: a case study of Luancheng County in Hebei Province." Water Resources, Journal of Geographical Sciences.

Kahn, Katherine, et al. (2008) "Characterization of the shallow groundwater system in an alpine watershed: Handcart Gulch, Colorado, USA". Hydrogeology Journal.

Kasper, Joshua, et al. (2010) "Simulated impacts of artificial groundwater recharge and discharge on the source area and source volume of an Atlantic Coastal Plain stream, Delaware, USA. Hydrogeology Journal. 
Langel, Richard, Gannon, J. (2011) "Use of Numerical Modeling to Evaluate the Quantity and Quality of Induced Surface Water Recharge for the City of Dunlap." lowa Department of Natural Resources.

Lawrence, Fisk, and McFarland Inc. (1987) "Water, Wastewater, and Drainage Studies: Prepared for RRM Design Group and Nipomo Mesa Technical Study Sponsors"

Lawson, A.C., (1895) "In Names and Definitions of the Geologic Units of California." USGS Bulletin 826, p27 Provided by references in Lewy Richard's Geology Report (1994).

Lewy, Richard H (1994) “The Geology of AG-Nipomo Mesa Area - San Luis Obispo County, California”. DWR. Provided by Water Systems Consulting.

Muleta, Misgana (2015) Hydrology Course. California Polytechnic State University.

Nelson, T.P and Lachmar, T.E. (2013) "Design of a groundwater model to determine the feasibility of extending an artificial salmon-spawning stream: case study for Marx Creek, near Hyder, Alaska." Applied Water Science.

NRCS (2016) "Web Soil Survey - Home". http://websoilsurvey.sc.egov.usda.gov/App/HomePage.htm

Palma, Heyddy, and Bently, Laurence (2007). "A regional-scale groundwater flow model for the Leon-Chinandega aquifer, Nicaragua". Hydrogeology Journal. 
R. Rejani, Madan K. Jha, S. N. Panda, R. Mull (2008) "Simulation Modeling for Efficient Groundwater Management in Balasore Coastal Basin, India" Water Resources Management.

Schlumberger (2016) "A Review of Finite Difference Grid Types." Schlumberger Water Services.

http://www.novametrixgm.com/pdfs/

VMOD_Flex_WhitePaper_Grid_Types.pdf

SLO County (2015) "Geology - Open Data Initiative." San Luis Obispo County GIS. http://gis.slocounty.opendata.ArcGIS.com/datasets/ 046e2b2931e0478bbcc9d5ae145a3561_54?geometry=$125.636 \% 2 \mathrm{C} 34.673 \% 2 \mathrm{C}-116.941 \% 2 \mathrm{C} 36.017$

Sorensen, Paul (6/7/2016) Personal Communication. GSI Consultants, Inc.

Taylor, Shane (6/8/2016) Personal Communication. AGPW.

Thiem, Günther (1906) "Hydrologische methoden" (in German). Leipzig: J. M. Gebhardt.

Theis, C.V. (1935) "The relation between the lowering of the piezometric surface and the rate and duration of discharge of a well using ground-water storage." American Geophysical Union Transactions, pt 2, p. 519-524.

Todd Engineers (2007). "Water Balance Study for the Northern Cities Area". Prepared for the cities of Pismo Beach, Grover Beach, AG, and Oceano. Provided by Water Systems Consulting. 
Todd Engineers (2009) "2008 Annual Monitoring Report Northern Cities Management Area". Provided by Water Systems Consulting.

Todd Engineers (2010) "2009 Annual Monitoring Report Northern Cities Management Area". Provided by Water Systems Consulting.

United States Census (2010) "2010 Census Interactive Population Search". http://www.census.gov/2010census/popmap/ipmtext.php?fl=06:0653294

USGS (1982) "United States Geological Survey Water-supply Paper"

U.S. Government Printing Office, 1982.

Waterloo Hydrogeologic (2015) Visual MODFLOW® Flex.

The Weather Channel (2016) "AG, CA Monthly Weather Forecast - weather.com"

Weber and Associates (1990) "In Draft Environmental Impact Report for the Rancho Grande Subdivision, 1991, Denise Duffy and Associates, Monterey, CA., Prepared for the City of AG, p9"

Zume, Joseph T. and Tarhule, Aondover A. (2011) "Modelling the response of an alluvial aquifer to anthropogenic and recharge stresses in the United States Southern Great Plains." Journal of Earth System Science. 